Portland State University

PDXScholar

\title{
Symbiosis in Archaea: Functional and Phylogenetic Diversity of Marine and Terrestrial Nanoarchaeota and their Hosts
}

Emily Joyce St. John

Portland State University

Follow this and additional works at: https://pdxscholar.library.pdx.edu/open_access_etds

Part of the Bacteriology Commons, and the Biology Commons

Let us know how access to this document benefits you.

\section{Recommended Citation}

St. John, Emily Joyce, "Symbiosis in Archaea: Functional and Phylogenetic Diversity of Marine and Terrestrial Nanoarchaeota and their Hosts" (2019). Dissertations and Theses. Paper 4939.

https://doi.org/10.15760/etd.6815

This Thesis is brought to you for free and open access. It has been accepted for inclusion in Dissertations and Theses by an authorized administrator of PDXScholar. Please contact us if we can make this document more accessible: pdxscholar@pdx.edu. 
Symbiosis in Archaea: Functional and Phylogenetic Diversity of Marine and Terrestrial Nanoarchaeota and their Hosts

$$
\text { by }
$$

Emily Joyce St. John

\begin{abstract}
A thesis submitted in partial fulfillment of the
\end{abstract} requirements for the degree of

\author{
Master of Science \\ in \\ Biology
}

Thesis Committee:

Anna-Louise Reysenbach, Chair

Anne W. Thompson

Rahul Raghavan

Portland State University

2019 
(C) 2019 Emily Joyce St. John 


\begin{abstract}
The Nanoarchaeota are an enigmatic lineage of Archaea found in deep-sea hydrothermal vents and geothermal springs across the globe. These small $(\sim 100-400 \mathrm{~nm})$ hyperthermophiles live ectosymbiotically with diverse hosts from the Crenarchaeota. Despite their broad distribution in high-temperature environments, very few Nanoarchaeota have been successfully isolated in co-culture with their hosts and nanoarchaeote genomes are poorly represented in public databases. However, the Nanoarchaeota provide unique insights into the structure and function of symbiosis in the archaeal domain. This study describes novel nanoarchaeotes from multiple geothermal habitats, using a combination of direct cultivation techniques and genomic analysis. A new nanoarchaeote from a New Zealand hot spring, Candidatus Nanoclepta minutus, was isolated in co-culture with its host. Like other terrestrial Nanoarchaeota, Cand. Ncl. minutus harbors genes for gluconeogenesis and archaeal flagella. Zestosphaera tikiterensis, the New Zealand host, was also isolated in pure culture and characterized. Phylogenetic analysis showed that both Cand. Ncl. minutus and Z. tikiterensis are new genera in the Nanoarchaeota and Crenarchaeota, respectively. Metagenome-assembled genomes (MAGs) from the Nanoarchaeota were also recovered from deep-sea hydrothermal vent sites. These MAGs capture a wide range of diversity in the Nanoarchaeota, representing three new species and two novel genera. Key nanoarchaeotal features were identified in the MAGs, including marker genes for archaeal flagella, gluconeogenesis and CRISPR-Cas regions. These studies greatly contribute to our understanding of nanoarchaeotal ecophysiology and provide key insights into the coding potential and diversity of Nanoarchaeota and their hosts.
\end{abstract}




\section{Dedication}

I dedicate this thesis to Brady St. John, my best friend, partner and husband, for his unending faith in me. 


\section{Acknowledgements}

First of all, I would like to thank Dr. Anna-Louise Reysenbach. Thank-you for your endless support and patience, and for inspiring me to explore the beautiful and strange world of extremophiles. Without you, none of this would be possible. I would also like to thank my committee members, Dr. Anne Thompson and Dr. Rahul Raghavan, for their insight and support throughout this process. Thanks to Dr. Mircea Podar for many thoughtful email discussions and to Dr. Annie Lindgren for always being available to talk. I would also like to thank the members of the Reysenbach Lab, especially Jennifer Meneghin and Yitai Liu - working with both of you has been a privilege and a joy. Thank-you to my each one of my friends and family, especially my husband Brady thanks for walking with me through this process and always seeing the best in me. Finally, I would like to thank Leila for her exuberance and zest for life and her phenomenal hair. Research was funded by grants to Anna-Louise Reysenbach from the National Science Foundation (OCE1235432, OCE1558795, OCE0728391 and DEB1134877) and the National Aeronautics and Space Administration (NNX16AJ66G). 


\section{Table of Contents}

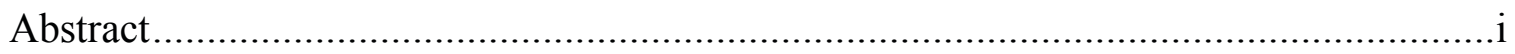

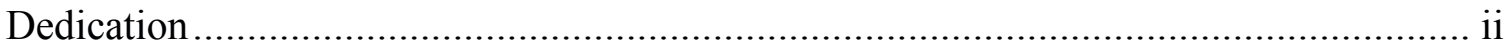

Acknowledgements ............................................................................... ii

List of Tables .................................................................................................... vii

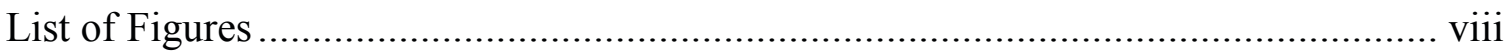

Chapter 1: Introduction......................................................................................

Diversity and exploration of the archaeal domain ................................................. 1

Global distribution of nanoarchaeotes .............................................................4

Diversity within nanoarchaeote-host systems .......................................................5

Nanoarchaeote-host interaction dynamics ..........................................................8

Shared genomic features of cultivated nanoarchaeotes ....................................... 11

Unique features of various nanoarchaeotes ............................................................. 14

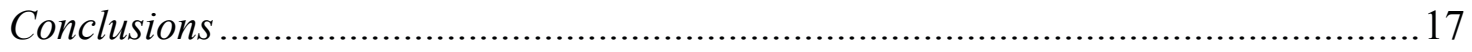

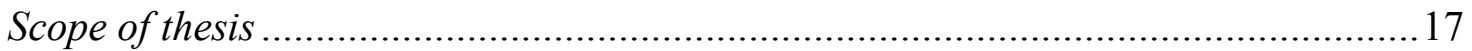

Chapter 2: A New Symbiotic Nanoarchaeote (Candidatus Nanoclepta minutus) and its Host (Zestosphaera tikiterensis gen. nov., sp. nov.) from a New Zealand Hot Spring.....31

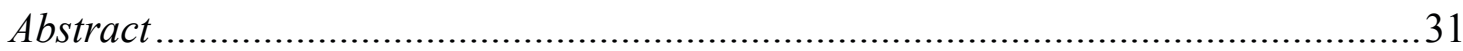

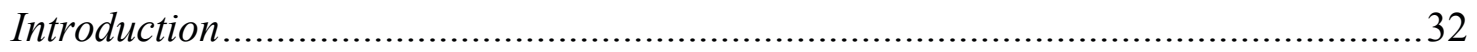

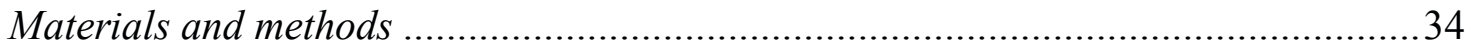

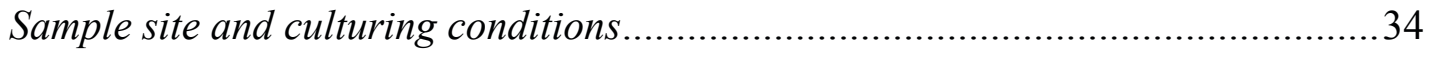

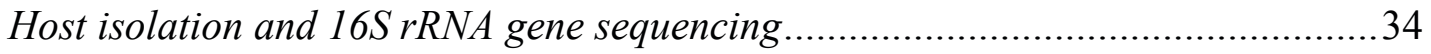

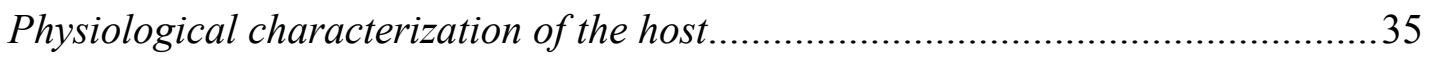


Core and intact lipid preparation and analysis ................................... 36

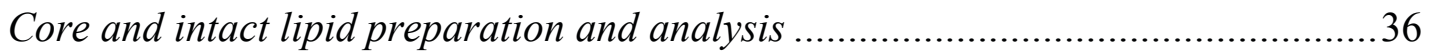

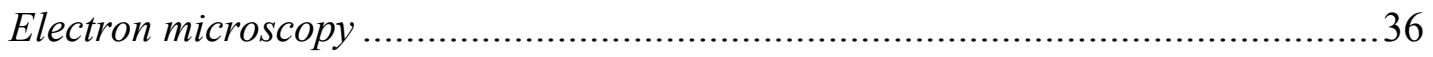

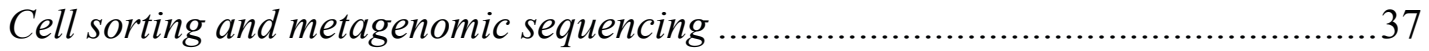

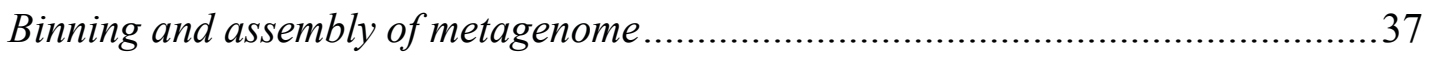

Accessibility of data and biological material.................................................. 38

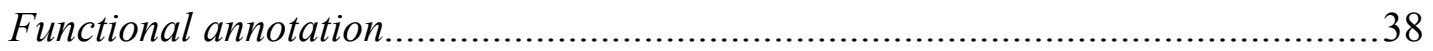

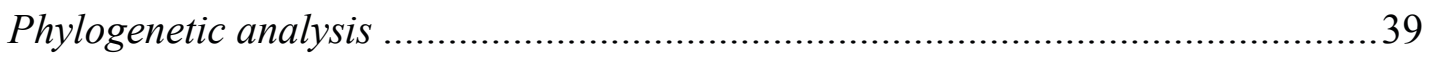

Analysis of predicted $r R N A$ and $t R N A$ intron sequences ....................................40

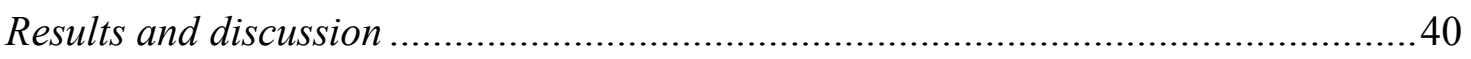

Establishment of a stable nanoarchaeotal-host enrichment culture ........................40

Isolation of the nanoarchaeote in co-culture and the host in pure culture ..............42

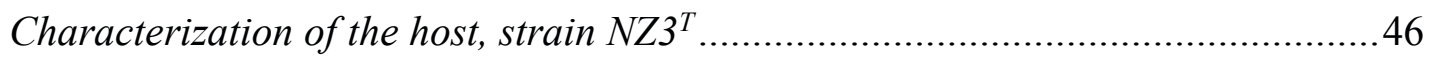

The genome of strain Ncl-1 more closely resembles its terrestrial relatives than

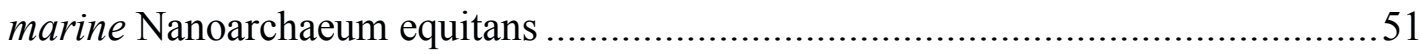

Metabolic insights from the draft genome of the host, $\mathrm{NZ3}^{T}$...............................59

Proposal of a novel Candidatus taxon in the Nanoarchaeota and a novel genus and

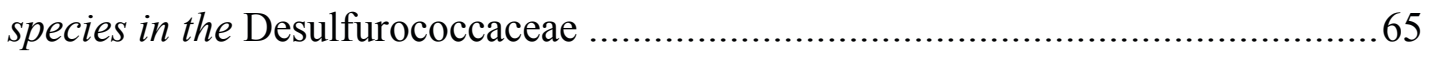

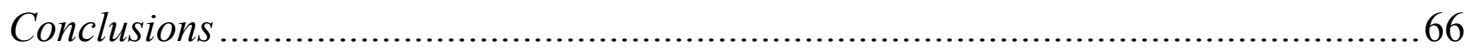

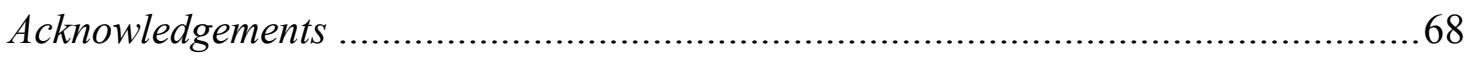

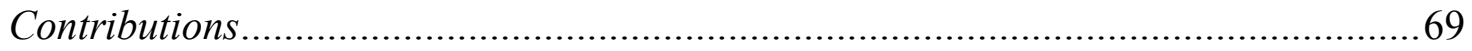

Chapter 3: Deep-sea Hydrothermal Vent Metagenome-Assembled Genomes Provide

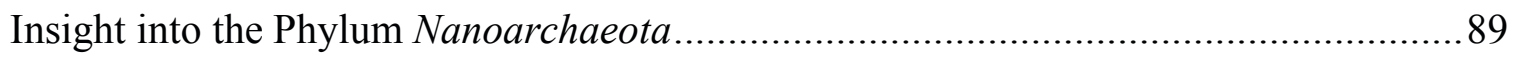

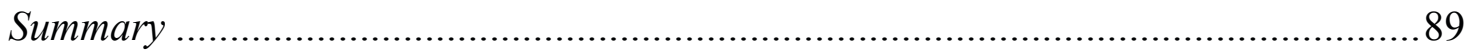


vi

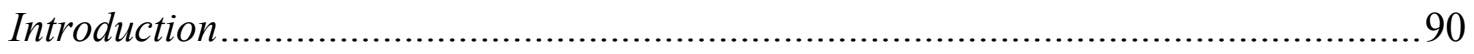

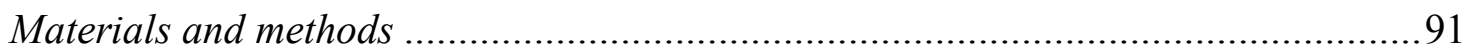

Sample collection and processing ............................................................... 91

Metagenomic sequencing, assembly and binning ......................................... 91

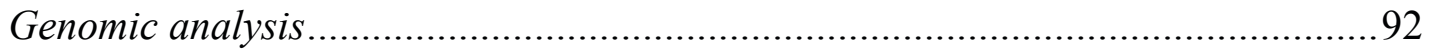

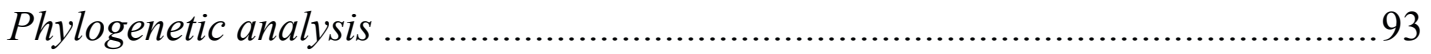

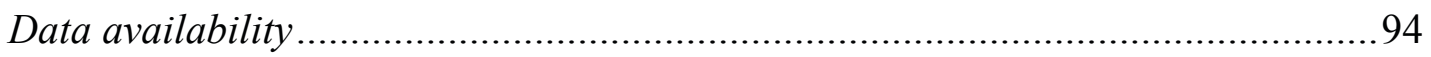

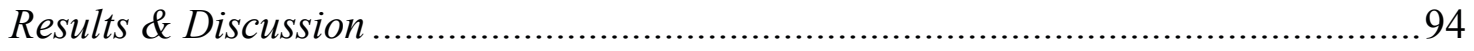

Phylogenetic analysis of nanoarchaeotal MAGs .............................................94

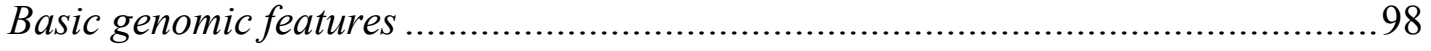

Comparative analysis of nanoarchaeotal coding potential .............................. 100

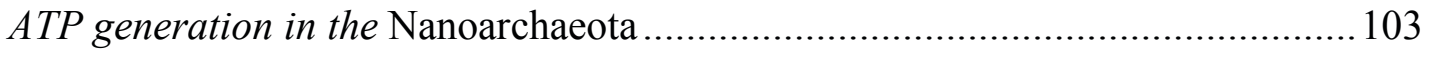

Ecophysiology of deep-sea Nanoarchaeota and their hosts ............................... 106

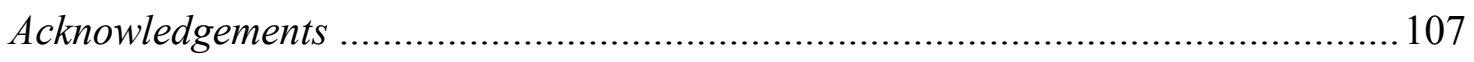

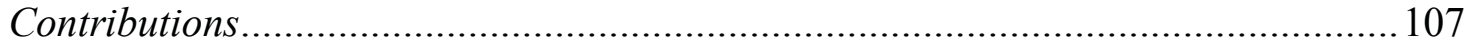

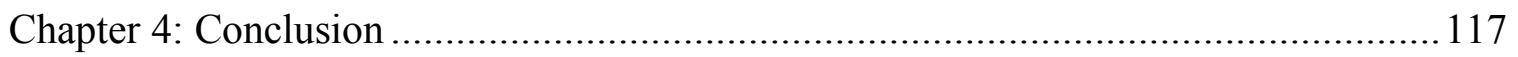

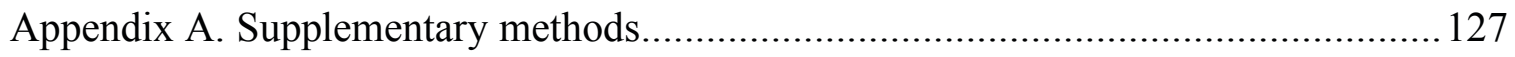

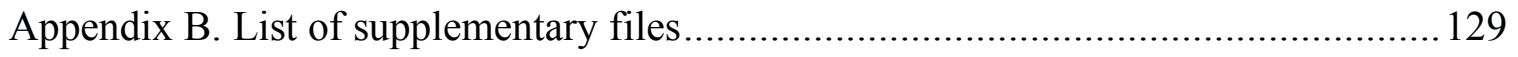




\section{List of Tables}

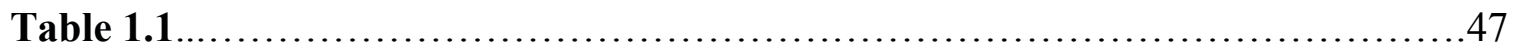

Characteristics distinguishing strain $\mathrm{NZ3}^{\mathrm{T}}$ from other representative species in the Desulfurococcaceae.

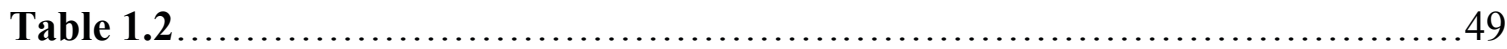

$\mathrm{NZ3}^{\mathrm{T}}$ IPLs identification.

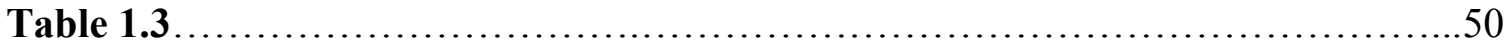

Features of the nanoarchaeote strain Ncl-1 and the host strain $\mathrm{NZ3}^{\mathrm{T}}$ and their closest cultivated relatives, based on our re-analysis of reference genomes.

Table 1.4.....

Comparison of genomic features in strain Ncl-1 and other Nanoarchaeota.

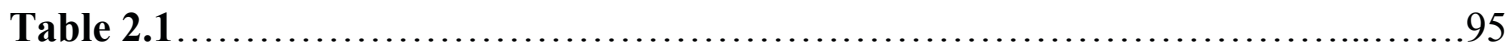

Geological features and chemical composition of end-member fluids from deep-sea hydrothermal vent sites. 


\section{List of Figures}

Figure 1.1.

Negatively stained transmission electron micrographs (TEM) of the New Zealand enrichment culture.

Figure 1.2.

Maximum likelihood phylogenetic tree of Nanoarchaeota based on 16S rRNA gene sequences.

Figure 1.3.

Predicted secondary structure and placement of intervening sequences in the 16S rRNA gene of strain $\mathrm{NZ3}^{\mathrm{T}}$.

Figure 1.4. 45

16S rRNA gene maximum likelihood phylogenetic tree of select Desulfurococcaceae.

Figure 1.5.

MS-spectra of intact polar lipid peaks identified in Table 1.2.

Figure 1.6.

HPLC-MS traces of the core lipids of $\mathrm{NZ3}^{\mathrm{T}}$.

Figure 1.7....

LC-MS analysis of the NZ3 ${ }^{\mathrm{T}}$ intact polar lipid extract.

Figure 1.8.

Phylogenetic analysis of 16 concatenated ribosomal proteins (rpL2, 3, 4, 5, 6, 15, 16, 18 , 22, 24 and rpS3, 8, 10, 17, 19) using RAxML.

Figure 1.9. .53

Circos-based genome alignments comparing overall protein homology between strain Ncl-1 and (A) Cand. Nps. acidilobi, (B) N. equitans and (C) the NZ13 draft genome, and between (D) strain $\mathrm{NZ3}^{\mathrm{T}}$ and Ignisphaera aggregans.

Figure 1.10. .56

Comparison of the archaeal flagellar gene arrangement in (A) strain Ncl-1, (B) Cand. Nps. acidilobi and (C) Pyrococcus furiosus.

Figure 1.11.

Gene arrangement of the CRISPR-Cas locus in (A) strain Ncl-1 and (B) N. equitans.

Figure 1.12

Maximum likelihood phylogenetic tree of archaeal $\operatorname{coo} S$ genes. 


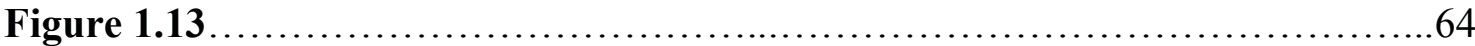
Maximum likelihood phylogenetic analysis of coenzyme $\mathrm{F}_{420}$-reducing hydrogenases.

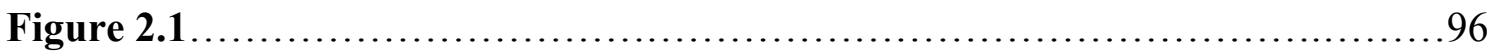
Maximum-likelihood phylogenetic tree based on eight concatenated ribosomal proteins.

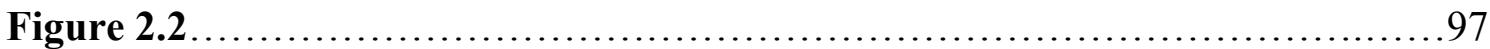
Average amino acid identity analysis of novel deep-sea Nanoarchaeota MAGs and their cultivated relatives.

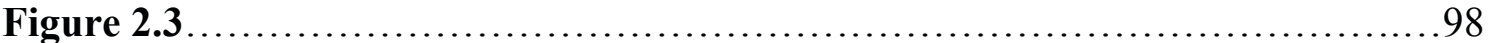

Maximum-likelihood phylogenetic analysis of nanoarchaeotal 16S rRNA genes (710 nucleotide positions).

Figure 2.4. 101 Pan-genome analysis of cultivated Nanoarchaeota and deep-sea nanoarchaeotal MAGs produced in Anvi'o [14,15].

Figure 2.5. 104

Reconstruction of the potential metabolic pathway for ATP generation in MC-1.

Figure 3.1 120

Current understanding of metabolism in the Nanoarchaeota and nanoarchaeote-host interactions. 


\section{Chapter 1: Introduction}

Diversity and exploration of the archaeal domain

Karl Woese's 1977 discovery of the archaeal domain dramatically shifted and expanded our view of the universal tree of life. Prior to this discovery, the Archaea or

"Archaebacteria" were thought to represent divergent members of the Bacteria [66,77]. However, Woese's 16S ribosomal RNA (rRNA) gene trees revealed that the Archaea were very unique on the molecular level, often more similar to their eukaryotic relatives than to the Bacteria $[73,74]$. Because of the small number of cultivated archaeal lineages, the Archaea were thought to be exclusively extremophilic or methanogenic, limited to a few specific niches across the planet. The archaeal domain was initially divided into two main kingdoms, which are now called phyla: the thermophilic Crenarchaeota and the Euryarchaeota, comprised of methanogens, halophiles, thermophiles and sulfate reducers [74].

Exploration into the third domain of life quickly began to reveal the true extent of archaeal diversity, both on the phylogenetic and physiological level. A third archaeal phylum, the Korarchaeota, was discovered in the early 1990's based on 16S rRNA gene sequences. Like the Crenarchaeota, the Korarchaeota are a thermophilic lineage, and were detected in a geothermal spring in Yellowstone National Park (YNP) [5]. However, korarchaeotal 16S rRNA genes sequences branched deep within the archaeal tree of life, prior to the split between Euryarchaeota and Crenarchaeota [4,5]. The Korarchaeota represented the first phylum-level division in the Archaea to be proposed without a single cultivated representative, setting a precedent for many later-described lineages. Around the same time period, archaeal 16S rRNA gene sequences from marine environments 
were also amplified and sequenced $[16,22]$ and a cold-loving archaeal lineage was found associated with a marine sponge [54], revealing that the Archaea were not solely limited to methanogenic and extremophilic lifestyles. Hints regarding the physiology of these moderate archaeal lineages came from a fosmid clone obtained from a soil sample, which contained both archaeal rRNA and genes typically involved in ammonia oxidation [69]. Shortly thereafter, ammonia oxidation was demonstrated in a cultivated isolate [37]. Although initially identified as cold Crenarchaeota, these temperate taxa were found to be widely distributed in marine and terrestrial environments [62] and were later proposed to represent a novel mesophilic phylum, the Thaumarchaeota [6]. The unique ability of some Thaumarchaeota to oxidize ammonia suggested that Archaea may play major roles in global biogeochemical cycling that were previously overlooked.

Yet another archaeal phylum, the Nanoarchaeota, was proposed in the early 2000's, once again expanding our understanding of archaeal diversity and physiology. These ultra-small Archaea were first identified in anaerobic enrichment cultures, where they were seen attached to the outer surface of hyperthermophilic Crenarchaeota [33]. Sequencing revealed that Nanoarchaeum equitans, the first identified nanoarchaeote, harbored a highly unique 16S rRNA gene. This gene could not be amplified using traditional archaeal 16S rRNA gene primers [33], explaining why previous diversity studies failed to detect the lineage. Direct cultivation studies showed that $N$. equitans required direct cell-to-cell contact with its crenarchaeotal host for survival, although the host did not need any nanoarchaeotes [33]. Whole genome sequencing also revealed that N. equitans contained a small, reduced genome with few biosynthetic genes, consistent with its host-dependent lifestyle [71]. The Nanoarchaeota-host system became the first 
described interspecies symbiosis between two members of the Archaea, once again demonstrating the diversity and functional flexibility of the archaeal domain.

Since the identification of these first archaeal phyla, metagenomic and single-cell sequencing techniques have revolutionized the study of microbiology, leading to the proposal of many new archaeal phyla and higher-order divisions $[3,36,60,61,63,76]$. Today, the Archaea are understood to be ubiquitous, thriving in both extreme and temperate environments across the globe. Key lineages of abundant, widely distributed Archaea have been discovered in subsurface and aquatic environments, contributing significantly to biogeochemical cycling $[3,41,60]$, while other lineages of divergent Archaea have provided insights into the relationship between the archaeal and eukaryotic domains $[63,76]$. As genetic material has continued to increase, the archaeal tree of life has also undergone significant restructuring, with several higher-order groupings proposed as a means to categorize major archaeal phyla $[27,61,76]$.

In the time since the discovery of the Nanoarchaeota, several other archaeal lineages with reduced genomes have been identified, largely by metagenomics and single-cell genome sequencing $[2,10,46,61]$. These taxa have been grouped with the Nanoarchaeota to form the DPANN superphylum, based on their tendency to cluster together in phylogenetic analyses [61]. The DPANN superphylum was originally named for five key lineages (the Diapherotrites, Parvarchaeota, Aenigmarchaeota, Nanohaloarchaeota, and Nanoarchaeota) but now includes several additional phylumlevel designations $[10,61]$. Although they harbor relatively small genomes and often have small cell sizes, members of the DPANN are highly diverse, and DPANN sequences have been recovered from a wide range of environments, including hypersaline habitats, 
groundwater, alpine lakes and acid mine drainage [2,10,46,48]. Although some Archaea in the DPANN superphylum are thought to be free-living [46], no organism from the group has been successfully isolated in axenic culture. Genomic evidence also suggests that particular DPANN lineages may rely on a host or partner for survival, like the Nanoarchaeota [10]. In situ imaging and enrichment cultivation have revealed intimate associations between two different members of the DPANN and Euryarchaeota $[2,15,26]$, suggesting that interspecies dependence may be a hallmark of some taxa in this group.

Despite the recovery of many DPANN genome sequences, the placement of the entire superphylum in the archaeal tree of life, and the Nanoarchaeota in particular, remains unclear $[7,10,51]$. It also continues to be debated whether or not the DPANN superphylum truly represents a monophyletic group [10,51,61]. Nonetheless, the discovery of diverse DPANN taxa suggests that the host-dependent lifestyle of the Nanoarchaeota may be widely distributed across multiple archaeal lineages. As the first characterized symbiosis between two Archaea, the Nanoarchaeota and their hosts greatly expand our understanding of the nature and evolution of interspecies interaction in the third domain of life, and they may provide valuable insights into the adaptations that allow diverse, small archaeal lineages to thrive across the globe.

\section{Global distribution of nanoarchaeotes}

The first cultivated nanoarchaeote, $N$. equitans, was discovered in enrichment cultures from Kolbeinsey Ridge, a shallow marine hydrothermal vent site near the coast of Iceland [33]. However, with the development of nanoarchaeotal-specific primers, 
sequences related to $N$. equitans were soon identified in geothermal sites around the world, including hot springs in YNP, New Zealand, Chile, Kamchatka and central Asia [9,12,13,30]. 16S rRNA gene diversity studies also identified nanoarchaeotal-like sequences in lower temperature environments, including hypersaline ponds and the photic zone of Yellowstone Lake $[9,13]$. While it is possible that Nanoarchaeota survive in lower temperature environments, the sequences identified in the photic zone of Yellowstone Lake may also represent cells that have drifted away from geothermal vent sites on the lake floor [35]. In either case, however, it appears that Nanoarchaeota predominantly inhabit high-temperature habitats. Nanoarchaeotal genomic signatures have also been identified at deep-sea hydrothermal vent sites along the Eastern Lau Spreading Center, Mid-Atlantic Ridge, Guaymas Basin and East Pacific Rise [20,21,30,39]. A 16S rRNA gene sequence study at East Pacific Rise demonstrated that Nanoarchaeota and their hosts may be among the first organisms to colonize young deep-sea hydrothermal vent deposits [39], suggesting that Nanoarchaeota-host pairings may play a key role in the ecology of high-temperature hydrothermal systems. This study also recovered nanoarchaeotal sequences both in the presence and absence of Ignicoccus-like sequences, providing the first hint that nanoarchaeotes may associate with diverse hosts [39].

\section{Diversity within nanoarchaeote-host systems}

Despite their broad distribution across geothermal environments, only three Nanoarchaeota-host systems have been successfully cultivated in the laboratory setting, one of which is described in Chapter 2. A fourth nanoarchaeote-host system has also 
been extensively described by single-cell genome sequencing. Cultivated nanoarchaeotes vary in size, but they have consistently small cell diameters $(\sim 100-400 \mathrm{~nm})$, and each nanoarchaeote relies on a distinct host from the Crenarchaeota $[33,64,75]$. The three cultivated nanoarchaeote-host pairings all appear to be specific, although the crenarchaeotal hosts are highly diverse.

N. equitans, the first described nanoarchaeote, associates with Ignicoccus hospitalis, a hyperthermophilic Crenarchaeota with a highly streamlined genome [52]. I. hospitalis fixes carbon using the efficient dicarboxylate/4-hydroxybutyrate cycle [32,52] and obtains energy via sulfur reduction [49]. Members of the Ignicoccus are relatively unique among the Archaea due to the extensive double membrane surrounding their cells [31,49]. I. hospitalis has a large periplasmic space between its inner and outer membrane, which often contains vesicles and/or protrusions [29,49]. Energy generation in I. hospitalis takes place across the energized outer membrane, which houses an ATP synthase complex and enzymatic machinery needed to generate a proton gradient [38]. This extensive endomembrane system likely has played a key role in the evolution of the N. equitans-I. hospitalis interaction.

To explore the diversity of nanoarchaeotes in high-temperature terrestrial settings, a second and third cultivated nanoarchaeote-host system were isolated from geothermal springs in YNP and New Zealand. The YNP nanoarchaeote, Candidatus Nanopusillus acidilobi, was obtained from Cistern Spring, an acidic geothermal pool [75]. Cand. Nps. acidilobi associates with the acidophilic lineage Acidilobus sp. 7A [75]. Unlike autotrophic I. hospitalis, Acidilobus sp. 7A is a heterotroph that ferments protein- and carbohydrate-rich substrates [75]. Chapter 2 describes the cultivation of the New 
Zealand nanoarchaeote, Candidatus Nanoclepta minutus, from a circum-neutral hot spring in New Zealand [64]. Cand. Ncl. minutus lives on the surface of Zestosphaera tikiterensis, the first representative of a novel genus in the Crenarchaeota [64]. Direct characterization in Chapter 2 showed that $Z$. tikiterensis is also a heterotroph that degrades proteinaceous substrates and requires thiosulfate for growth [64]. In contrast to I. hospitalis, neither of the cultivated terrestrial hosts have a double membrane system. Instead, both Acidilobus sp. 7A and Z. tikiterensis encode for an S-layer, a protein-based lattice that envelops the cell $[64,75]$.

Several additional nanoarchaeote-host pairings have also been identified using single-cell genome sequences from hot springs in YNP. Because of the close relationship between the Nanoarchaeota and their hosts, single-cell genome sequencing techniques often recover both nanoarchaeotal and host DNA, providing a method of assessing host diversity. Putative nanoarchaeote hosts from YNP span several genera and include lineages related to the Sulfolobales, Metallosphaera, Caldivirga, Thermocladium and Vulcanisaeta $[35,44,53]$. Despite this diverse array of hosts, however, single-cell amplified nanoarchaeotes show high 16S rRNA gene sequence similarity ( $>95 \%)$ to the cultivated lineage Cand. Nps. acidilobi [35], suggesting that YNP Nanoarchaeota may undergo frequent host-switching events. It is currently unclear what may be driving this rapid host diversification. However, both nanoarchaeote and host cell envelope structure may play a crucial role. An analysis of synonymous versus non-synonymous mutations in single-cell amplified YNP nanoarchaeotal genomes suggested that hypothetical cellsurface proteins in the Nanoarchaeota undergo rapid evolution [35], which may provide the novel mutations needed to facilitate new host associations. Additionally, several of 
the putative host lineages likely have S-layers $[53,70]$, a similarity that may allow for more frequent host-switching events.

Although no Nanoarchaeota have been cultivated from deep submarine hydrothermal vent environments, three nanoarchaeotal metagenome-assembled genomes (MAGs) have been obtained from deep-sea hydrothermal vents sites across the world [65], as described in Chapter 3. However, without cultivation or single-cell sequencing approaches, it is nearly impossible to determine what host organism(s) associate with these Nanoarchaeota. No Ignicoccus-like bins were recovered from any of these deepsea metagenomes, but one data set contained a bin closely related to the New Zealand host lineage Zestosphaera [65]. This suggests that marine nanoarchaeotes may associate with multiple hosts, not just I. hospitalis, and some of these host organisms may resemble their terrestrial counterparts on the phylogenetic level.

\section{Nanoarchaeote-host interaction dynamics}

Although all three cultivated nanoarchaeotes have an ectosymbiotic lifestyle, most of our understanding of Nanoarchaeota/host interactions comes from the N. equitans-I. hospitalis system, which has been studied for over 15 years and can be cultivated in large volumes using an anaerobic fermenter [33]. Like all cultivated nanoarchaeotes, $N$. equitans largely relies on its host for the production of metabolic building blocks $[64,71,75]$. Labelling studies have demonstrated that $I$. hospitalis-synthesized lipids and amino acids are transferred to $N$. equitans $[34,49]$. Likely, this exchange takes place via a pore-like structure that connects I. hospitalis and $N$. equitans, where the cytoplasm of host and nanoarchaeote appear to meet [29]. While studies of the N. equitans- 
I. hospitalis system are much more extensive, electron microscopy has also revealed a similar pore-type formation between terrestrial nanoarchaeote $\mathrm{Cand}$. Ncl. minutus and its host, shown in Chapter 2 [64], and membrane stretching at the attachment site of Cand. Nps. acidilobi and Acidilobus sp. 7A [75]. Due to the differences in host cell envelope, the mechanism of association in these terrestrial nanoarchaeote-host systems may be very different compared to that of $N$. equitans and I. hospitalis [53]. Nevertheless, imaging studies suggest an equally intimate attachment between all cultivated Nanoarchaeota, which may involve cytoplasmic bridging.

In the laboratory setting, different nanoarchaeotes appear to have variable effects on their respective hosts. Although $N$. equitans does not significantly affect the growth rate or final population of $I$. hospitalis cells, the growth curves of the two organisms are not synchronized during cultivation $[25,49]$. N. equitans cells continue dividing exponentially after I. hospitalis enters stationary phase, and nanoarchaeotes may eventually outnumber I. hospitalis cells by a factor of ten [25,49]. Also, infection with nanoarchaeotes can hamper or even halt the ability of $I$. hospitalis to divide, indicating a high cost for individual host cells [49]. In contrast, the growth of the YNP nanoarchaeote Cand. Nps. acidilobi is synchronized closely with that of its host, Acidilobus sp. 7A, with Acidilobus cells consistently outnumbering nanoarchaeotes [75]. Growth profiles of pure culture and co-cultured Acidilobus sp. 7A also show no appreciable difference [75]. Overall, this may suggest that Cand. Nps. acidilobi is less damaging to host growth and survival than N. equitans. In the Cand. Ncl. minutus-Z. tikiterensis system, discussed in Chapter 2, direct counts of host cells and qPCR-derived counts of nanoarchaeotes also appear to be synchronous, pointing to a system more similar to the YNP 
nanoarchaeote/host symbiosis [64]. Notably, Chapter 2 also reveals that Cand. Ncl. minutus is able to grow to much higher densities in complex enrichment cultures compared to co-culture with Z. tikiterensis [64]. Although Z. tikiterensis functions as the obligate and primary host for Cand. Ncl. minutus, it is possible that other lineages provide nutrients or small molecules that encourage nanoarchaeote growth. To date, all cultivated nanoarchaeote-host pairings appear to be specific, and most cross-infection studies have been largely unsuccessful $[49,75]$. Although rare host-switching events have been observed in the laboratory, none of these novel Nanoarchaeota-pairings have been maintained (Mircea Podar, personal communication). However, this does not rule out the possibility that nanoarchaeotes engage in a variety of interactions with diverse organisms in their natural geothermal habitats, all while maintaining their obligate host associations.

Proteomic data comparing pure I. hospitalis cultures and N. equitans-I. hospitalis co-cultures has also revealed some of the effects of Nanoarchaeota association on the host. I. hospitalis cells show differential changes in transcriptional regulator expression when cultivated with $N$. equitans, suggesting that nanoarchaeote association causes highly controlled, specific changes within the host $[24,25]$. Over time, co-cultivation with $N$. equitans also causes increases in expression of host carbon fixation and energy generation genes, likely in response to the increased metabolic demands from the nanoarchaeotes [25]. Stress proteins are shown to be highly expressed in the I. hospitalis proteome, although the organism does not appear to mount a significant defensive response to nanoarchaeotal infection [24,25]. High levels of stress proteins were also detected in the proteome of YNP host Acidilobus sp. 7A when co-cultivated with its 
Nanoarchaeota [75]. However, because no proteomic data from pure Acidilobus sp. 7A cultures is available, it is unclear whether or not these proteins are expressed in reaction to nanoarchaeotal infection, or if they represent a constitutive response to environmental stressors. In the future, comparative proteomic studies such as those performed on the $N$. equitans-I. hospitalis system will be pivotal in determining whether or not terrestrial hosts react to their respective nanoarchaeotes in a similar manner.

\section{Shared genomic features of cultivated nanoarchaeotes}

Like many obligate symbionts and parasites, cultivated Nanoarchaeota have reduced genomes, ranging in size from 0.491 (N. equitans) to $0.606 \mathrm{Mbp}$ (Cand. Nps. acidilobi) [71,75]. Although described Nanoarchaeota have a fairly extensive set of genes used in cell replication, RNA transcription and protein translation, they have lost most biosynthetic capabilities [64,71,75]. Without these core functions, Nanoarchaeota rely on host-produced cofactors, nucleotides, lipids and amino acids [71]. As shown in Chapter 2, each of the three genomes also encode split protein-coding genes, which are in multiple open reading frames spread across the genome [64,71,75]. At least some of these split genes likely maintain their functionality, as demonstrated for the split alanyltRNA synthase in N. equitans [71]. Although the three cultivated Nanoarchaeota share a common set of split protein-coding genes, several unique split genes are also scattered across the three genomes. Some of these split genes have also been recovered in singlecell nanoarchaeotal genomes from YNP $[44,53]$ and Nanoarchaeota MAGs from deepsea hydrothermal vents [65], as described in Chapter 3. These patterns of distribution suggest that the last common ancestor of described nanoarchaeotal lineages already had 
split protein-coding genes and that genomic fragmentation has continued to occur after these taxa diverged $[53,64]$. Because of the fast evolving nature of the reduced and fragmented Nanoarchaeota genomes, the positioning of the nanoarchaeotal lineage and the DPANN group in the archaeal tree remains unclear $[8,17,61,71,72]$. However, split protein-coding genes in the Nanoarchaeota are typically seen as a derived feature, resulting from genome degradation due to host association [53].

In addition to their lack of biosynthetic genes, cultivated Nanoarchaeota do not have any apparent means of ATP production. Although N. equitans encodes a partial ATP synthase, the complex is quite divergent and cannot undergo conformational changes, which are necessary for enzyme functionality [42]. Additionally, as discussed in Chapter 2, no ATP synthase complex genes could be identified in the genomes of Cand. Nps. acidilobi or Cand. Ncl. minutus [64,75], suggesting this method of ATP generation is not functional across nanoarchaeotal lineages. The glycolysis pathway, which can produce minimal ATP through substrate-level phosphorylation, is also not complete in any of the three cultivated nanoarchaeotal genomes $[64,71,75]$. One deepsea Nanoarchaeota MAG reported in Chapter 3 contains genes for the pentose bisphosphate pathway, which may provide a way for the nanoarchaeote to produce minimal ATP after circumventing the early steps of glycolysis [65]. However, this pathway is thus far restricted to one nanoarchaeotal MAG, and it is unknown whether or not these enzymes are functional in vivo. Without a widely-distributed means of synthesizing ATP, most Nanoarchaeota likely rely on their hosts for ATP production. Co-cultures of $N$. equitans and I. hospitalis have been shown to contain less ATP than pure I. hospitalis cultures, supporting this hypothesis and suggesting that nanoarchaeotes 
are utilizing host-produced ATP to fuel their own metabolic processes [28]. Complete and partial dependence on host ATP has been identified previously in obligate intracellular symbionts and parasites, including pathogenic Chlamydia and the insect symbiont Cardinium [14,50]. Both of these intracellular organisms contain ATP transporters to import host-produced ATP across the membrane [50,67], which have not been identified in the Nanoarchaeota. However, nanoarchaeotes may siphon ATP directly away from their hosts through the pore-like bridge connecting the two organisms.

Despite their small size and highly reduced gene content, the three cultivated Nanoarchaeota have efficient genomes with high coding density. Compared to obligate intracellular Bacteria, the nanoarchaeotes have maintained a higher level of genomic integrity and avoided extensive genome collapse [71]. As shown in Chapter 3, the three cultivated Nanoarchaeota have also retained their DNA repair mechanisms $[65,71]$, which are often lost in endosymbiotic lineages [43], allowing them to avoid a buildup of deleterious mutations. Also, Nanoarchaeota have the added advantage of exposure to the outside environment, which provides them with avenues for horizontal gene transfer (HGT) from viruses and neighboring cells $[44,47]$. Based on genomic analysis of the $N$. equitans-I. hospitalis system, HGT also appears to occur between the host and nanoarchaeotal symbiont [71], which may help Nanoarchaeota compensate for gene loss events. The differences between nanoarchaeotal genomes and those of obligate endosymbiotic Bacteria may point to the different selection pressures affecting genome size and structure in these diverse environments [47]. In the case of endosymbionts, isolation within the host typically leads to massive gene loss and degradation, with few mechanisms for recovering lost functions $[33,35]$. However, genome reduction in the 
Nanoarchaeota may be a product of both host dependence and the high-temperature geothermal habitat, which tends to select for smaller cell volumes, streamlined genomes and shorter gene variants, all while avoiding the extreme isolation of the intercellular environment [47].

\section{Unique features of various nanoarchaeotes}

Although all cultivated Nanoarchaeota share a similar ectosymbiotic lifestyle, their genomes harbor some key differences. N. equitans has the smallest genome of any cultivated Nanoarchaeota and shows more extensive gene loss and reduction compared to its terrestrial relatives, which is especially evident in its RNA systems [71]. $N$. equitans is lacking the RNase $\mathrm{P}$ complex, previously thought to be ubiquitous across all life [19]. RNase P performs a crucial step in the generation of mature RNA molecules by trimming the 5' leader sequence from precursor tRNAs [19]. However, N. equitans can function without RNase $\mathrm{P}$ due to its shifted tRNA promoter regions, which allow precursor tRNAs to be transcribed without a leader sequence [58]. Both cultivated terrestrial Nanoarchaeota appear to retain the enzyme (Chapter 2), and RNase P protein subunits have been identified in multiple nanoarchaeotal MAGs from marine hydrothermal vents (Chapter 3) [64,65,75], suggesting that RNase P is typically maintained across nanoarchaeotal lineages. The loss of RNase P in N. equitans likely reflects the high level of genomic reduction found in this particular Nanoarchaeota $[53,58]$. Trans-encoded tRNA genes in the $N$. equitans genome also support a scenario of extensive genome re-arrangement [53]. These split tRNA genes are encoded in multiple pieces, which are fused into functional tRNAs after transcription using a 
nanoarchaeotal splicing endonuclease [55-57]. Since their discovery in N. equitans, trans-spliced tRNA genes have also been identified in several lineages of free-living Crenarchaeota $[11,23]$. Potentially, these split tRNA genes represent a defense mechanism used to avoid integration of viral DNA, which targets conserved tRNA gene sequences, or they may be the product of previous insertion events [57,59]. Alternately, it has also been proposed that these trans-encoded tRNA genes represent an ancestral gene form, which carries implications for the evolutionary history of extant tRNA genes [18]. To date, no split tRNA genes have been identified in any nanoarchaeotal lineage outside of $N$. equitans $[44,53,64,75]$.

Genomic evidence suggests that diverse Nanoarchaeota interact with the abundant viral populations found in geothermal environments. CRISPR-Cas cassettes have been identified in N. equitans [55,71] and Cand. Ncl. minutus [64], and cas genes have been discovered in deep-sea nanoarchaeotal MAGs [65], as discussed in Chapters 2 and 3, respectively. Integrated prophage DNA has also been found in single-cell amplified nanoarchaeotal genomes from YNP [44,45]. However, no CRISPR-Cas regions were detected in YNP Nanoarchaeota genomes [44,53,75], suggesting that defense mechanisms against viral infection may not be distributed across all nanoarchaeotal lineages. While viruses may pose a threat to nanoarchaeotal cells, they may also provide a reservoir of genetic material which could serve to replace lost gene functions through HGT [67].

Compared to N. equitans, both terrestrial nanoarchaeotes have somewhat expanded genomes, and both contain genes that are lacking their marine relative, which is shown in Chapter 2. Most notably, Cand. Nps. acidilobi and Cand. Ncl. minutus both 
encode genes for the archaeal flagellum, which are expressed in the proteome of Cand. Nps. acidilobi [75] and are visible by electron microscopy in Cand. Ncl. minutus [64]. Unlike most Archaea, however, the archaeal flagellar genes are not encoded in an operon [1], once again pointing to patterns of genome reshuffling in the Nanoarchaeota. Currently, the function of the archaeal flagella is unclear, especially given the apparent inability of cultivated nanoarchaeotes to produce ATP needed to fuel motility. However, as discussed further in Chapter 2, it is possible that the Nanoarchaeota may use their archaeal flagella only when attached to their hosts, fueling motility with host-produced ATP [64]. Alternately, the archaeal flagella may have a function in the association between Nanoarchaeota and their hosts [53,64,75]. Both terrestrial nanoarchaeotes also encode genes for the gluconeogenic pathway, which are highly expressed in the Cand. Nps. acidilobi proteome [75]. Likely, these enzymes aid in the production of sugars for cell-surface glycosylation $[64,75]$. This process may play a key role in the Nanoarchaeota-host association [75], potentially facilitating the wide diversity of nanoarchaeote-host pairings identified in YNP hot springs [35]. Although archaeal flagella and gluconeogenic genes were not detected in the genome of $N$. equitans [71], their distribution does not appear to be governed by habitat type alone. In Chapter 3 , marker genes for gluconeogenesis and archaeal flagella were also identified in nanoarchaeotal MAGs from geographically distant deep-sea hydrothermal vents, suggesting these features may be widely distributed across the Nanoarchaeota [65]. Once again, this pattern suggests that $N$. equitans represents a more highly reduced lineage compared to other described nanoarchaeotes. However, as more Nanoarchaeota- 
host pairings are identified, additional ecophysiological patterns may emerge that are not yet apparent.

\section{Conclusions}

The Nanoarchaeota represent a diverse, widely distributed lineage thriving in geothermal environments around the world. The highly specialized host-dependent lifestyle of the nanoarchaeotes provides unique insights into interspecies relationships across the Archaea. However, the three described Nanoarchaeota-host systems defy easy classification. Although the nanoarchaeotes initially resemble parasites, relying on their hosts for the majority of metabolic products, they cause fewer detrimental effects to the host than expected. Marine and terrestrial Nanoarchaeota also appear to interact with their hosts in different ways, as evidenced by unique growth patterns during cultivation. To date, no positive benefits of Nanoarchaeota infection have been demonstrated in the laboratory setting, although nanoarchaeotal association may provide yet unknown benefits to hosts in their diverse natural communities. Further cultivation and genome sequencing will be crucial to understanding the intricacies of the Nanoarchaeota-host interaction, and the role this symbiotic system plays in the ecology of hot springs and deep-sea hydrothermal vents.

Scope of thesis

Although our understanding of nanoarchaeotal diversity and physiology has advanced significantly since the discovery of $N$. equitans in the early 2000's, many questions regarding nanoarchaeotal biology remain unanswered. Despite the prevalence 
of nanoarchaeotal 16S rRNA gene sequences in high-temperature environments, few Nanoarchaeota have been cultivated with their hosts, and only a small number of nanoarchaeote genomes have been sequenced. To assess the functional and phylogenetic diversity of nanoarchaeotes from geographically distant hot spring environments, a new Nanoarchaeota-host system from New Zealand was cultivated and described on the genomic level, as reported in Chapter 2. The similarities between the New Zealand and YNP nanoarchaeotes and their divergence from marine $N$. equitans suggested that terrestrial nanoarchaeotes may harbor a unique set of features lacking in their marine relatives. To further investigate this question, nanoarchaeote MAGs were recovered from deep submarine hydrothermal vent sites (Chapter 3). However, genomic analysis of these MAGs revealed no clear pattern between marine and terrestrial lineages in terms of coding potential. Nonetheless, the studies presented in Chapters 2 and 3 display the phylogenetic diversity of the Nanoarchaeota and provide fresh insights into this enigmatic phylum. 
References

[1] Albers, S.-V., Jarrell, K.F. (2015) The archaellum: how Archaea swim. Front. Microbiol. 6, 23, https://doi.org/10.3389/fmicb.2015.00023.

[2] Baker, B.J., Comolli, L.R., Dick, G.J., Hauser, L.J., Hyatt, D., Dill, B.D., Land, M.L., Verberkmoes, N.C., Hettich, R.L., Banfield, J.F. (2010) Enigmatic, ultrasmall, uncultivated Archaea. Proc. Natl. Acad. Sci. U. S. A. 107(19), 88068811.

[3] Baker, B.J., Saw, J.H., Lind, A.E., Lazar, C.S., Hinrichs, K.-U., Teske, A.P., Ettema, T.J.G. (2016) Genomic inference of the metabolism of cosmopolitan subsurface Archaea, Hadesarchaea. Nat Microbiol 1, 16002, https://doi.org/10.1038/nmicrobiol.2016.2.

[4] Barns, S.M., Delwiche, C.F., Palmer, J.D., Pace, N.R. (1996) Perspectives on archaeal diversity, thermophily and monophyly from environmental rRNA sequences. Proc. Natl. Acad. Sci. U. S. A. 93(17), 9188-9193.

[5] Barns, S.M., Fundyga, R.E., Jeffries, M.W., Pace, N.R. (1994) Remarkable archaeal diversity detected in a Yellowstone National Park hot spring environment. Proc. Natl. Acad. Sci. U. S. A. 91(5), 1609-1613.

[6] Brochier-Armanet, C., Boussau, B., Gribaldo, S., Forterre, P. (2008) Mesophilic Crenarchaeota: proposal for a third archaeal phylum, the Thaumarchaeota. Nat. Rev. Microbiol. 6, 245-252.

[7] Brochier-Armanet, C., Forterre, P., Gribaldo, S. (2011) Phylogeny and evolution of the Archaea: one hundred genomes later. Curr. Opin. Microbiol. 14, 274-281.

[8] Brochier, C., Gribaldo, S., Zivanovic, Y., Confalonieri, F., Forterre, P. (2005) 
Nanoarchaea: representatives of a novel archaeal phylum or a fast-evolving euryarchaeal lineage related to Thermococcales? Genome Biol. 6(5), R42, https://doi.org/10.1186/gb-2005-6-5-r42.

[9] Casanueva, A., Galada, N., Baker, G.C., Grant, W.D., Heaphy, S., Jones, B., Yanhe, M., Ventosa, A., Blamey, J., Cowan, D.A. (2008) Nanoarchaeal 16S rRNA gene sequences are widely dispersed in hyperthermophilic and mesophilic halophilic environments. Extremophiles 12, 651-656.

[10] Castelle, C.J., Wrighton, K.C., Thomas, B.C., Hug, L.A., Brown, C.T., Wilkins, M.J., Frischkorn, K.R., Tringe, S.G., Singh, A., Markillie, L.M., Taylor, R.C., Williams, K.H., Banfield, J.F. (2015) Genomic expansion of domain Archaea highlights roles for organisms from new phyla in anaerobic carbon cycling. Curr. Biol. 25(6), P690-P701.

[11] Chan, P.P., Cozen, A.E., Lowe, T.M. (2011) Discovery of permuted and recently split transfer RNAs in Archaea. Genome Biol. 12, R38, https://doi.org/10.1186/gb2011-12-4-r38.

[12] Chernyh, N.A., Mardanov, A. V., Gumerov, V.M., Miroshnichenko, M.L., Lebedinsky, A. V., Merkel, A.Y., Crowe, D., Pimenov, N. V., Rusanov, I.I., Ravin, N. V., Moran, M.A., Bonch-Osmolovskaya, E.A. (2015) Microbial life in Bourlyashchy, the hottest thermal pool of Uzon Caldera, Kamchatka. Extremophiles 19(6), 1157-1171.

[13] Clingenpeel, S., Kan, J., Macur, R.E., Woyke, T., Lovalvo, D., Varley, J., Inskeep, W.P., Nealson, K., McDermott, T.R. (2013) Yellowstone Lake Nanoarchaeota. Front. Microbiol. 4, 274, https://doi.org/10.3389/fmicb.2013.00274. 
[14] Collingro, A., Köstlbacher, S., Mussmann, M., Stepanauskas, R., Hallam, S.J., Horn, M. (2017) Unexpected genomic features in widespread intracellular Bacteria: evidence for motility of marine Chlamydiae. ISME J. 11(10), 23342344.

[15] Comolli, L.R., Banfield, J.F. (2014) Inter-species interconnections in acid mine drainage microbial communities. Front. Microbiol. 5, 367, https://doi.org/10.3389/fmicb.2014.00367.

[16] DeLong, E.F. (1992) Archaea in coastal marine environments. Proc. Natl. Acad. Sci. U. S. A. 89(12), 5685-5689.

[17] Di Giulio, M. (2014) The split genes of Nanoarchaeum equitans have not originated in its lineage and have been merged in another Nanoarchaeota: A reply to Podar et al. J. Theor. Biol. 349, 167-169.

[18] Di Giulio, M. (2008) Transfer RNA genes in pieces are an ancestral character. EMBO Rep. 9(9), 820.

[19] Evans, D., Marquez, S.M., Pace, N.R. (2006) RNase P: interface of the RNA and protein worlds. Trends Biochem. Sci. 31(6), 333-341.

[20] Flores, G.E., Campbell, J.H., Kirshtein, J.D., Meneghin, J., Podar, M., Steinberg, J.I., Seewald, J.S., Tivey, M.K., Voytek, M.A., Yang, Z.K., Reysenbach, A.L. (2011) Microbial community structure of hydrothermal deposits from geochemically different vent fields along the Mid-Atlantic Ridge. Environ. Microbiol. 13(8), 2158-2171.

[21] Flores, G.E., Shakya, M., Meneghin, J., Yang, Z.K., Seewald, J.S., Geoff Wheat, C., Podar, M., Reysenbach, A.-L. (2012) Inter-field variability in the microbial 
communities of hydrothermal vent deposits from a back-arc basin. Geobiology $10(4), 333-346$.

[22] Fuhrman, J.A., McCallum, K. (1992) Novel major archaebacterial group from marine plankton. Nature 356(6365), 148-149.

[23] Fujishima, K., Sugahara, J., Kikuta, K., Hirano, R., Sato, A., Tomita, M., Kanai, A. (2009) Tri-split tRNA is a transfer RNA made from 3 transcripts that provides insight into the evolution of fragmented tRNAs in Archaea. Proc. Natl. Acad. Sci. 106(8), 2683-2687.

[24] Giannone, R.J., Huber, H., Karpinets, T., Heimerl, T., Küper, U., Rachel, R., Keller, M., Hettich, R.L., Podar, M. (2011) Proteomic characterization of cellular and molecular processes that enable the Nanoarchaeum equitans-Ignicoccus hospitalis relationship. PLoS One 6(8), e22942, https://doi.org/10.1371/journal.pone.0022942.

[25] Giannone, R.J., Wurch, L.L., Heimerl, T., Martin, S., Yang, Z., Huber, H., Rachel, R., Hettich, R.L., Podar, M. (2015) Life on the edge: functional genomic response of Ignicoccus hospitalis to the presence of Nanoarchaeum equitans. ISME J. 9(1), $101-114$.

[26] Golyshina, O. V., Toshchakov, S. V., Makarova, K.S., Gavrilov, S.N., Korzhenkov, A.A., La Cono, V., Arcadi, E., Nechitaylo, T.Y., Ferrer, M., Kublanov, I. V., Wolf, Y.I., Yakimov, M.M., Golyshin, P.N. (2017) “ARMAN” Archaea depend on association with euryarchaeal host in culture and in situ. Nat. Commun. 8, 60, https://doi.org/10.1038/s41467-017-00104-7.

[27] Guy, L., Ettema, T.J.G. (2011) The archaeal "TACK" superphylum and the origin 
of eukaryotes. Trends Microbiol. 19(12), 580-587.

[28] Hamerly, T., Tripet, B.P., Tigges, M., Giannone, R.J., Wurch, L., Hettich, R.L., Podar, M., Copié, V., Bothner, B. (2015) Untargeted metabolomics studies employing NMR and LC-MS reveal metabolic coupling between Nanoarchaeum equitans and its archaeal host Ignicoccus hospitalis. Metabolomics 11, 895-907.

[29] Heimerl, T., Flechsler, J., Pickl, C., Heinz, V., Salecker, B., Zweck, J., Wanner, G., Geimer, S., Samson, R.Y., Bell, S.D., Huber, H., Wirth, R., Wurch, L., Podar, M., Rachel, R. (2017) A complex endomembrane system in the archaeon Ignicoccus hospitalis tapped by Nanoarchaeum equitans. Front. Microbiol. 8, 1072, https://doi.org/10.3389/fmicb.2017.01072.

[30] Hohn, M.J., Hedlund, B.P., Huber, H. (2002) Detection of 16S rDNA sequences representing the novel phylum "Nanoarchaeota": Indication for a wide distribution in high temperature biotopes. Syst. Appl. Microbiol. 25, 551-554.

[31] Huber, H., Burggraf, S., Mayer, T., Wyschkony, I., Rachel, R., Stetter, K.O. (2000) Ignicoccus gen. nov., a novel genus of hyperthermophilic, chemolithoautotrophic Archaea, represented by two new species, Ignicoccus islandicus sp. nov. and Ignicoccus pacificus sp. nov. Int. J. Syst. Evol. Microbiol. 50(6), 2093-2100.

[32] Huber, H., Gallenberger, M., Jahn, U., Eylert, E., Berg, I.A., Kockelkorn, D., Eisenreich, W., Fuchs, G. (2008) A dicarboxylate/4-hydroxybutyrate autotrophic carbon assimilation cycle in the hyperthermophilic archaeum Ignicoccus hospitalis. Proc. Natl. Acad. Sci. 105(22), 7851-7856.

[33] Huber, H., Hohn, M.J., Rachel, R., Fuchs, T., Wimmer, V.C., Stetter, K.O. (2002) 
A new phylum of Archaea represented by a nanosized hyperthermophilic symbiont. Nature 417(6884), 63-67.

[34] Jahn, U., Summons, R., Sturt, H., Grosjean, E., Huber, H. (2004) Composition of the lipids of Nanoarchaeum equitans and their origin from its host Ignicoccus sp. strain KIN4/I. Arch. Microbiol. 190(5), 1743-1750.

[35] Jarett, J.K., Nayfach, S., Podar, M., Inskeep, W., Ivanova, N.N., Munson-McGee, J., Schulz, F., Young, M., Jay, Z.J., Beam, J.P., Kyrpides, N.C., Malmstrom, R.R. (2018) Single-cell genomics of co-sorted Nanoarchaeota suggests novel putative host associations and diversification of proteins involved in symbiosis. Microbiome 6(161), https://doi.org/10.1186/s40168-018-0539-8.

[36] Jungbluth, S.P., Amend, J.P., Rappé, M.S. (2017) Metagenome sequencing and 98 microbial genomes from Juan de Fuca Ridge flank subsurface fluids. Sci. Data 4, 170037, https://doi.org/10.1038/sdata.2017.37.

[37] Könneke, M., Bernhard, A.E., De La Torre, J.R., Walker, C.B., Waterbury, J.B., Stahl, D.A. (2005) Isolation of an autotrophic ammonia-oxidizing marine archaeon. Nature 437(22), 543-546.

[38] Kuper, U., Meyer, C., Muller, V., Rachel, R., Huber, H. (2010) Energized outer membrane and spatial separation of metabolic processes in the hyperthermophilic archaeon Ignicoccus hospitalis. Proc. Natl. Acad. Sci. 107(7), 3152-3156.

[39] McCliment, E.A., Voglesonger, K.M., O’Day, P.A., Dunn, E.E., Holloway, J.R., Cary, S.C. (2006) Colonization of nascent, deep-sea hydrothermal vents by a novel archaeal and nanoarchaeal assemblage. Environ. Microbiol. 8(1), 114-125.

[40] McCutcheon, J.P., Moran, N.A. (2012) Extreme genome reduction in symbiotic 
Bacteria. Nat. Rev. Microbiol. 10, 13-26.

[41] Meng, J., Xu, J., Qin, D., He, Y., Xiao, X., Wang, F. (2014) Genetic and functional properties of uncultivated MCG Archaea assessed by metagenome and gene expression analyses. ISME J. 8, 650-659.

[42] Mohanty, S., Jobichen, C., Chichili, V.P.R., Velázquez-Campoy, A., Low, B.C., Hogue, C.W.V., Sivaraman, J. (2015) Structural basis for a unique ATP synthase core complex from Nanoarchaeum equitans. J. Biol. Chem. 290(45), 2728027296.

[43] Moran, N.A., Plague, G.R. (2004) Genomic changes following host restriction in Bacteria. Curr. Opin. Genet. Dev. 14, 627-633.

[44] Munson-McGee, J.H., Field, E.K., Bateson, M., Rooney, C., Stepanauskas, R., Young, M.J. (2015) Nanoarchaeota, their Sulfolobales host, and Nanoarchaeota virus distribution across Yellowstone National Park hot springs. Appl. Environ. Microbiol. 81(22), 7860-7868.

[45] Munson-McGee, J.H., Peng, S., Dewerff, S., Stepanauskas, R., Whitaker, R.J., Weitz, J.S., Young, M.J. (2018) A virus or more in (nearly) every cell: ubiquitous networks of virus-host interactions in extreme environments. ISME J. 12, 17061714.

[46] Narasingarao, P., Podell, S., Ugalde, J.A., Brochier-Armanet, C., Emerson, J.B., Brocks, J.J., Heidelberg, K.B., Banfield, J.F., Allen, E.E. (2012) De novo metagenomic assembly reveals abundant novel major lineage of Archaea in hypersaline microbial communities. ISME J. 6, 81-93.

[47] Nicks, T., Rahn-Lee, L. (2017) Inside out: archaeal ectosymbionts suggest a 
second model of reduced-genome evolution. Front. Microbiol. 8, 384, https://doi.org/10.3389/fmicb.2017.00384.

[48] Ortiz-Alvarez, R., Casamayor, E.O. (2016) High occurrence of Pacearchaeota and Woesearchaeota (Archaea superphylum DPANN) in the surface waters of oligotrophic high-altitude lakes. Environ. Microbiol. Rep. 8(2), 210-217.

[49] Paper, W., Jahn, U., Hohn, M.J., Kronner, M., Näther, D.J., Burghardt, T., Rachel, R., Stetter, K.O., Huber, H. (2007) Ignicoccus hospitalis sp. nov., the host of “Nanoarchaeum equitans.” Int. J. Syst. Evol. Microbiol. 57(Pt 4), 803-808.

[50] Penz, T., Schmitz-Esser, S., Kelly, S.E., Cass, B.N., Müller, A., Woyke, T., Malfatti, S.A., Hunter, M.S., Horn, M. (2012) Comparative genomics suggests an independent origin of cytoplasmic incompatibility in Cardinium hertigii. PLoS Genet. 8(10), e1003012, https://doi.org/10.1371/journal.pgen.1003012.

[51] Petitjean, C., Deschamps, P., López-Garciá, P., Moreira, D. (2014) Rooting the domain Archaea by phylogenomic analysis supports the foundation of the new kingdom Proteoarchaeota. Genome Biol. Evol. 7(1), 191-204.

[52] Podar, M., Anderson, I., Makarova, K.S., Elkins, J.G., Ivanova, N., Wall, M.A., Lykidis, A., Mavromatis, K., Sun, H., Hudson, M.E., Chen, W., Deciu, C., Hutchison, D., Eads, J.R., Anderson, A., Fernandes, F., Szeto, E., Lapidus, A., Kyrpides, N.C., Saier Jr, M.H., Richardson, P.M., Rachel, R., Huber, H., Eisen, J.A., Koonin, E. V., Keller, M., Stetter, K.O. (2008) A genomic analysis of the archaeal system Ignicoccus hospitalis-Nanoarchaeum equitans. Genome Biol. 9(11), R158, https://doi.org/10.1186/gb-2008-9-11-r158.

[53] Podar, M., Makarova, K.S., Graham, D.E., Wolf, Y.I., Koonin, E. V., Reysenbach, 
A.-L. (2013) Insights into archaeal evolution and symbiosis from the genomes of a nanoarchaeon and its inferred crenarchaeal host from Obsidian Pool, Yellowstone National Park. Biol. Direct 8, 9, https://doi.org/10.1186/1745-6150-8-9.

[54] Preston, C.M., Wu, K.Y., Molinski, T.F., DeLong, E.F. (1996) A psychrophilic crenarchaeon inhabits a marine sponge: Cenarchaeum symbiosum gen. nov., sp. nov. Proc. Natl. Acad. Sci. U. S. A. 93(13), 6241-6246.

[55] Randau, L. (2012) RNA processing in the minimal organism Nanoarchaeum equitans. Genome Biol. 13(7), R63, https://doi.org/10.1186/gb-2012-13-7-r63.

[56] Randau, L., Calvin, K., Hall, M., Yuan, J., Podar, M., Li, H., Söll, D. (2005) The heteromeric Nanoarchaeum equitans splicing endonuclease cleaves noncanonical bulge-helix-bulge motifs of joined tRNA halves. Proc. Natl. Acad. Sci. U. S. A. 102(50), 17934-17939.

[57] Randau, L., Pearson, M., Söll, D. (2005) The complete set of tRNA species in Nanoarchaeum equitans. FEBS Lett. 579(13), 2945-2947.

[58] Randau, L., Schröder, I., Söll, D. (2008) Life without RNase P. Nature 453(7191), $120-123$.

[59] Randau, L., Söll, D. (2008) Transfer RNA genes in pieces. EMBO Rep. 9(7), 623628.

[60] Rinke, C., Rubino, F., Messer, L.F., Youssef, N., Parks, D.H., Chuvochina, M., Brown, M., Jeffries, T., Tyson, G.W., Seymour, J.R., Hugenholtz, P. (2018) A phylogenomic and ecological analysis of the globally abundant Marine Group II Archaea (Ca. Poseidoniales ord. nov.). ISME J., https://doi.org/10.1038/s41396018-0282-y. 
[61] Rinke, C., Schwientek, P., Sczyrba, A., Ivanova, N.N., Anderson, I.J., Cheng, J.F., Darling, A., Malfatti, S., Swan, B.K., Gies, E.A., Dodsworth, J.A., Hedlund, B.P., Tsiamis, G., Sievert, S.M., Liu, W.-T., Eisen, J.A., Hallam, S.J., Kyrpides, N.C., Stepanauskas, R., Rubin, E.M., Hugenholtz, P., Woyke, T. (2013) Insights into the phylogeny and coding potential of microbial dark matter. Nature 499(7459), 431-437.

[62] Schleper, C., Jurgens, G., Jonuscheit, M. (2005) Genomic studies of uncultivated Archaea. Nat. Rev. Microbiol. 3(6), 479-488.

[63] Spang, A., Saw, J.H., Jørgensen, S.L., Zaremba-Niedzwiedzka, K., Martijn, J., Lind, A.E., van Eijk, R., Schleper, C., Guy, L., Ettema, T.J.G. (2015) Complex Archaea that bridge the gap between prokaryotes and eukaryotes. Nature 521(7551), 173-179.

[64] St. John, E., Liu, Y., Podar, M., Stott, M.B., Meneghin, J., Chen, Z., Lagutin, K., Mitchell, K., Reysenbach, A.-L. (In press) A new symbiotic nanoarchaeote (Candidatus Nanoclepta minutus) and its host (Zestosphaera tikiterensis gen. nov., sp. nov.) from a New Zealand hot spring. Syst. Appl. Microbiol., https://doi.org/10.1016/j.syapm.2018.08.005.

[65] St. John, E., Meneghin, J., Flores, G.E., Reysenbach, A.-L. (In review) Deep-sea hydrothermal vent metagenome-assembled genomes provide insight into the phylum Nanoarchaeota. Environ. Microbiol. Rep.

[66] Taylor, G.T., John Pirt, S. (1977) Nutrition and factors limiting the growth of a methanogenic bacterium (Methanobacterium thermoautotrophicum). Arch. Microbiol. 113(1-2), 17-22. 
[67] Tjaden, J., Winkler, H.H., Schwöppe, C., Van Der Laan, M., Möhlmann, T., Neuhaus, H.E. (1999) Two nucleotide transport proteins in Chlamydia trachomatis, one for net nucleoside triphosphate uptake and the other for transport of energy. J. Bacteriol. 181(4), 1196-1202.

[68] Touchon, M., Moura De Sousa, J.A., PC Rocha, E. (2017) Embracing the enemy: the diversification of microbial gene repertoires by phage-mediated horizontal gene transfer. Curr. Opin. Microbiol. 38, 66-73.

[69] Treusch, A.H., Leininger, S., Kietzin, A., Schuster, S.C., Klenk, H.P., Schleper, C. (2005) Novel genes for nitrite reductase and Amo-related proteins indicate a role of uncultivated mesophilic Crenarchaeota in nitrogen cycling. Environ. Microbiol. 7(12), 1985-1995.

[70] Veith, A., Klingl, A., Zolghadr, B., Lauber, K., Mentele, R., Lottspeich, F., Rachel, R., Albers, S.V., Kletzin, A. (2009) Acidianus, Sulfolobus and Metallosphaera surface layers: structure, composition and gene expression. Mol. Microbiol. 73(1), 58-72.

[71] Waters, E., Hohn, M.J., Ahel, I., Graham, D.E., Adams, M.D., Barnstead, M., Beeson, K.Y., Bibbs, L., Bolanos, R., Keller, M., Kretz, K., Lin, X., Mathur, E., Ni, J., Podar, M., Richardson, T., Sutton, G.G., Simon, M., Soll, D., Stetter, K.O., Short, J.M., Noordewier, M. (2003) The genome of Nanoarchaeum equitans: insights into early archaeal evolution and derived parasitism. Proc. Natl. Acad. Sci. U. S. A. 100(22), 12984-12988.

[72] Williams, T.A., Embley, T.M. (2014) Archaeal "dark matter" and the origin of eukaryotes. Genome Biol. Evol. 6(3), 474-481. 
[73] Woese, C.R., Fox, G.E. (1977) Phylogenetic structure of the prokaryotic domain: the primary kingdoms. Proc. Natl. Acad. Sci. U. S. A. 74(11), 5088-5090.

[74] Woese, C.R., Kandler, O., Wheelis, M.L. (1990) Towards a natural system of organisms: proposal for the domains Archaea, Bacteria, and Eucarya. Proc. Natl. Acad. Sci. U. S. A. 87(12), 4576-4579.

[75] Wurch, L., Giannone, R.J., Belisle, B.S., Swift, C., Utturkar, S., Hettich, R.L., Reysenbach, A.-L., Podar, M. (2016) Genomics-informed isolation and characterization of a symbiotic Nanoarchaeota system from a terrestrial geothermal environment. Nat. Commun. 7, 12115, https://www. http://doi.org/10.1038/ncomms12115.

[76] Zaremba-Niedzwiedzka, K., Caceres, E.F., Saw, J.H., Bäckström, D., Juzokaite, L., Vancaester, E., Seitz, K.W., Anantharaman, K., Starnawski, P., Kjeldsen, K.U., Stott, M.B., Nunoura, T., Banfield, J.F., Schramm, A., Baker, B.J., Spang, A., Ettema, T.J.G. (2017) Asgard Archaea illuminate the origin of eukaryotic cellular complexity. Nature 541(7637), 353-358.

[77] Zeikus, J.G. (1977) The biology of methanogenic Bacteria. Bacteriol. Rev. 41(2), $514-541$. 
Chapter 2: A New Symbiotic Nanoarchaeote (Candidatus Nanoclepta minutus) and its Host (Zestosphaera tikiterensis gen. nov., sp. nov.) from a New Zealand Hot Spring

\author{
St. John, E, Liu, Y, Podar, M, Stott, MB, Meneghin, J, Chen, Z, Lagutin, K, Mitchell, K, \\ Reysenbach, A-L (In press). Systematic and Applied Microbiology. \\ https://doi.org/10.1016/j.syapm.2018.08.005.
}

\title{
Abstract
}

Three thermophilic Nanoarchaeota-Crenarchaeota symbiotic systems have been described. We obtained another stable anaerobic enrichment culture at $80^{\circ} \mathrm{C}, \mathrm{pH} 6.0$ from a New Zealand hot spring. The nanoarchaeote $(\mathrm{Ncl}-1)$ and its host $\left(\mathrm{NZ3}^{\mathrm{T}}\right)$ were isolated in co-culture and their genomes assembled. The small $(\sim 200 \mathrm{~nm})$ flagellated cocci were often attached to larger cocci. Based on 16S rRNA gene similarity $(88.4 \%)$ and average amino acid identity (52\%), Ncl-1 is closely related to Candidatus Nanopusillus acidilobi. Their genomes both encode for archaeal flagella and partial glycolysis and gluconeogenesis pathways, but lack ATP synthase genes. Like Nanoarchaeum equitans, Ncl-1 has a CRISPR-Cas system. Ncl-1 also likely relies on its crenarchaeotal host for most of its biosynthetic needs. The host $\mathrm{NZ3}^{\mathrm{T}}$ was isolated and grows on proteinaceous substrates but not on sugars, alcohols, or fatty acids. NZ3 ${ }^{\mathrm{T}}$ requires thiosulfate and grows best at $82^{\circ} \mathrm{C}, \mathrm{pH} 6.0 . \mathrm{NZ}^{\mathrm{T}}$ is most closely related to the Desulfurococcaceae, Ignisphaera aggregans ( $\sim 92 \%$ 16S rRNA gene sequence similarity, $45 \%$ AAI). Based on phylogenetic, physiological and genomic data, Ncl-1 and NZ3 ${ }^{\mathrm{T}}$ 
represent novel genera in the Nanoarchaeota and Desulfurococcaceae, respectively, with the proposed names Candidatus Nanoclepta minutus and Zestosphaera tikiterensis gen. nov., sp. nov., type strain NZ3 ${ }^{\mathrm{T}}\left(=\mathrm{DSMZ} 107634^{\mathrm{T}}=\mathrm{OCM} 1213^{\mathrm{T}}=\mathrm{JCM} 32895^{\mathrm{T}}\right)$.

\section{Introduction}

The Archaea still remain the most unexplored of life's domains, despite a ubiquitous distribution and a diversity that may parallel that of the Bacteria. Many new lineages without cultivated representatives have been discovered through metagenomic and single cell genomic approaches, giving rise to a significant increase in new archaeal phyla and divisions $[4,7,89,95,105]$. One exception is the Nanoarchaeota, a phylum with only two representatives in culture [36,113]. The first isolate, Nanoarchaeum equitans, was obtained from a shallow marine hydrothermal site off Iceland and forms an obligate parasitic relationship with its autotrophic archaeal host, Ignicoccus hospitalis [36]. With its highly reduced genome, $N$. equitans lacks most primary biosynthetic functions and has to acquire many metabolic precursors from its host [111]. The second nanoarchaeote in culture was obtained from an acidic hot spring in Yellowstone National Park (YNP) [113]. This terrestrial representative, Candidatus Nanopusillus acidilobi, is also an obligate symbiont, and its host is an acidophile and heterotroph, Acidilobus sp. 7A. Like its marine relative, Cand. Nps. acidilobi shows extensive genome reduction and requires its host for most primary biosynthetic and energetic needs, yet it has retained some potential for glycolysis and gluconeogenesis, expresses archaeal flagella genes and lacks a membrane ATP synthase complex [113]. The differences between the two cultivated nanoarchaeotes point to how diverse symbiotic associations may be within the 
Nanoarchaeota. Additional terrestrial Nanoarchaeota symbiotic systems were characterized based on single cell sequencing from geothermal acidic pools in YNP $[72,89]$. Even though these environmental nanoarchaeote genomes were very similar to Cand. Nps. acidilobi, their implied hosts were quite dissimilar and more closely related to Sulfolobus than Acidilobus [72,89].

Based on 16S rRNA gene surveys, Nanoarchaeota have been detected globally in terrestrial and marine hot springs. These include many sites in YNP $[16,34,71,72]$, Kamchatka [15,34], Chile [14], Central Asia [14], China [14], New Zealand [14], and deep-sea vents in the Atlantic [24] and Pacific oceans [26,34,67,73]. These different nanoarchaeotes form phylogenetic clades that can be separated somewhat by geographical region. It is therefore likely that as more members of this group and their hosts are characterized, a much better understanding of their biology and evolutionary history will emerge.

Here, we report on the enrichment and isolation of a third nanoarchaeote in stable co-culture with its host. This nanoarchaeote was obtained from a terrestrial hot spring in New Zealand and more closely resembles its relatives from YNP than N. equitans. We also describe the isolation and characterization of the host, a novel genus in the Desulfurococcaceae. The Nanoarchaeota-host system highlights the need for formal recognition and classification for organisms that can be cultivated, but only in the presence of a symbiotic partner. 
Materials and methods

Sample site and culturing conditions

Samples from "Cooking Pots" hot springs at Hell's Gate, Tikitere, New Zealand $\left(38.0654^{\circ} \mathrm{S}, 176.3595^{\circ} \mathrm{E}\right)$ were inoculated into anaerobic enrichment media: Deutsche Sammlung von Mikroorganismen und Zellkulturen (DSMZ) media \#88 with (g/L): $\mathrm{Na}_{2} \mathrm{O}_{3} \mathrm{~S}_{2} .5 \mathrm{H}_{2} \mathrm{O}, 2.0 ; \mathrm{NaOH}, 0.16$; yeast extract, 0.5; tryptone, 0.5; resazurin, 0.001; $\mathrm{FeCl}_{3} .6 \mathrm{H}_{2} \mathrm{O}, 0.004 ; \mathrm{MnCl}_{2} .4 \mathrm{H}_{2} 0,0.00036$; and $10 \mathrm{~mL}$ additional trace mineral solution DSMZ \#141 and dispensed under $\mathrm{N}_{2} / \mathrm{CO}_{2}(80 / 20, \mathrm{v} / \mathrm{v})$ and $\mathrm{pH}$ adjusted to $6.0-6.1$. The enrichments were incubated at $80^{\circ} \mathrm{C}$ for four days and checked by phase contrast microscopy. DNA was extracted using the Qiagen DNeasy Blood and Tissue DNA kit and the presence of Nanoarchaeota was checked using nanoarchaeotal-specific 16S rRNA gene primers [34]. Nanoarchaeotal-positive enrichment cultures were monitored over many transfers and maintained stably for over two years. A nanoarchaeote-host coculture was isolated after several dilution-to-extinction transfers. Subsequently, the coculture was transferred into, and routinely grown in, the above media with the following modifications: $0.5 \mathrm{~g} / \mathrm{L}$ casein hydrolysate, $1.0 \mathrm{~g} / \mathrm{L}$ yeast extract, $1.0 \mathrm{~g} / \mathrm{L}$ tryptone, 0.0625 $\mathrm{g} / \mathrm{L}$ L-cysteine- $\mathrm{HCl}$ and $10 \mathrm{~mL} / \mathrm{L}$ glycerol.

\section{Host isolation and 16S rRNA gene sequencing}

The host was isolated by several series of dilution-to-extinction transfers in the described modified enrichment media. Genomic DNA was extracted as above, and the purity of the isolate was verified by PCR and sequencing of the 16S rRNA gene. Due to the presence of introns in the host $16 \mathrm{~S}$ rRNA gene, two overlapping primer sets were 
utilized for sequencing: 4F (5'-TCCGGTTGATCCTGCCRG-3'), 907RN (5'CCGYCAATTCMTTTRAGTTT-3'), 341FA (5'-CCTAYGGGGYGCASCAGGCG-3') and 1492R (5'-GGTTACCTTGTTACGACTT-3'). PCR conditions consisted of initial denaturation at $94^{\circ} \mathrm{C}$ for $5 \mathrm{~min}$, followed by 35 cycles of $94^{\circ} \mathrm{C}$ for $30 \mathrm{~s}, 55^{\circ} \mathrm{C}$ for $30 \mathrm{~s}$, and $72^{\circ} \mathrm{C}$ for $1 \mathrm{~min} 30 \mathrm{~s}$, followed by a final elongation cycle at $72^{\circ} \mathrm{C}$ for $7 \mathrm{~min}$.

\section{Physiological characterization of the host}

Unless otherwise noted, all characterization studies were carried out in triplicate at $80-85^{\circ} \mathrm{C}$ in sealed anaerobic Balch tubes. Cell density was monitored by phase contrast microscopy with a Petroff-Hausser counting chamber. Use of carbon sources was determined at a $0.1 \%(\mathrm{w} / \mathrm{v})$ final concentration using a modified enrichment media with reduced yeast extract $(0.01 \% \mathrm{w} / \mathrm{v})$ and no casein hydrolysate, tryptone, or glycerol. Cultures were transferred at least once to minimize carry-over. The carbon sources that were tested included yeast extract, tryptone, casamino acids, gelatin, acetate, butyrate, cellulose, fructose, glucose, glycerol, mannose, propionate, sorbitol, ribose, starch, sucrose and xylose.

Alternate electron acceptor use was determined by replacing L-cysteine-HCl and thiosulfate in the enrichment media with a variety of electron acceptors at both 2.5 and 10 $\mathrm{mM}$ final concentrations. To prevent sublimation, elemental sulfur $(2.5$ and $10 \mathrm{mM})$ was added directly to media in individual Balch tubes prior to autoclaving at $105^{\circ} \mathrm{C}$ for 1 hour [25]. Potential electron acceptors included elemental sulfur, nitrate, thiosulfate, sulfite and L-cysteine-HCl. A positive growth response was only recorded after three consecutive transfers in the same medium. 
To assess the $\mathrm{pH}$ range of isolate growth, enrichment media was supplemented with $25 \mathrm{mM}$ MES (pH 5.5-6.0) and $25 \mathrm{mM}$ MOPS (pH 6.3-6.8) [78]. The $\mathrm{pH}$ was adjusted to the desired range prior to autoclaving. Oxygen tolerance was tested by adding defined volumes $(0-10 \%, \mathrm{v} / \mathrm{v})$ of filtered oxygen directly to anaerobic culture tubes containing media with $10 \mathrm{mM}$ thiosulfate but lacking L-cysteine $\mathrm{HCl}$. Requirement for $\mathrm{NaCl}$ was determined using $0-1 \% \mathrm{NaCl}(\mathrm{w} / \mathrm{v})$.

\section{Core and intact lipid preparation and analysis}

Lipids were recovered using a modified Bligh and Dyer method [9], and polar head groups were removed by acidic methanolysis [79]. Core and intact lipids were analyzed using a modified version of the protocol described by Elling et al, 2016 [22]. Liquid chromatography-mass spectrometry (LCMS) was performed using a Shimadzu 8040-LCMS system equipped with a photodiode array detector and a triple quadrupole low resolution MS utilizing an ESI source for ionization and Q3 scanning from 300 to $2000 \mathrm{~m} / \mathrm{z}$. Lipids were identified based on comparison with published mass spectrometry data $[69,115]$. Additional methodologies for core and intact polar lipid analysis are available in Appendix A.

\section{Electron microscopy}

Negatively stained cells were prepared for transmission electron microscopy (TEM) by spotting $5 \mu \mathrm{L}$ of culture onto formvar-carbon copper grids (Ted Pella, 400 mesh), and stained with $2 \%(\mathrm{w} / \mathrm{v})$ uranyl acetate for $15 \mathrm{~s}$ and air dried. The micrographs were taken at acceleration voltage of $200 \mathrm{kV}$ using a FEI TECNAI F-20 TEM. 
qPCR assay

qPCR was performed using the QuantiTect ${ }^{\circledR}$ SYBR ${ }^{\circledR}$ Green PCR kit (Qiagen). Standards were developed with double-stranded 16S rRNA gene blocks (500bp, gBlocks ${ }^{\circledR}$, Integrated DNA Technologies) containing 165 bp regions flanking the target qPCR product. The qPCR primers were specific for the New Zealand nanoarchaeote: 515F-NZ (5'-GTGGGCAAGAGAGGTGG-3') and 650R-NZ (5'-CGGCTCCTTCCGTC CCCTAG-3') and were used at $0.2 \mu \mathrm{M}$ final concentration. qPCR reaction conditions were as follows: $95^{\circ} \mathrm{C}$ for $15 \mathrm{~min}$, followed by 35 cycles of $94^{\circ} \mathrm{C}$ for $15 \mathrm{~s}, 55^{\circ} \mathrm{C}$ for $30 \mathrm{~s}$, $72^{\circ} \mathrm{C}$ for $30 \mathrm{~s}$, followed by melt curve analysis from 55 to $95^{\circ} \mathrm{C}$.

\section{Cell sorting and metagenomic sequencing}

To obtain low diversity metagenomes, enrichment cultures containing nanoarchaeotes were sorted using flow cytometry as described previously [89]. To ensure recovery of nanoarchaeotes, multiple cells (5-10) were sorted into each well. After multiple displacement amplification (MDA), wells were screened using nanoarchaeotal-specific PCR primers [34,89]. Two wells with positive nanoarchaeotal amplification were selected for sequencing using the Illumina MiSeq. Adaptor sequences and low-quality regions were trimmed using Trim Galore [52]. After trimming, the two datasets yielded approximately 4.0 and 4.5 million paired-end reads, respectively.

\section{Binning and assembly of metagenome}

To maximize recovery of Nanoarchaeota and host genomes, raw reads from the two low diversity metagenomes were merged into one dataset. Reads were initially 
assembled using IDBA-UD v.1.1.0 [85,86]. Contigs $\geq 5 \mathrm{~kb}$ were binned using MaxBin v.1.4.5 [112]. To enhance data recovery, the combined dataset was re-assembled using the SPAdes genome assembler v.3.9.1-Linux [8]. Supervised binning of contigs $\geq 2.5 \mathrm{~kb}$ was performed using emergent self-organizing mapping (ESOM) based on tetranucleotide frequency [109]. Both the IDBA-UD and SPAdes assemblies were then merged and viewed in Geneious v.10.0.2 [46] for manual contig extension, curation and identification of misassembled regions. Completeness and contamination of final draft genomes was assessed using CheckM [84].

\section{Accessibility of data and biological material}

Draft genomes of the New Zealand nanoarchaeote and its host are available in Genbank under accession numbers MWMI00000000 and NBVN00000000, respectively. 16S rRNA genes of the above strains have also been deposited under accession numbers MH298645 and MH252993. Project details are available in the NCBI BioProject database (PRJNA363059), and sampling metadata can be found in the NCBI BioSample database for the New Zealand nanoarchaeote (SAMN06250747) and its host (SAMN06648824). The nanoarchaeote-host co-culture has also been deposited in the Oregon Culture Collection of Methanogens (OCM 1214), and the host has been deposited in the OCM $\left(\mathrm{OCM} 1213^{\mathrm{T}}\right)$, the DSMZ (DSM 107634 $)$ and the JCM (JCM 32895 $)$.

\section{Functional annotation}

After assembly, open reading frames were predicted and annotated using the Rapid Annotation and Subsystem Technology (RAST) server [5,11,82]. Additional 
annotation (Appendix B, File S1, Table A1-A2) was performed using the updated Archaeal Clusters of Orthologous Genes (arCOG) database [64,65]. As needed, annotations were cross-referenced using the NCBI Basic Local Alignment Search Tool (BLAST) [3] and the NCBI Conserved Domain (CD) Database [66,77]. Ribosomal RNAs were predicted with Infernal v.1.1.2 [75] and Rfam v.12.0 [74] and tRNAs were predicted with the tRNAscan-SE 2.0 web server [60]. Hydrogenases were predicted using the HydDB web server [104]. Circos ribbon plots [53] were used to compare overall genomic synteny between draft genomes and their closest described relatives. Pairwise average amino acid identity matrices were generated using the ANI/AAI Matrix Calculator [96].

\section{Phylogenetic analysis}

To assess the phylogenetic placement of the nanoarchaeote and its host, their $16 \mathrm{~S}$ rRNA genes were aligned using the Geneious Aligner [46] and hypervariable regions were manually masked. Maximum-likelihood analysis was inferred with RAxML v.8.2.8 [106] under the GTRGAMMA model with 1000 replicate bootstrap trees, and trees were viewed using the Interactive Tree of Life [58]. 16S rRNA gene similarity was also assessed using EzBioCloud [48,114] and pairwise Geneious alignments. Additional phylogenetic trees were built using a set of 16 ribosomal proteins [4] extracted with PhyloSift v.1.0.1 [19]. After each set of ribosomal proteins was aligned in Muscle [20], alignments were concatenated in Geneious and maximum-likelihood analysis was performed using the PROTGAMMALG model as described. This model was also used to build single gene trees. 
Analysis of predicted $r R N A$ and $t R N A$ intron sequences

Transfer RNA introns in strain Ncl-1 were predicted using tRNAscan-SE [60].

To search for the presence of Group I and Group II introns, Ncl-1 tRNAs with predicted introns were screened against custom Group I intron covariance models (CMs) generated by Nawrocki et al. [76] and the Rfam v.14.0 database [44,45,74] using Infernal [75]. As previously described [76], all hits with an E-value $<=0.001$ were considered in these analyses. The same approach was also used to classify introns in the strain NZ3 ${ }^{\mathrm{T}} 16 \mathrm{~S}$ rRNA gene sequence. In both cases, intron sequences were also translated into all six potential translation frames using Geneious [46] and screened against the CD Database [66,77]. A high E-value threshold (0.1) was set to ensure the detection of low-homology matches. The Mfold web server [118] was used to predict the secondary structure of introns in the $\mathrm{NZ3}^{\mathrm{T}} 16 \mathrm{~S}$ rRNA gene sequence.

\section{Results and discussion}

Establishment of a stable nanoarchaeotal-host enrichment culture Initial enrichments containing the New Zealand nanoarchaeote were complex (Fig. 1.1A) and often dominated by Bacteria belonging to the Thermodesulfobacteriaceae ( $97.47 \%$ similar in 16S rRNA gene sequence to Thermodesulfobacterium geofontis $[32,48,114])$. Other members of these enrichments included the Korarchaeota, Thermoanaerobacteraceae related to the Caldanaerobacter, Dictyoglomus sp., Fervidobacterium sp., Thermofilum sp., Pyrobaculum sp. and some unclassified Thermoprotei related to Desulfurococcus and Ignisphaera. Notably, some enrichments had up to $20 \%$ korarchaeotal sequences. Tracking the initial enrichment 
cultures by barcoded 16S rRNA gene sequencing (data not shown) revealed that Thermodesulfobacteriaceae reached stationary phase after $120 \mathrm{~h}$.

Thermodesulfobacteriaceae were also in highest relative abundance when the Korarchaeota were prevalent. Potentially, Thermodesulfobacteriaceae stimulated korarchaeotal growth by scavenging molecular hydrogen, as proposed by Elkins et al. [21]. The Caldanaerobacter sp. and Fervidobacterium sp. grew rapidly and reached stationary phase of growth after $24 \mathrm{~h}$, while the Dictyoglomus sp. peaked after $72 \mathrm{~h}$ and the Korarchaeota after $144 \mathrm{~h}$. The Thermoprotei and nanoarchaeotes were in very low relative sequence abundance and reached stationary growth phase around $72 \mathrm{~h}$ of incubation. From these enrichments, we successfully isolated pure cultures of strains related to Dictyoglomus, Thermofilum, Thermodesulfobacterium, Caldanaerobacter, Desulfurococcus and Ignisphaera.

Based on qPCR, the abundance of nanoarchaeotes in the enrichments increased with additional transfers, but then plateaued around 4-8 x 106 nanoarchaeotes $/ \mathrm{mL}$. Several early enrichments showed nanoarchaeotes attached to some, but not all, cocci (Fig. 1.1B). Nanoarchaeotal qPCR numbers closely tracked direct counts of the cocci in the cultures. Addition of sodium sulfide $(0.005 \% \mathrm{w} / \mathrm{v})$ did not stimulate nanoarchaeotal growth. Starch $(0.5 \% \mathrm{w} / \mathrm{v})$ and the presence of hydrogen in the headspace inhibited growth. Highest nanoarchaeotal numbers were obtained between $80-85^{\circ} \mathrm{C}$ although they were still detected at $60^{\circ} \mathrm{C}$ and at $90^{\circ} \mathrm{C}$.

Early dilution-to-extinction series were not successful in isolating the New Zealand nanoarchaeote and its host. No nanoarchaeotes could be detected in initial serial dilutions greater than $10^{-3}$. Possibly the dilutions were outgrown by some other members 
of the enrichment, particularly the fastidious Thermodesulfobacteriaceae. Furthermore, attempts to obtain colonies with nanoarchaeotes on solid media roll tubes $\left(\right.$ Gelrite $^{\mathrm{TM}}$, Research Products International) were unsuccessful. As repeated attempts to isolate pure nanoarchaeotal-host cultures by these methods were not successful, additional approaches to stimulate nanoarchaeotal growth and obtain less complex enrichments were used. A series of defined enrichments were reconstructed by combining several of the isolate cultures described above. Cultures were grown for four days and then inoculated with nanoarchaeotes by adding $0.22 \mu \mathrm{m}$-filtered spent nanoarchaeote-containing media $(10 \%$ $\mathrm{v} / \mathrm{v})$. These mixed cultures were then monitored by qPCR after four, five and six days of incubation. Very low nanoarchaeotal numbers were detected in one reconstructed culture after six days of incubation. This culture was then reinoculated several times into fresh media until a stable culture was established. The resulting mixed culture had 2-5 x $10^{7}$ nanoarchaeotes $/ \mathrm{mL}$. All further isolation attempts and metagenomic analyses of the nanoarchaeote-host system were conducted using this reconstructed culture.

Isolation of the nanoarchaeote in co-culture and the host in pure culture

Subsequently, we successfully isolated the New Zealand nanoarchaeote and its crenarchaeotal host in co-culture by screening several $10^{-3}$ dilutions of the reconstructed culture by PCR. The purity of the co-cultures was confirmed by PCR of the Nanoarchaeota and host 16S rRNA genes. On the basis of 16S rRNA gene sequence, the nanoarchaeote (strain $\mathrm{Ncl}-1$ ) was most closely related $(96.6 \%)$ to a clone sequence (Genbank EF562624.1, [14]) from Tokaanu hot springs in New Zealand and only 88.\% and $84.4 \%$ similar to Cand. Nps. acidilobi and N. equitans, respectively. Phylogenetic 

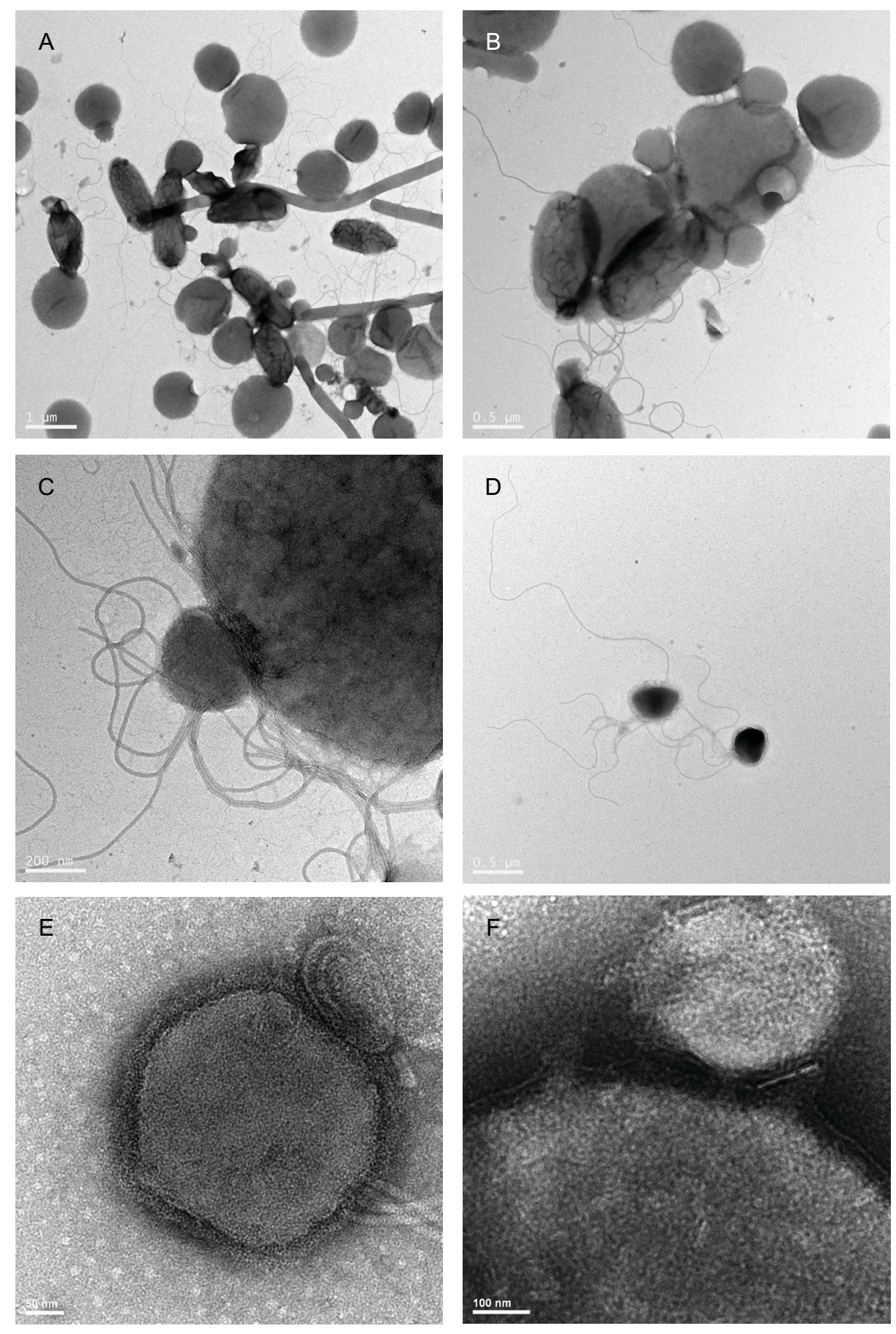

Figure 1.1. Negatively stained transmission electron micrographs (TEM) of the New Zealand enrichment culture. (A) Enrichment culture with nanoarchaeotes, (B) several nanoarchaeotes attached to host coccus, $(C)$ nanoarchaeote attached to host with lophotrichous archaeal flagella, (D) unattached nanoarchaeotes with lophotrichous flagella, (E) detailed view of archaeal flagella attachment, and (F) cell connection between host and nanoarchaeote. 


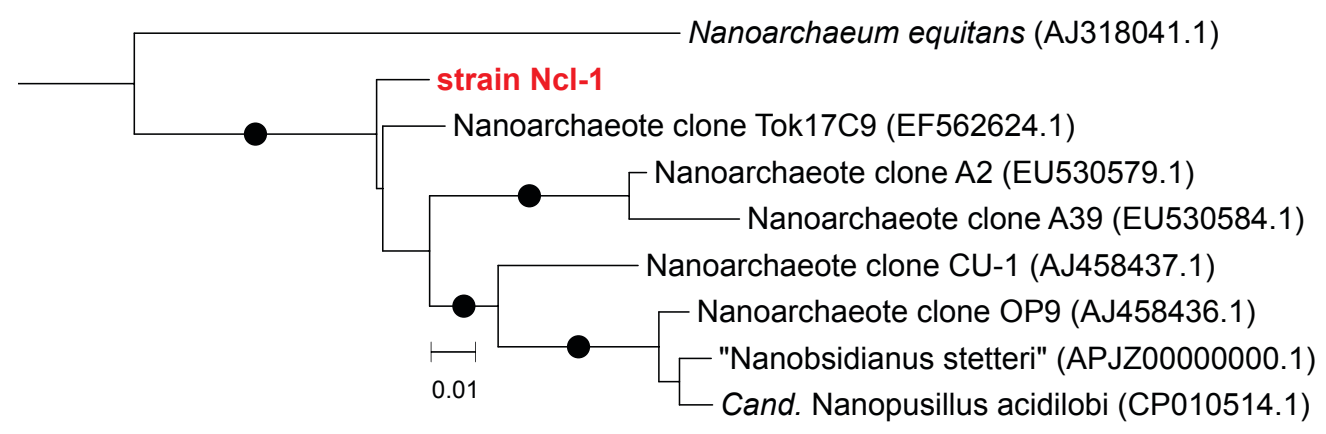

Figure 1.2. Maximum likelihood phylogenetic tree of Nanoarchaeota based on 16S rRNA gene sequences. Bootstrap support of $\geq 70 \%$ is shown by closed circles. Desulfurococcaceae were used as the outgroup. The scale bar indicates 0.01 nucleotide substitutions per site.

analysis of the 16S rRNA gene also confirmed the position of Ncl-1 in the Nanoarchaeota (Fig. 1.2).

The New Zealand host (strain NZ3 ${ }^{\mathrm{T}}$ ) was also isolated after several rounds of dilution-to-extinction transfers of the co-culture. The purity of the isolate was verified by amplification and sequencing of the 16S rRNA gene, which was found to contain four introns (2273 bp total gene length; Fig. 1.3). Introns in archaeal 16S rRNA genes have been widely reported in the Crenarchaeota, particularly in the Desulfurococcales and Thermoproteales $[13,39,41,61,80,108]$, and often encode homing endonucleases which may facilitate their spread throughout microbial communities $[1,41,61]$. The largest of the four predicted introns in the $\mathrm{NZ}^{\mathrm{T}} 16 \mathrm{~S}$ rRNA gene has extensive secondary structure and contains a predicted homing endonuclease, while the other three introns form small hairpin structures [118]. However, none of the intron sequences showed significant 


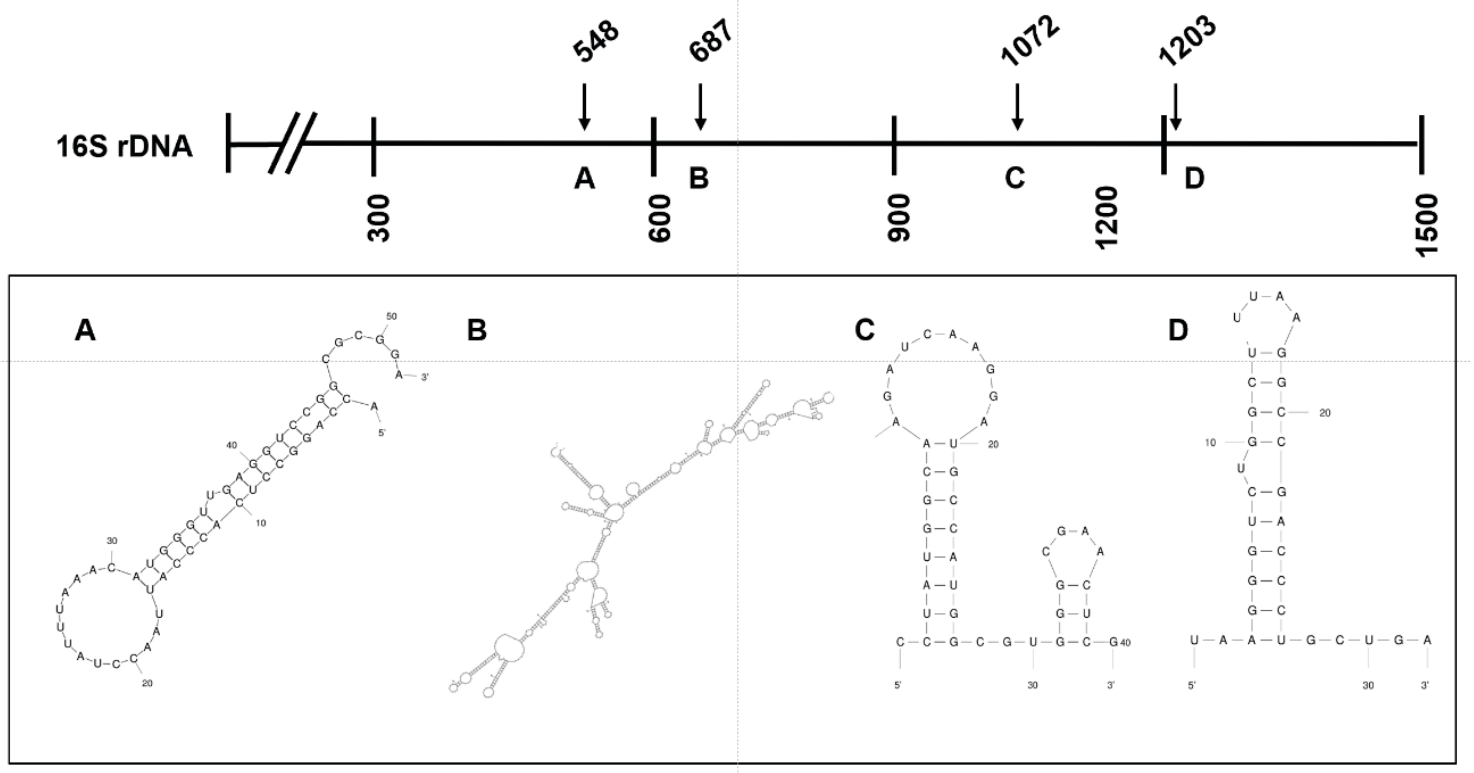

Figure 1.3. Predicted secondary structure and placement of intervening sequences in the 16S rRNA gene of strain NZ3 ${ }^{\mathrm{T}}$. Structures were predicted and drawn in Mfold. Only the most energetically favorable conformations are presented.

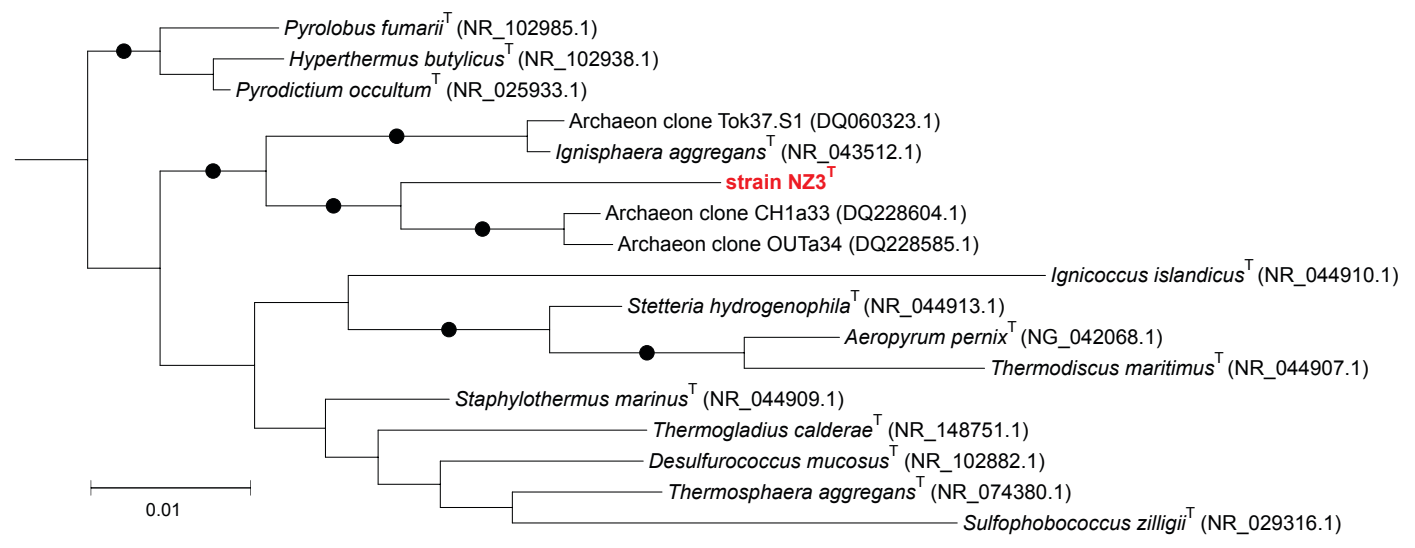

Figure 1.4. 16S rRNA gene maximum likelihood phylogenetic tree of select Desulfurococcaceae. Pyrodictiaceae were used as the outgroup, and filled circles indicate $\geq 70 \%$ bootstrap support. The scale bar represents 0.1 substitutions per nucleotide. 
homology (E-value $<=0.001)$ to Group I or Group II introns found in the Archaea. After trimming the introns from the sequence, the $N Z 3^{\mathrm{T}} 16 \mathrm{~S}$ rRNA gene showed highest sequence similarity ( $93 \%$ ) to clones from deep-sea hydrothermal vents (Genbank DQ228585.1, DQ228604.1, unpublished) and 92\% to Ignisphaera aggregans [78]. Based on maximum likelihood phylogenetic analysis of the $16 \mathrm{~S}$ rRNA gene, strain NZ3 ${ }^{\mathrm{T}}$ formed a deeply-branching clade in the Desulfurococcaceae with I. aggregans (Fig. 1.4).

\section{Characterization of the host, strain $N Z 3^{T}$}

The morphology of strain $\mathrm{NZ} 3^{\mathrm{T}}$ was analyzed using phase contrast microscopy and TEM. Cells were coccoid, approximately $1 \mu \mathrm{m}$ in diameter, and no archaeal flagella were observed. $\mathrm{NZ3}^{\mathrm{T}}$ grew between 60 and $90^{\circ} \mathrm{C}$, growing best between $82-83^{\circ} \mathrm{C}$ (Table 1.1). No growth was observed at 55 or $95^{\circ} \mathrm{C}$. The isolate grew from $\mathrm{pH} 4.9$ and 7.2 , with optimal growth at $\mathrm{pH} 6.0$, but no growth observed at $\mathrm{pH} 4.6$ or 7.2.

Strain $\mathrm{NZ3}^{\mathrm{T}}$ grew well on peptide-rich substrates $(0.1 \% \mathrm{w} / \mathrm{v})$, including yeast extract, tryptone, casamino acids and gelatin. However, no growth was observed on sugars, fatty acids, or alcohols, including fructose, glucose, mannose, ribose, sucrose, xylose, acetate, butyrate, propionate, sorbitol, glycerol, cellulose or starch. Thiosulfate (2.5-10 $\mathrm{mM})$ was required as a terminal electron acceptor and could not be replaced by 2.5 or $10 \mathrm{mM}$ L-cysteine-HCl, sulfite, nitrate or elemental sulfur.

Strain $\mathrm{NZ3}^{\mathrm{T}}$ grew in the presence of $0-0.5 \% \mathrm{NaCl}(\mathrm{w} / \mathrm{v})$, but no growth was observed at $1 \% \mathrm{NaCl} . \mathrm{NZ}^{\mathrm{T}}$ is an obligate anaerobe, as trace amounts of oxygen in the headspace $(3 \% \mathrm{v} / \mathrm{v})$ inhibited growth. 
Table 1.1. Characteristics distinguishing strain $\mathrm{NZ} 3^{\mathrm{T}}$ from other representative species in the Desulfurococcaceae.

Strains: $1, \mathrm{NZ3}^{\mathrm{T}}$ (this study); 2, Ignisphaera aggregans AQ1.S1 ${ }^{\mathrm{T}}$ [78]; 3 , Desulfurococcus mucosus DSM2162 ${ }^{\mathrm{T}}[87,116]$; 4, Stetteria hydrogenophila DSM1227 ${ }^{\mathrm{T}}$ [43]; 5, Ignicoccus islandicus $\mathrm{Kol}^{\mathrm{T}}$ [35].

\begin{tabular}{|c|c|c|c|c|c|}
\hline Characteristic & 1 & 2 & 3 & 4 & 5 \\
\hline \multicolumn{6}{|l|}{ Temperature for growth $\left({ }^{\circ} \mathrm{C}\right)$} \\
\hline $\begin{array}{l}\text { Range } \\
\text { (optimal) }\end{array}$ & $\begin{array}{c}60-90 \\
(82-83)\end{array}$ & $\begin{array}{l}85-98 \\
(92-95)\end{array}$ & $\begin{array}{l}\text { up to } 97 \\
(85)\end{array}$ & $\begin{array}{l}70-102 \\
(95)\end{array}$ & $\begin{array}{l}70-98 \\
(90)\end{array}$ \\
\hline \multicolumn{6}{|l|}{$\mathrm{pH}$ for growth } \\
\hline $\begin{array}{l}\text { Range } \\
\text { (optimal) }\end{array}$ & $\begin{array}{l}4.9-7.0 \\
(6.0)\end{array}$ & $\begin{array}{l}5.4-7.0 \\
(6.4)\end{array}$ & $\begin{array}{l}2.2-6.5^{*} \\
(5.5-6.0)\end{array}$ & $\begin{array}{c}4.5-7.0 \\
(6.0)\end{array}$ & $\begin{array}{l}3.8-6.5 \\
(5.8)\end{array}$ \\
\hline $\mathrm{NaCl}$ for growth $(\%, \mathrm{w} / \mathrm{v})$ & $0-0.5$ & $0-0.5$ & $\mathrm{x}$ & $0.5-6.0$ & $0.3-5.5$ \\
\hline Doubling time (hr) & 8 & 7.5 & 4 & 3.7 & 1.4 \\
\hline DNA G+C content $(\mathrm{mol} \%)$ & $41.9 * *$ & 52.9 & 53 & 65 & 41 \\
\hline Electron acceptors & thiosulfate & none & $\mathrm{S}^{\circ}$ & $\mathrm{S}^{\circ}$, thiosulfate & $\mathrm{S}^{\circ}$ \\
\hline \multicolumn{6}{|l|}{ Substrate utilization } \\
\hline Casamino acids & + & - & - & + & - \\
\hline Gelatin & + & ND & ND & ND & $+*$ \\
\hline Tryptone & + & ND & + & + & $+*$ \\
\hline Yeast extract & + & - & + & + & - \\
\hline Acetate & - & - & ND & - & - \\
\hline Butyrate & - & ND & ND & ND & ND \\
\hline Cellulose & - & ND & ND & ND & ND \\
\hline Fructose & - & ND & ND & ND & ND \\
\hline Glucose & - & + & ND & - & - \\
\hline Glycerol & - & ND & ND & ND & ND \\
\hline Mannose & - & + & ND & ND & ND \\
\hline Propionate & - & ND & ND & ND & ND \\
\hline Ribose & - & ND & ND & - & ND \\
\hline Sorbitol & - & ND & ND & ND & ND \\
\hline Starch & - & + & - & - & - \\
\hline Sucrose & - & $+/-$ & ND & ND & ND \\
\hline Xylose & - & - & ND & - & ND \\
\hline
\end{tabular}

+/-, weakly supported or enhanced growth; +*, stimulates growth; ND, no data available. *The $\mathrm{pH}$ range for Desulfurococcus mucosus indicates the ecological conditions in which the strain is found.

**Based on weighted average of $\% \mathrm{G}+\mathrm{C}$ across the draft genome. 
The membrane lipids of strain $\mathrm{NZ3}{ }^{\mathrm{T}}$ consisted of glycerol dialkyl glycerol tetraethers, with zero to four cyclopentane moieties with relative proportions of $39 \%$, $18 \%, 22 \%, 13 \%$ and $8 \%$ respectively (Fig. 1.5, 1.6). Although no lipid composition data is available for I. aggregans, the five core lipids found in $\mathrm{NZ}^{\mathrm{T}}$ were also identified in Thermosphaera aggregans, another member of the Desulfurococcaceae [37,100]. Intact polar lipid analysis of the polar head groups revealed the presence of monohexose, dihexose, trihexose, phosphoinositol and hexose phosphoinositol (Fig. 1.7, Table 1.2).

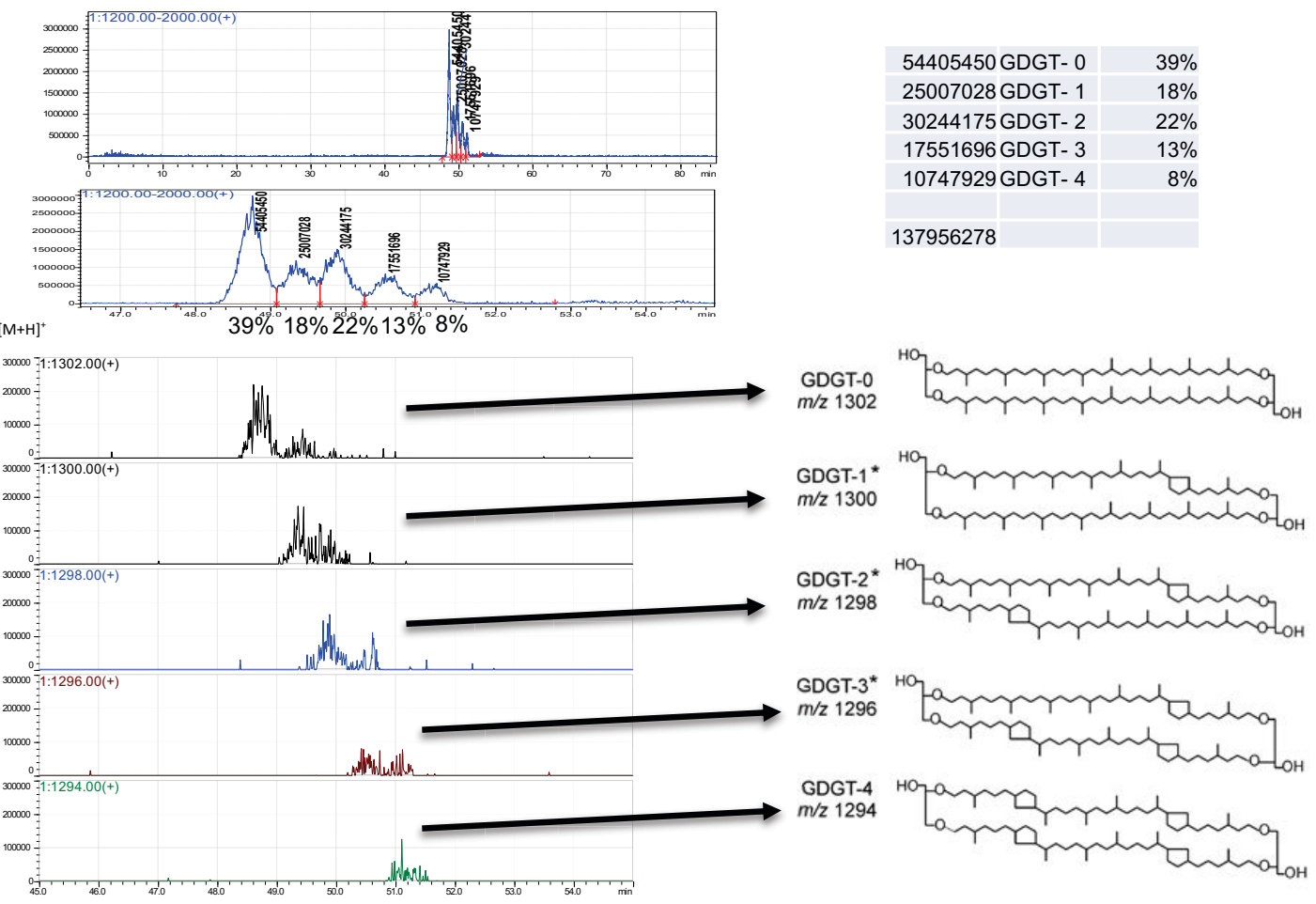

Figure 1.5. MS-spectra of intact polar lipid peaks identified in Table 1.2. Intact polar lipids analyzed in positive mode by UHPLC-ESI-MS. 
Table 1.2. $\mathrm{NZZ}^{\mathrm{T}}$ IPLs identification.

\begin{tabular}{|l|l|l|l|l|}
\hline $\begin{array}{l}\text { Polar head } \\
\text { group }\end{array}$ & $\begin{array}{l}\text { Intact polar } \\
\text { lipids* }\end{array}$ & $\begin{array}{l}\text { LC } \\
\text { retention } \\
\text { time (min.) }\end{array}$ & $\begin{array}{l}\text { m/z [molecular } \\
\text { ion adduct }{ }^{+}\end{array}$ & $\begin{array}{l}\text { Characteristic neutral } \\
\text { loss (DA) }\end{array}$ \\
\hline Hexose & Hex-GDGT(2) & 40.6 & $\begin{array}{l}1477.6\left[\mathrm{M}+\mathrm{NH}_{4}\right] \\
1482.5\left[\mathrm{M}+\mathrm{Na}^{2}\right]\end{array}$ & $\begin{array}{l}179.2, \text { loss of Hex+NH} \\
184.1, \text { loss of Hex+Na }\end{array}$ \\
\hline Dihexose** & diHex-GDGT(1) & 38.9 & $1641.6\left[\mathrm{M}+\mathrm{NH}_{4}\right]$ & \\
\hline $\begin{array}{l}\text { Trihexose } \\
\text { triHex-GDGT(0) }\end{array}$ & 36.3 & $1805.8\left[\mathrm{M}+\mathrm{NH}_{4}\right]$ & $\begin{array}{l}503.4, \text { loss of } \\
\text { triHex+NH }\end{array}$ \\
\hline $\begin{array}{l}\text { Phosphatidyl } \\
\text { inositol }\end{array}$ & PI-GDGT(0) & 32.5 & $1544.5[\mathrm{M}+\mathrm{H}]$ & \\
\hline $\begin{array}{l}\text { Hexose }+ \\
\text { phosphatidyl } \\
\text { inositol }\end{array}$ & Hex-PI-GDGT(0) & 28.5 & $\begin{array}{l}1706.6[\mathrm{M}+\mathrm{H}], \\
1723.6\left[\mathrm{M}+\mathrm{NH}_{4}\right]\end{array}$ & $\begin{array}{l}162.1, \text { loss of Hex } \\
179.2, \text { loss of Hex }+\mathrm{NH}_{3}\end{array}$ \\
\hline
\end{tabular}

* Number in parentheses for GDGTs denotes the number of cyclopentane moieties.

** Dihexose was detected in trace amounts and was identified only by molecular ion.
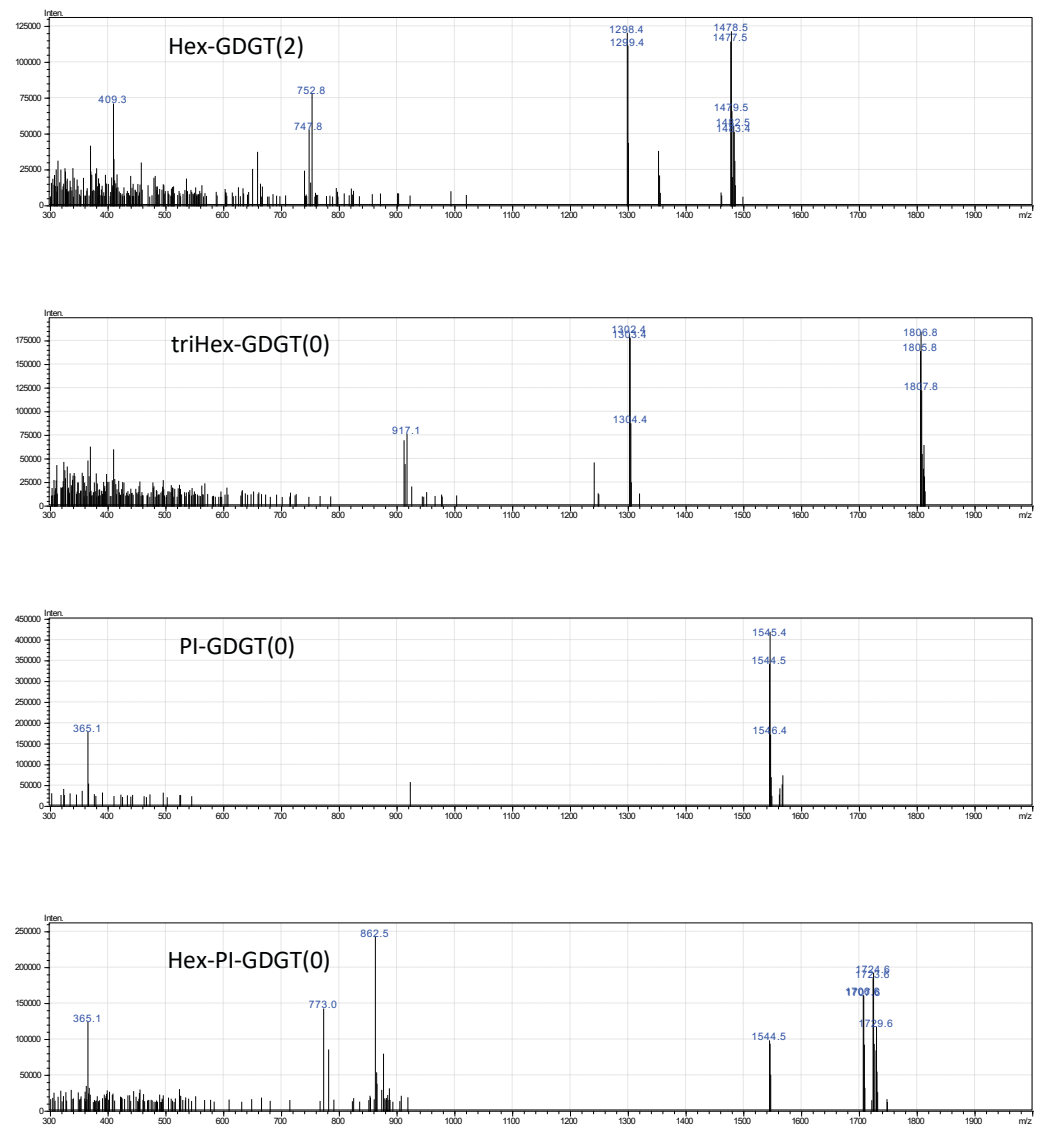

Figure 1.6. HPLC-MS traces of the core lipids of $\mathrm{NZ3}^{\mathrm{T}}$. The relative proportions of each glycerol dialkyl glycerol tetraethers (GDGT) are calculated as the area under each peak on the HPLC-MS trace. The cyclopentane rings are present as isomers of each of the GDGT compounds 


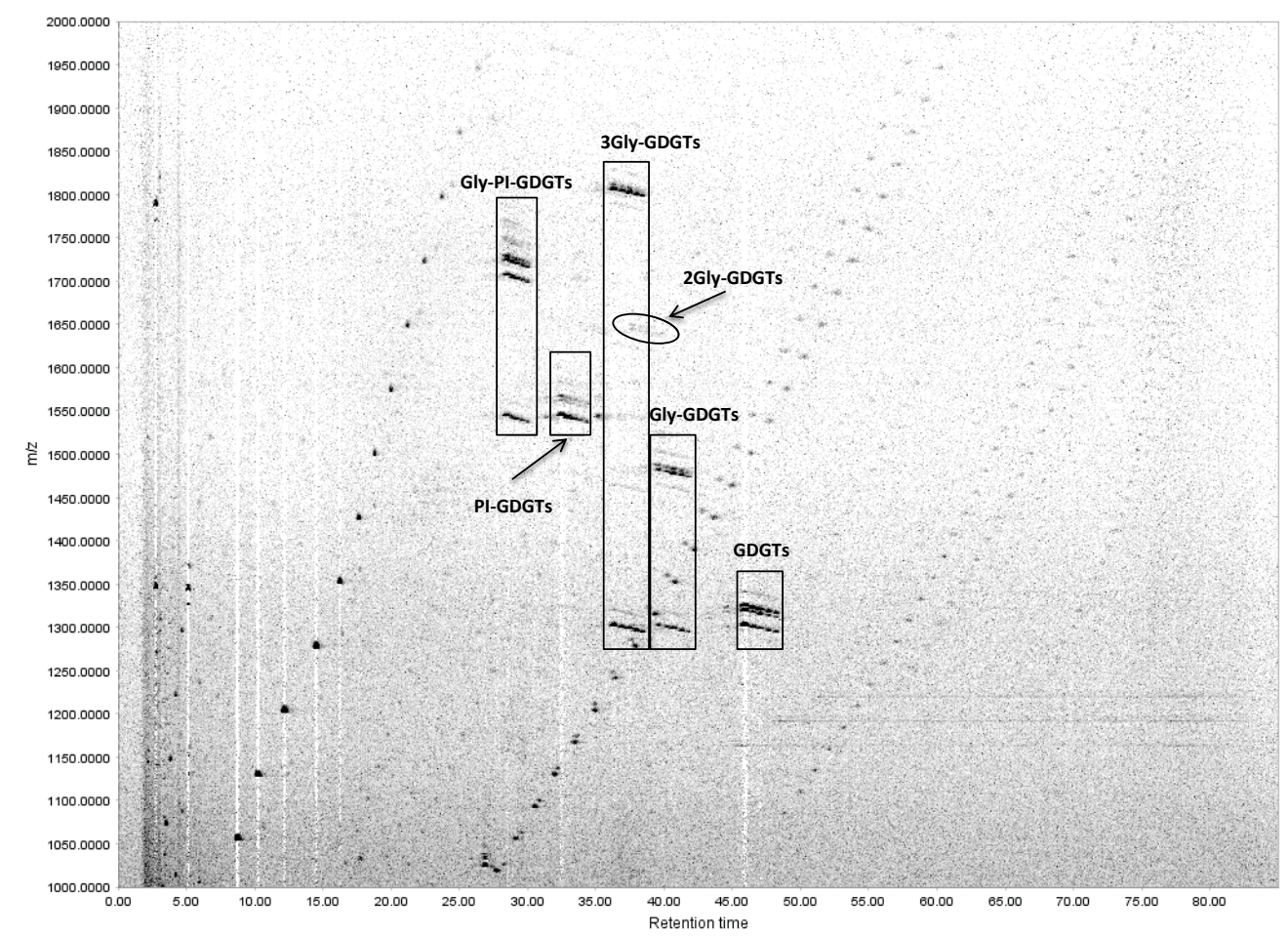

Figure 1.7. LC-MS analysis of the NZ3 ${ }^{\mathrm{T}}$ intact polar lipid extract. GDGT; glycerol dialkyl glycerol tetraethers, Gly; glycoside (monohexose), 2Gly; diglycoside (dihexose), 3Gly; triglycoside (trihexose), PI; phosphoinositol, Gly-PI; phosphoinositol.

Table 1.3. Features of the nanoarchaeote strain Ncl-1 and the host strain $\mathrm{NZ}^{\mathrm{T}}$ and their closest cultivated relatives, based on our re-analysis of reference genomes.

\begin{tabular}{|c|c|c|c|c|c|}
\hline & Strain Ncl-1 & $\begin{array}{l}\text { Cand. Nps. } \\
\text { acidilobi }\end{array}$ & N. equitans & ${\text { Strain } \mathbf{N Z 3}^{\mathrm{T}}}$ & I. aggregans \\
\hline Contigs & 9 & 1 & 1 & 19 & 1 \\
\hline Assembly size (bp) & 575637 & 605887 & 490885 & 1808184 & 1875953 \\
\hline$\% \mathrm{G}+\mathrm{C}$ & 32.2 & 24.2 & 31.6 & 41.9 & 35.7 \\
\hline Protein coding genes & 653 & 657 & 570 & 1961 & 2055 \\
\hline 5S, 16S, 23S rRNA & + & + & + & + & + \\
\hline tRNA genes & 41 & 43 & 41 & 49 & 47 \\
\hline CRISPR regions & 1 & 0 & 2 & 3 & 8 \\
\hline $\begin{array}{l}\% \text { arCOG classification } \\
(\text { E-value }<=0.00001)\end{array}$ & 73.51 & 75.19 & 71.75 & 80.32 & 81.51 \\
\hline Marker genes* & 121 of 149 & 119 of 149 & 118 of 149 & 241 of 245 & 245 of 245 \\
\hline Location & $\begin{array}{c}\mathrm{NZ} \\
\text { hot spring }\end{array}$ & $\begin{array}{c}\text { YNP } \\
\text { hot spring }\end{array}$ & $\begin{array}{l}\text { Shallow } \\
\text { marine vent }\end{array}$ & $\begin{array}{c}\mathrm{NZ} \\
\text { hot spring }\end{array}$ & $\begin{array}{c}\mathrm{NZ} \\
\text { hot spring }\end{array}$ \\
\hline
\end{tabular}

$\mathrm{NZ}=$ New Zealand; YNP = Yellowstone National Park.

*Determined using CheckM [84]. 
The genome of strain Ncl-1 more closely resembles its terrestrial relatives than marine Nanoarchaeum equitans

In order to gain insight into the relationship between the nanoarchaeote and its host, their draft genomes were obtained from single-cell sorted metagenomes of the enrichment. Using the 16S rRNA genes, the nanoarchaeote and host bins were identified. The nanoarchaeote strain Ncl-1 draft genome consists of nine contigs, totaling $0.576 \mathrm{Mbp}$, with a $32 \% \mathrm{G}+\mathrm{C}$ content (Table 1.3). Using CheckM, the draft genome contains 121 of the 149 marker genes used to estimate completeness, while the closed genomes of $N$. equitans and Cand. Nps. acidilobi have 118 and 119 of the marker genes, respectively. Ncl-1 is $52 \%$ similar to Cand. Nps. acidilobi and $43 \%$ similar to $N$. equitans based on average amino acid identity (AAI) [96], indicating genus-level divergence [51]. Concatenated ribosomal protein phylogeny also supports the position of Ncl-1 in the Nanoarchaeota (Fig. 1.8).

On a genomic level, Ncl-1 most closely resembles its terrestrial relatives, "Nanobsidianus stetteri” Nst1 and Cand. Nps. acidilobi (Table 1.3), and like other nanoarchaeotes, it lacks the genes encoding for the ability to synthesize most metabolic precursors such as nucleotides, amino acids, cofactors and lipids. Ncl-1 shows modest synteny with the genomes of Cand. Nps. acidilobi and N. equitans (Fig. 1.9A, B), and it is also highly syntenic with a nanoarchaeote draft genome obtained from a New Zealand hot spring enrichment metagenome collected in 2013 [47] (Fig. 1.9C). As "N. stetteri" Nst1 and Cand. Nps. acidilobi are very similar at the genomic level, the majority of the comparative analyses in this study were done with the closed genome of Cand. Nps. acidilobi. Like Cand. Nps. acidilobi, the Ncl-1 draft genome is about $100 \mathrm{~kb}$ larger than 
N. equitans, has partial glycolytic and gluconeogenic pathways, lacks an apparent ATP synthase complex and contains a full suite of archaeal flagellar genes [113].

In contrast to $N$. equitans, which only has one of the enzymes in the EmbdenMeyerhof-Parnas (EMP) glycolysis pathway [10], Ncl-1 encodes several of the EMP pathway genes. Like Cand. Nps. acidilobi, however, glucokinase, phosphofructokinase (PFK) and fructose 1,6-bisphosphate aldolase (FBPA) were not detected, suggesting the EMP pathway may not be functional for ATP production in terrestrial nanoarchaeotes. The non-phosphorylating glyceraldehyde-3-phosphate dehydrogenase (GAPN) and pyruvate kinase (PK) genes found in Cand. Nps. acidilobi were not found in the Ncl-1

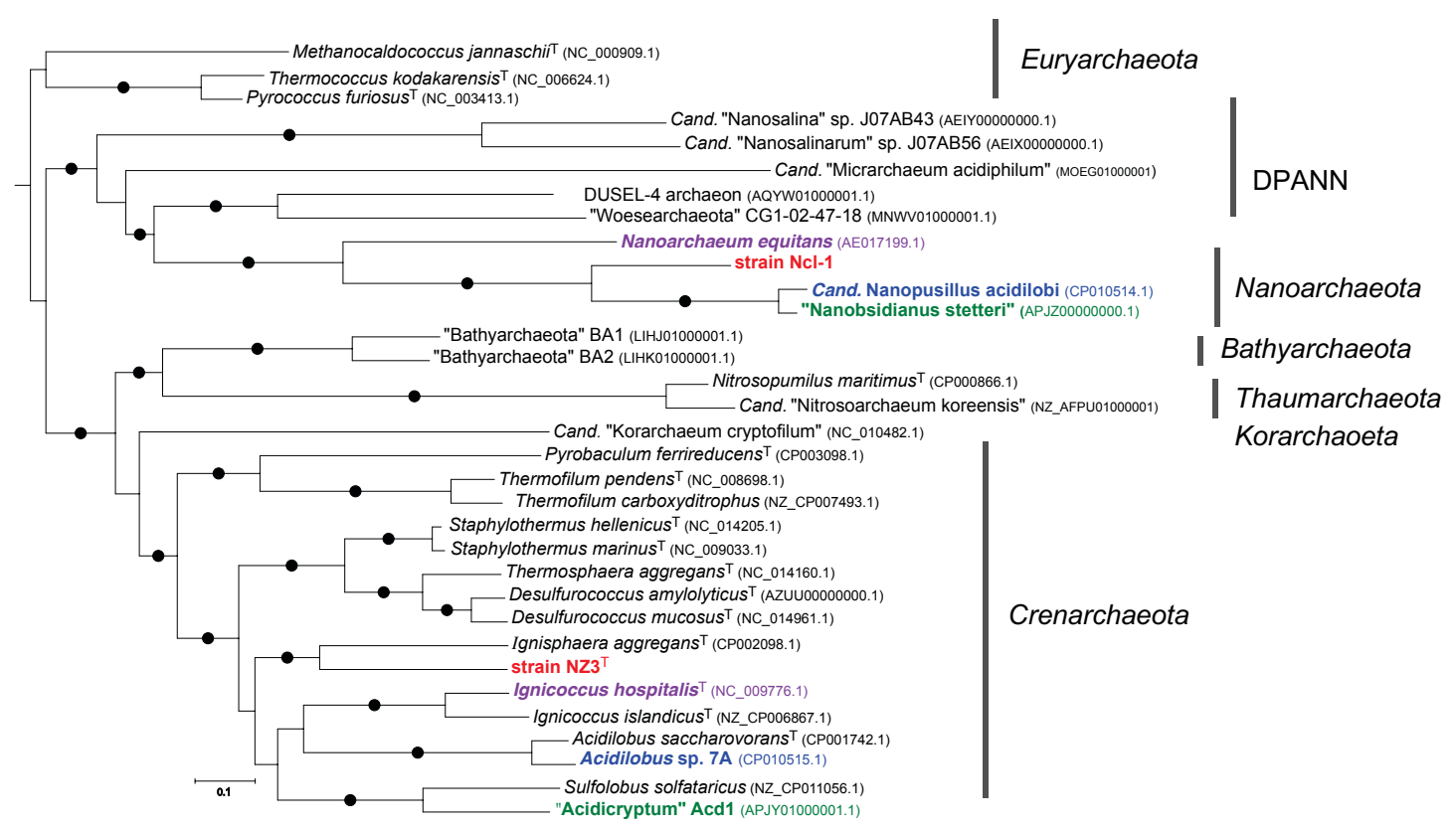

Figure 1.8. Phylogenetic analysis of 16 concatenated ribosomal proteins (rpL2, 3, 4, 5, $6,15,16,18,22,24$ and $\mathrm{rpS} 3,8,10,17,19)$ using RAxML. The tree was rooted in the Euryarchaeota. Closed circles represent bootstrap support of $\geq 70 \%$. The four different Nanoarchaeota-host systems are in red, blue, purple and green. The scale bar represents 0.1 amino acid substitutions per site. 

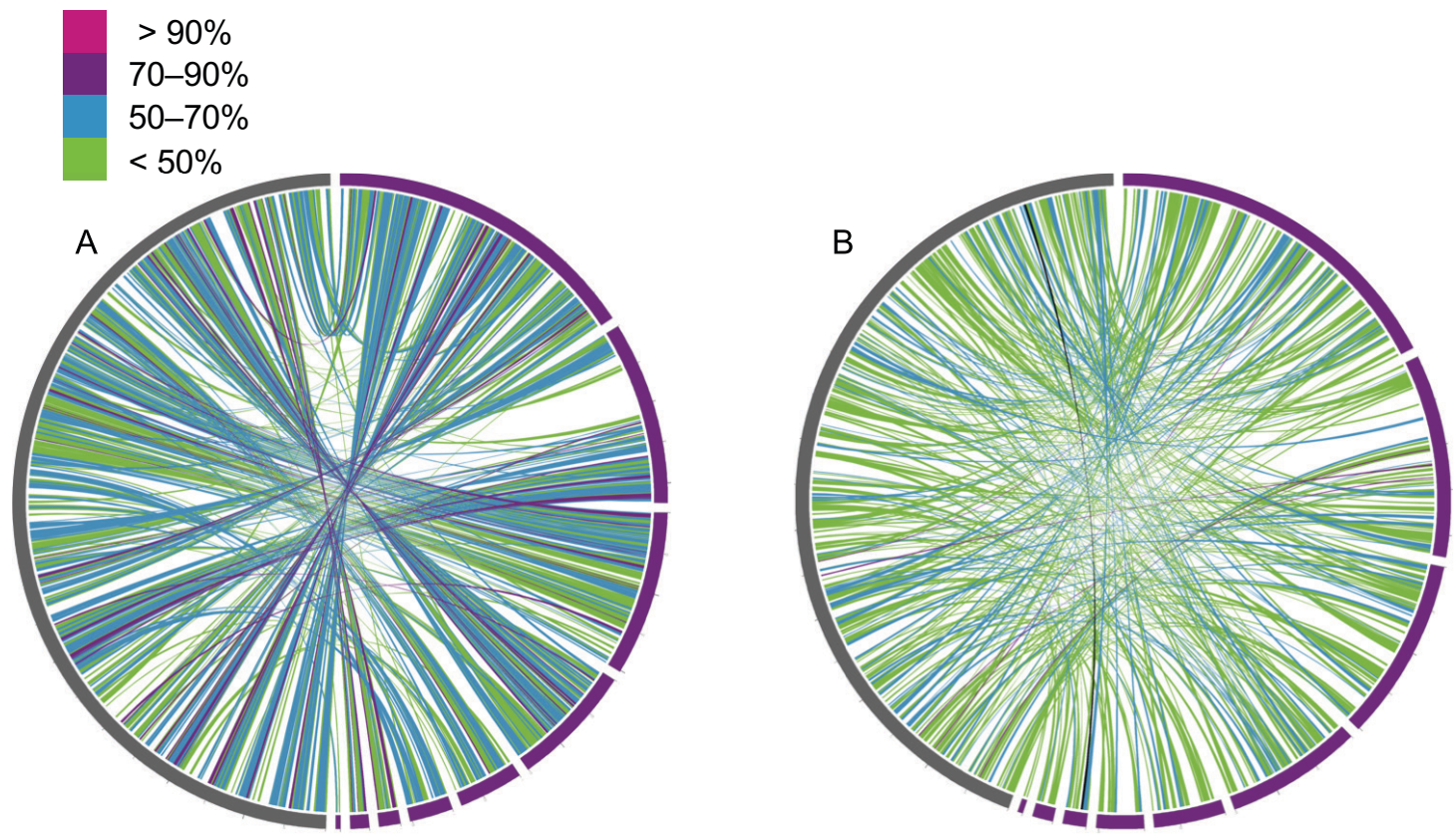

Cand. Nps. acidilobi

strain Ncl-1

$0.606 \mathrm{Mbp}$

$\sim 0.576 \mathrm{Mbp}$

N. equitans
$0.491 \mathrm{Mbp}$

strain Ncl-1

$\sim 0.576 \mathrm{Mbp}$
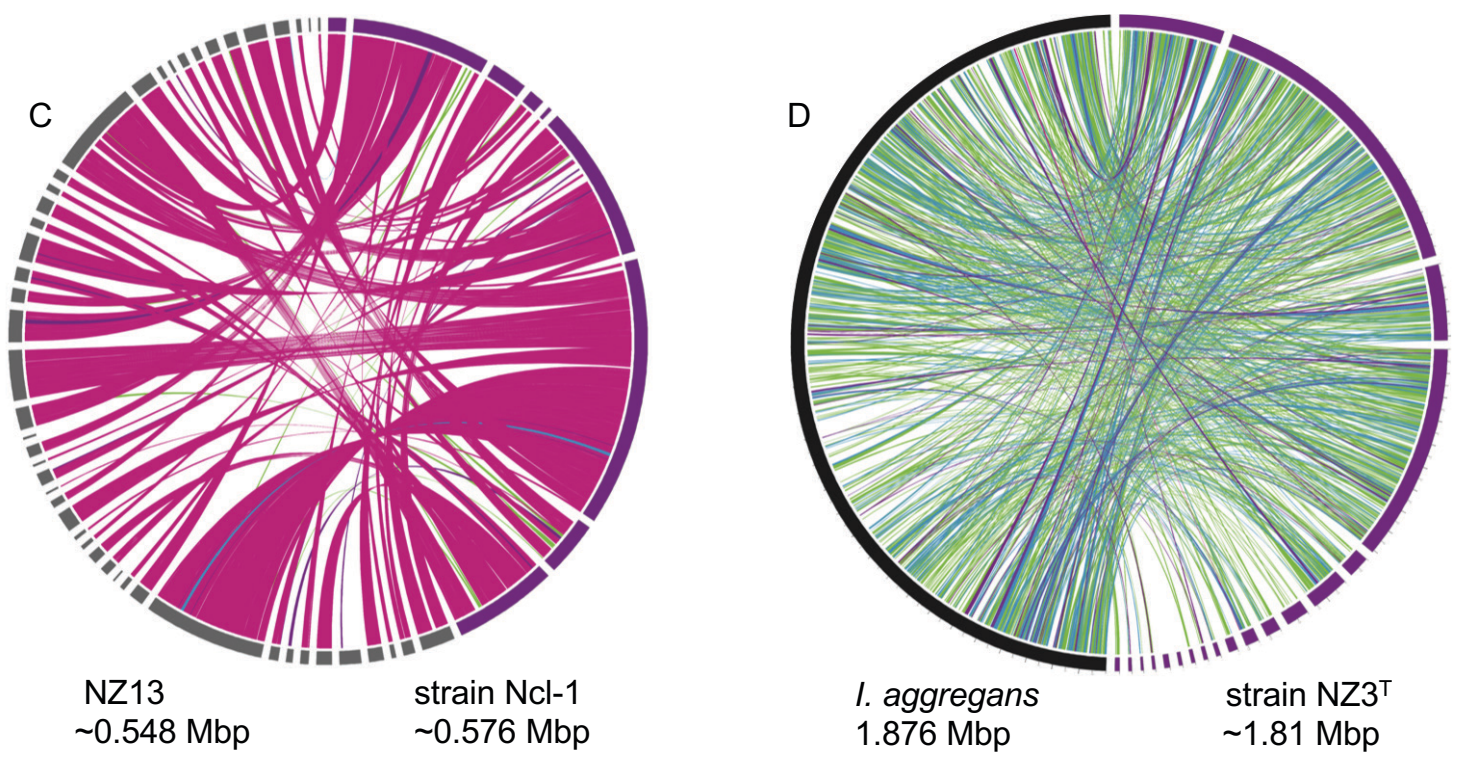

l. aggregans

$1.876 \mathrm{Mbp}$

strain NZ3 ${ }^{\top}$

$\sim 1.81 \mathrm{Mbp}$

Figure 1.9. Circos-based genome alignments comparing overall protein homology between strain Ncl-1 and (A) Cand. Nps. acidilobi, (B) N. equitans and (C) the NZ13 draft genome, and between (D) strain $\mathrm{NZ3}^{\mathrm{T}}$ and Ignisphaera aggregans. Colored lines link pairs of orthologs between genomes, with the color scaled to $\%$ amino acid similarity levels. 
draft genome, although the PK gene also was not expressed in the proteome of Cand. Nps. acidilobi [113]. As an alternative, the PK step may be catalyzed in both Cand. Nps. acidilobi and Ncl-1 by phosphoenolpyruvate synthase (PEPS, Ncl-1 451, 487), as reported in Thermococcus kodakarensis [10,38,113]. Nonetheless, the EMP glycolytic pathway is likely nonfunctional in either Cand. Nps. acidilobi or Ncl-1.

Most of the genes for gluconeogenesis, several which are bidirectional, are present in both terrestrial nanoarchaeotes (absent in N. equitans) and are expressed in the proteome of Cand. Nps. acidilobi [113]. It is therefore likely that gluconeogenesis can proceed to some extent in these two nanoarchaeotes and its primary role may be to synthesize activated sugars for protein and lipid glycosylation, as Cand. Nps. acidilobi has a glycosylated, lectin-reactive surface [113]. Although the glyceraldehyde-3phosphate dehydrogenase/phosphoglycerate kinase (GAPDH/PGK) couple was not detected in either Cand. Nps. acidilobi or Ncl-1, Wurch et al, 2016 [113] proposed that its function may be replaced by a reversible ferredoxin-dependent aldehyde oxidoreductase (Ncl-1 615). Furthermore, while both terrestrial nanoarchaeotes have an acetyl-CoA synthase (Ncl-1 481, 606), it was not expressed in the Cand. Nps. acidilobi proteome under tested culture conditions [113], leaving it unclear whether Cand. Nps. acidilobi and Ncl-1 can convert acetate to acetyl-CoA for gluconeogenesis, or if acetyl-CoA is obtained from their hosts or other sources.

Strain Ncl-1 has two ABC-type multidrug transporter subunits (Ncl-1 256-257), two ABC-type antimicrobial peptide transporter subunits (Ncl-1 473, 476), and two gene copies of a cation transport ATPase (Ncl-1 290, 573) which all show strong homology to transporters reported for Cand. Nps. acidilobi. However, the major facilitator 
superfamily permeases were not detected in the draft genome. In contrast, Ncl-1 has two Trk-system proteins involved in potassium uptake (Ncl-1 249-250) that have not previously been reported in the Nanoarchaeota. Both Cand. Nps. acidilobi and Ncl-1 have a highly reduced set of transporter genes, however, suggesting that transport proteins may not represent the primary mode of metabolite transfer between Nanoarchaeota and their hosts [113].

Strain Ncl-1 and Cand. Nps. acidilobi encode archaeal flagella using very similar gene arrangements (Fig. 1.10A-B), both containing the essential fla genes required for assembly and function [2], but lacking the traditional operon structure found in other Archaea (Fig. 1.10C). Like Cand. Nps. acidilobi, Ncl-1 has a flaD/E gene (Ncl-1 218) typical of Euryarchaeota [2]. TEM micrographs revealed that archaeal flagella genes are functional in strain Ncl-1 and expressed under cultivation conditions (Fig. 1.1C-E). Strain Ncl-1 is often seen with several $(\sim 5)$ lophotrichous archaeal flagella, both when associated (Fig. 1.1C) and detached from its host (Fig. 1.1D-E). If motile, the nanoarchaeotal flagella may play a role in host-seeking behavior, as proposed for marine obligate intracellular parasitic Chlamydiae [17], or they may allow the nanoarchaeote to detach and search for a new host [113]. Alternatively, the nanoarchaeotal flagella may mediate adhesion to surfaces $[40,117]$ or attachments between the symbiont and its host [99]. However, the presence of archaeal flagella presents a conundrum for both Ncl-1 and Cand. Nps. acidilobi, as neither possesses any apparent means of producing ATP to fuel motility. 


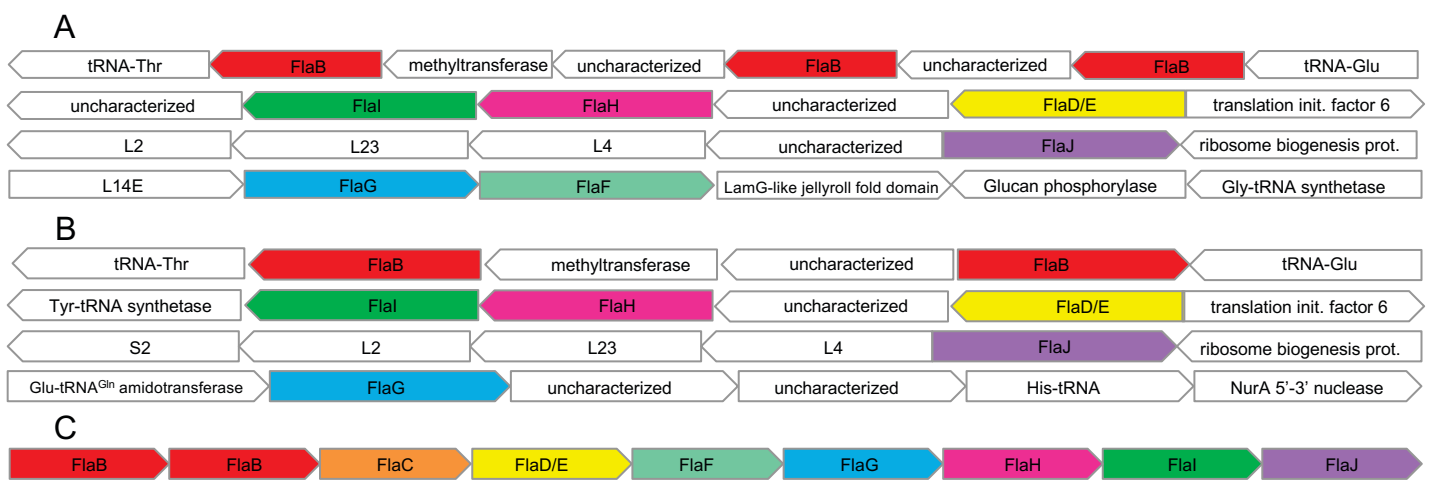

Figure 1.10. Comparison of the archaeal flagellar gene arrangement in (A) strain Ncl-1, (B) Cand. Nps. acidilobi and (C) Pyrococcus furiosus.

Strain Ncl-1 shares additional similarities with the central metabolic genes of $N$. equitans and Cand. Nps. acidilobi. Like all characterized nanoarchaeotes, Ncl-1 has a non-discriminating Glu-tRNA synthetase (Ncl-1 520) and both of the amidotransferase subunits required for transamidation of Glu-tRNA ${ }^{\text {Gln }}$ to Gln-tRNA ${ }^{\text {Gln }}$ (Ncl-1 159-160). Both Cand. Nps. acidilobi and Ncl-1 appear to synthesize Asn-tRNA ${ }^{\text {Asn }}$ directly via an asparaginyl-tRNA synthetase (Ncl-1 446), instead of using the transamidation reaction found in N. equitans. However, Ncl-1 encodes a class I lysyl-tRNA synthetase (Ncl-1 78) similar to marine N. equitans, thought to be the ancestral gene form [89], while Cand. Nps. acidilobi harbors the class II enzyme. Similar to Cand. Nps. acidilobi, Ncl-1 can also convert L-cysteine to L-alanine via a cysteine desulfurase (Ncl-1 421). Furthermore, Ncl-1 possesses some unique nucleotide biotransformation capabilities not found in either Cand. Nps. acidilobi or N. equitans, including a purine-nucleoside phosphorylase (Ncl-1 611), a CTP synthase (Ncl-1 590), and a nucleoside-triphosphatase THEP1 (Ncl-1 633). 
The Ncl-1 draft genome contains 41 tRNAs, encoding for all 20 standard amino acids. Like all described nanoarchaeotes, Ncl-1 contains several cis-spliced tRNAs which are common throughout the Archaea $[27,49,107,111,113]$. Although some of the cis-spliced tRNA genes found in Ncl-1 are shared by other Nanoarchaeota, the Ncl-1 intron sequences are unique (Appendix B, File S1, Table A3). In contrast, two tRNA intron sequences identified in Cand. Nps. acidilobi and "N. stetteri" Nst1 are identical, suggesting the intron sequence were already present in the last common ancestor of these two closely-related nanoarchaeotes. Although the host strain $\mathrm{NZ3}^{\mathrm{T}}$ also contains cisspliced tRNA genes, none of the intron sequences found in the host match the corresponding intron sequences in the Ncl-1 nanoarchaeote, suggesting these introns were not transferred horizontally from host to Nanoarchaeota. The Ncl-1 tRNA intron sequences did not show any significant homology (E-value $<=0.001)$ to Group II introns in the Rfam database [44] or to the custom set of Group I introns provided by Nawrocki et al. [76]. However, one large tRNA intron sequence in the Ncl-1 draft genome (tRNAAsp; 486 bp) contains a putative homing endonuclease domain (E-value 0.003) and complex secondary structure. Notably, this intronic sequence does not show significant homology (E-value $<=0.00001)$ to the putative homing endonuclease found in the host 16S rRNA gene intron, suggesting it was not acquired from the host.

The trans-spliced tRNAs identified in $N$. equitans [91,92] were not found in either Ncl-1 or Cand. Nps. acidilobi. Similarly, both the genomes of Cand. Nps. acidilobi and Ncl-1 encode for RNase P (inferred in Ncl-1 on the basis of RNase P protein subunits) while it was not identified in the genome of $N$. equitans $[59,93]$. The Ncl-1 draft genome has a common set of split protein coding genes, shared by all described nanoarchaeotes 
(Table 1.4). Fragmented protein coding genes have also been described in some members of the Euryarchaeota [111]. Split genes provide further evidence that genome reduction in the Nanoarchaeota resulted in stochastic fragmentation, with genes often split in the same location [89]. Some unique split genes also occur across the nanoarchaeote genomes, which is not surprising given the phylogenetic diversity of the three cultivated nanoarchaeotes. Genes with conserved split regions likely represent ancestral fragmentation sites, present in the last common ancestor of extant nanoarchaeotes, while proteins split in some but not all Nanoarchaeota may be more recent splitting events.

Similar to its marine relative $N$. equitans, Ncl-1 has a putative CRISPR-Cas system, which is the first described CRISPR-Cas system for a terrestrial nanoarchaeote [72,89,113]. The system contains 43 spacer regions and a suite of Type 1 cas genes. Although several of the cas genes show strong homology to their counterparts in $N$. equitans, the gene arrangement is quite different (Fig. 1.11) and the system contains an additional cas6 gene (Ncl-1 284) not identified in N. equitans. The target of the Ncl-1 CRISPR-Cas system is unclear as the spacer regions do not show significant homology (E-value $<=0.00001)$ to viral sequences in the NCBI nucleotide database or to the genome sequence of the host, strain NZ3 ${ }^{\mathrm{T}}$. Although no CRISPR-Cas system has been previously reported in terrestrial nanoarchaeotes, a nanoarchaeotal draft genome from Nymph Lake, YNP, showed evidence of integrated prophage DNA [72], demonstrating that geographically distant nanoarchaeotes are vulnerable to viral infection. 

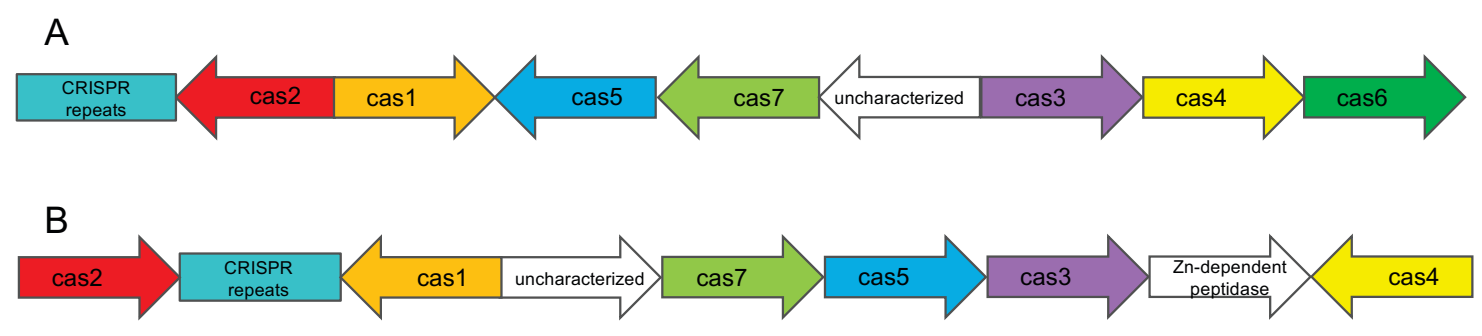

Figure 1.11. Gene arrangement of the CRISPR-Cas locus in (A) strain Ncl-1 and (B) $N$. equitans.

Metabolic insights from the draft genome of the host, $N Z 3^{T}$

To explore the metabolic capabilities of $\mathrm{NZ3}^{\mathrm{T}}$ further, the draft genome was reconstructed from low-diversity metagenomic data as previously described (Materials and Methods, pg. 37). The NZ3 ${ }^{\mathrm{T}}$ draft genome consists of 19 contigs, with a $41.9 \% \mathrm{G}+\mathrm{C}$ content and 97.5\% completion based on CheckM (Table 1.3). Phylogenetic reconstruction using a set of 16 ribosomal proteins (Fig. 1.8) confirmed the placement of $\mathrm{NZ3}^{\mathrm{T}}$ in the Desulfurococcaceae, in a deeply-branching clade with I. aggregans. The genome is $45 \%$ similar to I. aggregans based on AAI, which is consistent with the level of 16S rRNA gene sequence divergence between the two organisms [51]. The strain $\mathrm{NZ3}^{\mathrm{T}}$ genome also shows modest levels of synteny to I. aggregans (Fig. 1.9D), and the two strains are similar in size ( 1.808 Mbp and 1.876 Mbp, respectively) [29]. Fortynine tRNA genes (19 of 20 standard amino acids), three rRNA genes and RNase P were also identified in the $\mathrm{NZ3}^{\mathrm{T}}$ genome. Similar to Fervidicoccus fontis, another member of the Thermoprotei, NZ3 ${ }^{\mathrm{T}}$ appears to be auxotrophic for a variety of amino acids and coenzymes, such as biotin and coenzyme A [55]. 


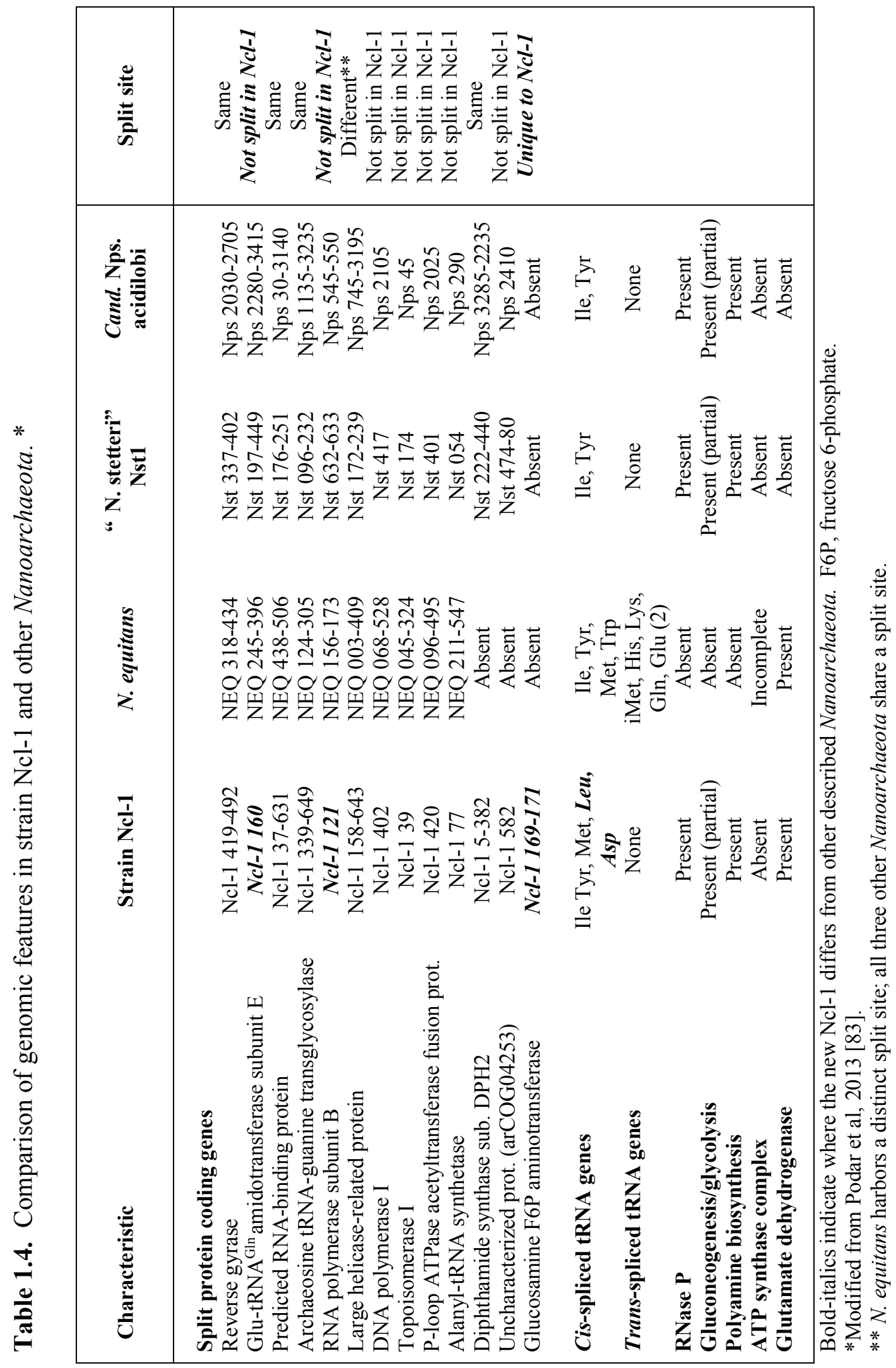


Consistent with its growth on peptide-rich substrates, the $N Z 3^{\mathrm{T}}$ draft genome contains secreted and cytosolic peptidases and proteases, and a suite of transporters to import dipeptides, oligopeptides and amino acids into the cell. Once inside the cell, amino acid degradation likely proceeds using pyruvate:ferredoxin oxidoreductases (NZ3 1006-1009;1927-1930) and indolepyruvate:ferredoxin oxidoreductases (NZ3 279-280; 1116-1117) as described for members of the Thermococcaceae $[33,62,63]$. Breakdown of amino acids provides $\mathrm{NZ3}^{\mathrm{T}}$ with limited ATP and a pool of reduced ferredoxin molecules.

The $\mathrm{NZ3}{ }^{\mathrm{T}}$ genome has incomplete gluconeogenesis and EMP glycolysis pathways, and the Entner-Doudoroff glycolysis pathway and pentose phosphate pathway were not detected. Possibly, NZ3 ${ }^{\mathrm{T}}$ may utilize an archaeal type III Rubisco (NZ3 708, 1082) to generate 3-phosphoglycerate (3-PGA) as proposed by Sato et al, 2007 [97]. 3PGA could then be converted to acetate using enzymes involved in glycolysis and amino acid fermentation, generating ATP for the cell.

Despite its dependence on thiosulfate as a terminal electron acceptor, no thiosulfate reductase gene was identified in the $N Z 3^{\mathrm{T}}$ draft genome. However, it is possible that the gene may be encoded in one of the unsequenced portions of the genome. Alternately, $\mathrm{NZ3}{ }^{\mathrm{T}}$ may utilize a divergent gene for thiosulfate reduction that has yet to be identified. Consistent with its lifestyle as an anaerobe, no cytochrome c oxidase or cytochrome $b d$ ubiquinol oxidase genes were found in the draft genome of $\mathrm{NZ3}^{\mathrm{T}}$.

Strain $\mathrm{NZ3}{ }^{\mathrm{T}}$ has several different hydrogenases, including two membrane-bound [NiFe] group $4 b$ hydrogenase clusters which evolve molecular hydrogen [31]. One of these clusters contains a putative catalytic carbon monoxide dehydrogenase subunit $\operatorname{coo} S$ 
(NZ3 969), suggesting that $N Z 3^{\mathrm{T}}$ may be able to conserve energy through carboxydotrophic hydrogenogenesis (coupling $\mathrm{CO}$ oxidation and proton reduction) in a similar manner to that of Thermococcus onnurineus and Thermococcus sp. AM4 $[56,102,103]$. The $\mathrm{NZ3}^{\mathrm{T}} \operatorname{cooS}$ gene shows strong phylogenetic relatedness to $\operatorname{coo} S$ genes found in known carboxydotrophs such as Thermococcus barophilus (Genbank NC_014804.1, [110]) and Thermococcus sp. AM4 (Genbank CP002952.1, [81]) (Fig. 1.12). However, direct cultivation studies under a $\mathrm{CO}$ atmosphere will be required to determine whether or not $\mathrm{CO}$ oxidation is functional in strain $\mathrm{NZ3}^{\mathrm{T}}$. The second $[\mathrm{NiFe}]$ group 4b hydrogenase cluster (NZ3 314-329) in the draft genome encodes a multi-subunit $\mathrm{Na}^{+} / \mathrm{H}^{+}$antiporter which may facilitate the formation of a sodium ion gradient across the membrane [31]. This sodium gradient may be used to generate ATP using an archaealtype ATP synthase (NZ3 1842-1845, 1847-1849), as reported for Desulfurococcus kamchatkensis, Pyrococcus furiosus, and Methanosarcina acetivorans [88,94,98]. The $\mathrm{NZ3}^{\mathrm{T}}$ genome also encodes a $[\mathrm{NiFe}]$ group $3 \mathrm{~A}$ hydrogenase cluster containing a coenzyme $\mathrm{F}_{420}$-reducing hydrogenase (NZ3 1861) similar to those found in methanogens and T. onnurineus $[31,42,56,57]$. Phylogenetic analysis clusters the NZ3 ${ }^{\mathrm{T}}$ gene with coenzyme $\mathrm{F}_{420}$-reducing hydrogenases from T. onnurineus and other non-methanogenic lineages with high confidence (Fig. 1.13). To our knowledge, this represents the first example of a coenzyme $\mathrm{F}_{420}$-reducing hydrogenase reported in the Crenarchaeota. As suggested for $T$. onnurineus, this hydrogenase likely does not utilize coenzyme $\mathrm{F}_{420}$, since there is no genomic evidence that either organism is capable of synthesizing the coenzyme $[42,57]$. While its function in non-methanogens remains unclear, transcriptomic data from $T$. onnurineus indicates that the coenzyme $\mathrm{F}_{420}$-reducing 


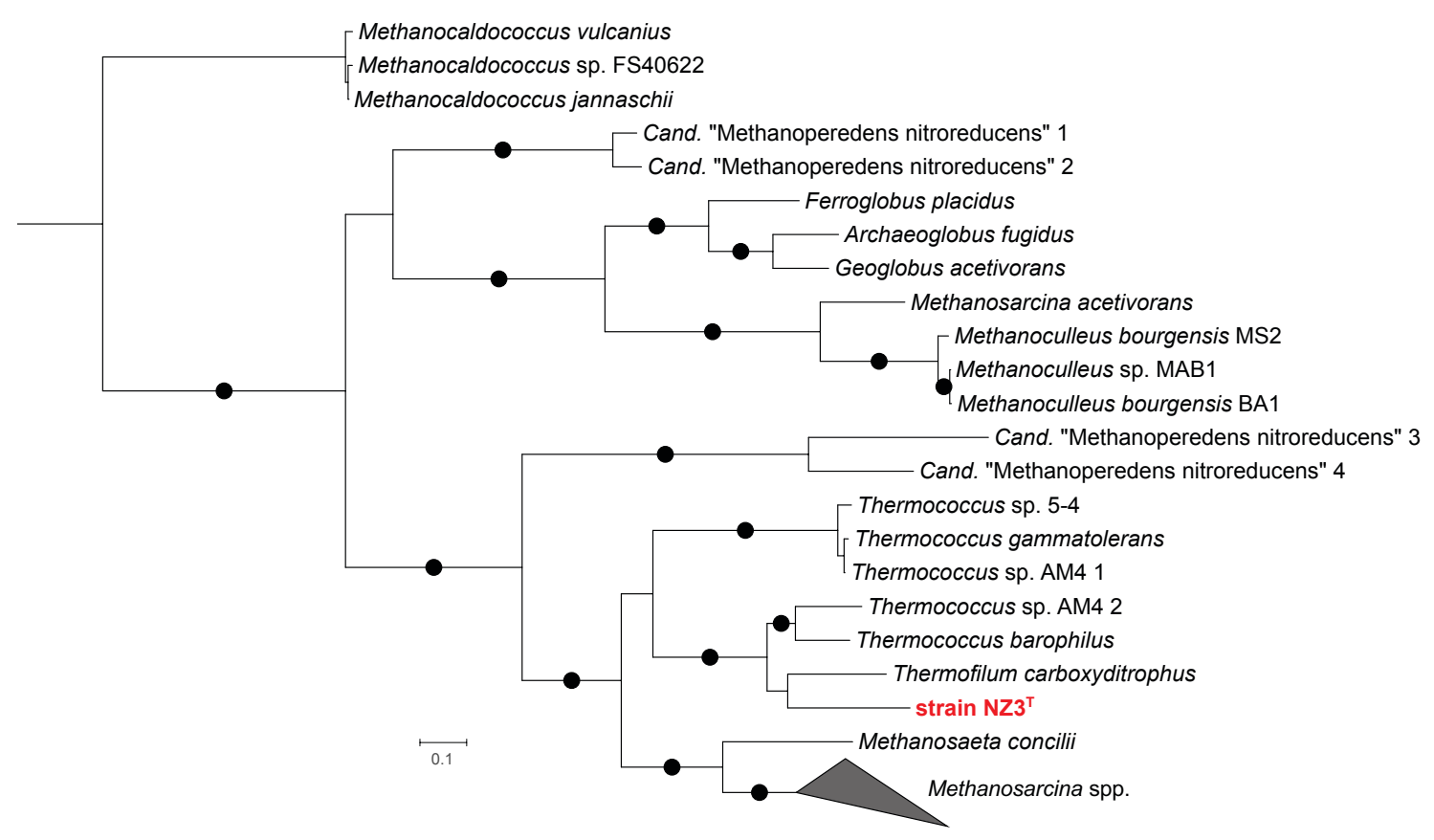

Figure 1.12. Maximum likelihood phylogenetic tree of archaeal cooS genes. Filled circles represent $\geq 70 \%$ bootstrap support. Scale bar indicates 0.1 amino acid substitutions per site.

hydrogenase impacts the expression of $\mathrm{CO}$ oxidation genes, potentially pointing to a larger role in central metabolism [57].

Genomic evidence suggests that NZ3 ${ }^{\mathrm{T}}$ encodes genes for synthesis of an S-layer (NZ3 717), similar to Acidilobus sp. 7A, the host of terrestrial Cand. Nps. acidilobi [113]. This is in contrast with I. hospitalis, the host of $N$. equitans, which has a distinctive double membrane system and lacks an S-layer $[83,90]$. Based on a recent study using electron tomography, the double membrane structure in I. hospitalis appears to play a crucial role in its association with $N$. equitans, as the host and symbiont form a cytoplasmic bridge at their attachment site [90]. A similar pore-like structure was detected between $\mathrm{NZ3}^{\mathrm{T}}$ and its nanoarchaeotal symbiont at their attachment site, with no membrane clearly visible between the cells (Fig. 1.1F) and suggests an equally intimate 
association between the terrestrial nanoarchaeote and its host. However, given the extreme differences in host outer membrane structure, it is likely that terrestrial nanoarchaeotes have evolved a unique mechanism of recognizing, attaching, and interacting with their hosts.

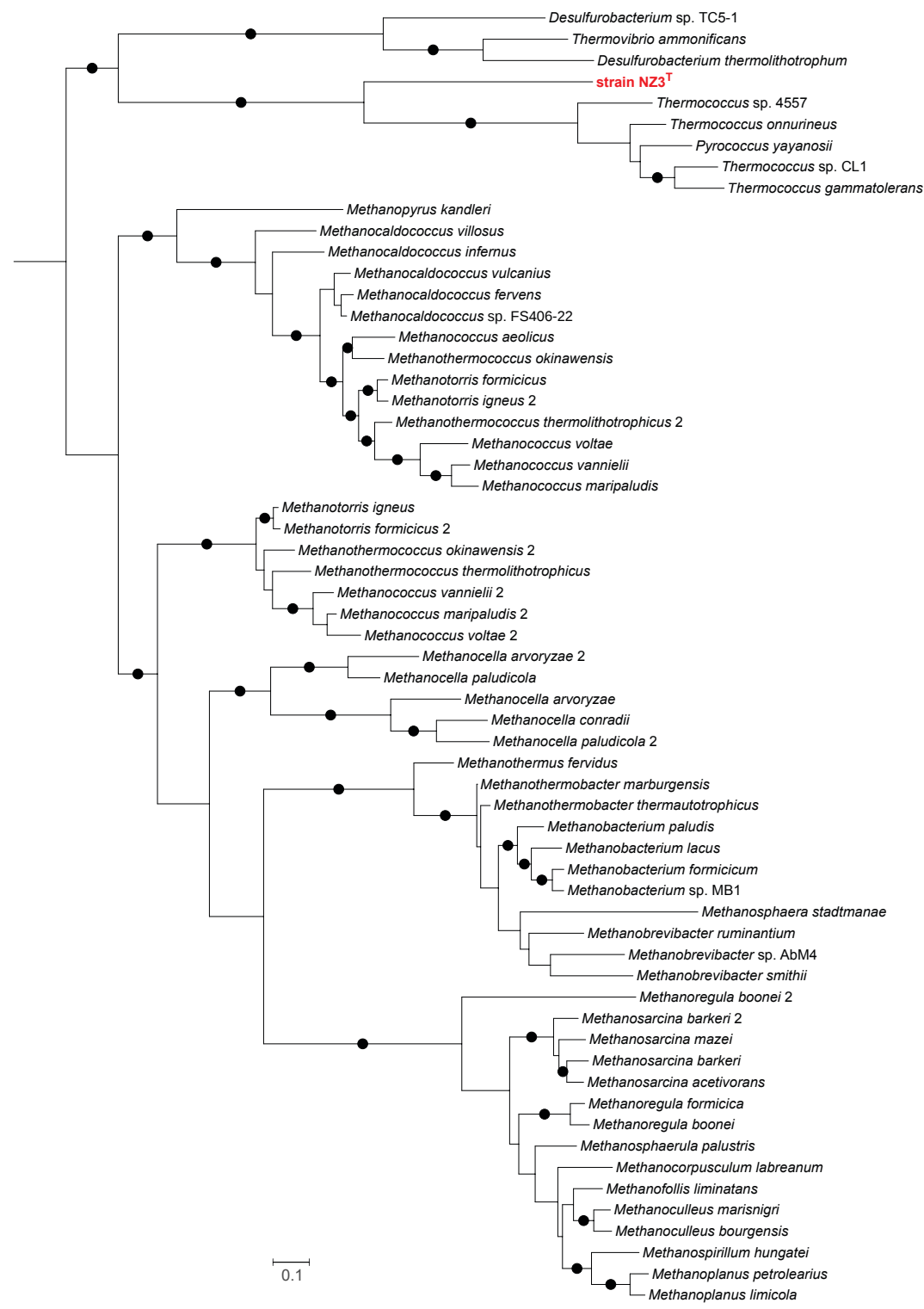

Figure 1.13. Maximum likelihood phylogenetic analysis of coenzyme $\mathrm{F}_{420}$-reducing hydrogenases. Enzyme sequences were obtained from the HydDB web server [104]. The scale shows 0.1 substitutions per amino acid, and filled circles represent $\geq 70 \%$ bootstrap support. 
Proposal of a novel Candidatus taxon in the Nanoarchaeota and a novel genus and species in the Desulfurococcaceae

The New Zealand nanoarchaeote strain Ncl-1 is distinct from its described relatives at both a phylogenetic and a genomic level. While 16S rRNA gene and concatenated ribosomal protein phylogenetic trees place Ncl-1 in the Nanoarchaeota, the $16 \mathrm{~S}$ rRNA gene of the strain is divergent from its described relatives ( $~ 84-88 \%$ gene sequence similarity). AAI analysis also suggests genus-level divergence between Ncl-1 and the cultivated taxa Cand. Nps. acidilobi and N. equitans (45-52\%). Although the genome of Ncl-1 shows stronger homology to its terrestrial relatives, it contains several genes not previously found in the Nanoarchaeota. Ncl-1 is also the first cultivated Nanoarchaeota from a New Zealand geothermal spring, and its host is a new crenarchaeotal genus. The clear phylogenetic divergence between Ncl-1 and other described nanoarchaeotes suggests that it represents a novel genus and species in the Nanoarchaeota. The formal proposal of a new Candidatus taxon in the Nanoarchaeota, Candidatus Nanoclepta minutus, is given in Appendix B, File S1, Table A4, with the Taxonumber CA00029.

Strain $\mathrm{NZ3}^{\mathrm{T}}$ forms a clade in the Desulfurococcaceae with Ignisphaera aggregans. However, $\mathrm{NZ3}^{\mathrm{T}}$ is only $\sim 92 \%$ similar to I. aggregans by $16 \mathrm{~S}$ rRNA gene similarity and $45 \%$ similar by AAI. Unlike I. aggregans, $\mathrm{NZ3}^{\mathrm{T}}$ requires thiosulfate as a terminal electron acceptor and grows well on several proteinaceous substrates but cannot use any sugars for growth. Moreover, $N Z 3^{\mathrm{T}}$ grows optimally between $82-83^{\circ} \mathrm{C}$, which is much lower than the optimal temperature $\left(92-95^{\circ} \mathrm{C}\right)$ of $I$. aggregans. Given these physiological and phylogenetic differences, we propose that strain $\mathrm{NZ}^{\mathrm{T}}$ represents a new 
species of a novel genus in the Desulfurococcaceae. The formal proposal of the novel genus Zestosphaera gen. nov. and the species Zestosphaera tikiterensis sp. nov. is provided in Appendix B, File S1, Table A4, with the Taxonumbers GA00064 and TA00512, respectively.

\section{Conclusions}

Here we expand on nanoarchaeote-host symbiotic systems by describing a fourth association. A stable co-culture containing a novel nanoarchaeote and its host, a new genus in the Desulfurococcaceae, was cultivated from a geothermal hot spring in New Zealand. The New Zealand nanoarchaeote closely resembles other terrestrial nanoarchaeotes, with the presence of archaeal flagella and no apparent ATP synthase genes, but it also contains a CRISPR-Cas system like its marine relative N. equitans. The fragmentation of archaeal flagellar genes and the presence of shared split protein-coding genes distributed among marine and terrestrial nanoarchaeotes provide further evidence that genome reduction and fragmentation in this lineage began before the marine and terrestrial taxa diverged. The mechanisms by which phylogenetically different hosts interact with their nanoarchaeotal symbionts remain elusive. However, as more nanoarchaeote-host systems are characterized, additional insights will emerge about the cell-cell interactions in these symbioses, and whether host metabolism and ultrastructure have played roles in the evolutionary history of the symbiosis.

The New Zealand Nanoarchaeota-host system also points to the challenges associated with describing a cultivated organism that is only viable in the presence of its host. Under the current system of nomenclature, regulated by the International Code of 
Nomenclature of Bacteria, a pure culture is required for the valid naming and recognition of a novel taxon $[50,54]$. However, no provision is made for obligate symbionts that are cultivated in the minimum consortium needed for growth (co-culture). For some intracellular pathogens, such as Lawsonia [68], Diplorickettsia [70], and members of the Chlamydiae [28,30], valid names may be assigned if the strain is cultivable in cell culture. However, this option is not available for many environmental taxa requiring a specific host for cultivation, such as ectosymbiotic Nanoarchaeota, or the diverse epibiotic Archaea and Bacteria that colonize ciliates [12,23,101]. While the Candidatus designation provides a means of identifying these novel lineages, it is a provisional status and implies that the organism will be isolated in the future, which is not feasible for obligate symbionts, parasites, or some epibionts [50]. Ultra-small genomes recovered from the archaeal DPANN superphylum $[6,95]$ and bacterial Candidate Phyla Radiation [18] suggest a large diversity of yet-uncultivated microbial taxa that may rely on hosts for survival. Looking ahead, as more of these lineages are discovered and cultivated, the coherent classification of symbionts will require a greater acceptance and standardization of the Candidatus designation, or a novel system of symbiont nomenclature. Further complicating matters are names that have become adopted as validly described through repeated use such as Nanoarchaeum equitans. 


\section{Acknowledgements}

We would like to thank Dr. Aharon Oren for providing correct etymology for our novel taxa, Dr. Kenneth Stedman for initial help with TEM, Dr. Richard Davis, John Donaho and Nicole Wagner for assistance in the bioinformatics, Kristen Brileya for developing the qPCR primers, Kira Makarova for guidance with protein annotation, and Stefan L'Haridon for many helpful discussions. We also thank Steve Allman, Zamin Yang and Dawn Klingeman from Oak Ridge National Laboratory (ORNL) for assistance with cell sorting, molecular biology techniques and MiSeq sequencing. ORNL is managed by UT-Battelle, LLC, for the U.S. Department of Energy under contract DEAC05-00OR22725. This research was funded through grants from the National Science Foundation (DEB1134877), the National Aeronautics and Space Administration (NNX16AJ66G), and the Geothermal Resources of New Zealand (GRN) Program at GNS Science. We acknowledge and thank Tikitere Trust for their enthusiasm for our research and assistance in access and sampling of the Hell's Gate geothermal features. TEM data acquisition was performed at the Portland State University Center for Electron Microscopy and Nanofabrication (CEMN), which is generously supported by the NSF, Murdock Charitable Trust, ONAMI, and FEI (currently Thermo Fisher Scientific). 
Contributions

Sampling was performed by ALR and MBS, and initial enrichment cultures were grown by ALR and YL. Negative staining for TEM was done by ALR, and ZC obtained TEM images. The NZ Nanoarchaeota-host system was isolated by YL. Z. tikiterensis was isolated by ESJ, who also identified the optimal $\mathrm{pH}$ and temperature, doubling time and electron acceptor use. YL determined carbon source usage, $\mathrm{NaCl}$ sensitivity, and temperature and $\mathrm{pH}$ minima and maxima for Z. tikiterensis. ESJ routinely extracted genomic DNA, monitored Nanoarchaeota numbers by qPCR, validated the purity of the Nanoarchaeota-host co-culture and the Z. tikiterensis isolate culture and validated the presence of $16 \mathrm{~S}$ rRNA introns in Z. tikiterensis. KL and KM extracted and identified the polar and intact lipids of Z. tikiterensis. iTAG sequencing and analysis and sorting, screening and amplification of single cells was done by ALR and MP. Assembly, trimming, and binning was performed by JM. ESJ performed manual curation and final binning in ESOM, followed by analysis of the coding potential of the Nanoarchaeota and its host. ESJ generated ribosomal protein and 16S rRNA gene trees, average amino acid identity analyses, Circos synteny plots and intron and gene arrangement diagrams. The manuscript was prepared by ALR and ESJ. 


\section{References}

[1] Aagaard, C., Dalgaard, J.Z., Garrett, R.A. (1995) Intercellular mobility and homing of an archaeal rDNA intron confers a selective advantage over intron- cells of Sulfolobus acidocaldarius. Proc. Natl. Acad. Sci. U. S. A. 92(26), 1228512289.

[2] Albers, S.-V., Jarrell, K.F. (2015) The archaellum: how Archaea swim. Front. Microbiol. 6, 23, https://doi.org/10.3389/fmicb.2015.00023.

[3] Altschul, S.F., Gish, W., Miller, W., Myers, E.W., Lipman, D.J. (1990) Basic local alignment search tool. J. Mol. Biol. 215(3), 403-410.

[4] Anantharaman, K., Brown, C.T., Hug, L.A., Sharon, I., Castelle, C.J., Probst, A.J., Thomas, B.C., Singh, A., Wilkins, M.J., Karaoz, U., Brodie, E.L., Williams, K.H., Hubbard, S.S., Banfield, J.F. (2016) Thousands of microbial genomes shed light on interconnected biogeochemical processes in an aquifer system. Nat. Commun. 7, 13219, https://doi.org/10.1038/ncomms13219.

[5] Aziz, R.K., Bartels, D., Best, A.A., DeJongh, M., Disz, T., Edwards, R.A., Formsma, K., Gerdes, S., Glass, E.M., Kubal, M., Meyer, F., Olsen, G.J., Olson, R., Osterman, A.L., Overbeek, R.A., McNeil, L.K., Paarmann, D., Paczian, T., Parrello, B., Pusch, G.D., Reich, C., Stevens, R., Vassieva, O., Vonstein, V., Wilke, A., Zagnitko, O. (2008) The RAST Server: rapid annotations using subsystems technology. BMC Genomics 9, 75, https://doi.org/10.1186/1471-21649-75.

[6] Baker, B.J., Comolli, L.R., Dick, G.J., Hauser, L.J., Hyatt, D., Dill, B.D., Land, M.L., Verberkmoes, N.C., Hettich, R.L., Banfield, J.F. (2010) Enigmatic, 
ultrasmall, uncultivated Archaea. Proc. Natl. Acad. Sci. U. S. A. 107(19), 88068811.

[7] Baker, B.J., Saw, J.H., Lind, A.E., Lazar, C.S., Hinrichs, K.-U., Teske, A.P., Ettema, T.J.G. (2016) Genomic inference of the metabolism of cosmopolitan subsurface Archaea, Hadesarchaea. Nat Microbiol 1, 16002, https://doi.org/10.1038/nmicrobiol.2016.2.

[8] Bankevich, A., Nurk, S., Antipov, D., Gurevich, A.A., Dvorkin, M., Kulikov, A.S., Lesin, V.M., Nikolenko, S.I., Pham, S., Prjibelski, A.D., Pyshkin, A. V., Sirotkin, A. V., Vyahhi, N., Tesler, G., Alekseyev, M.A., Pevzner, P.A. (2012) SPAdes: a new genome assembly algorithm and its applications to single-cell sequencing. J. Comput. Biol. 19(5), 455-477.

[9] Bligh, E.G., Dyer, W.J. (1959) A rapid method of total lipid extraction and purification. Can. J. Biochem. Physiol. 37(8), 911-917.

[10] Bräsen, C., Esser, D., Rauch, B., Siebers, B., Brasen, C., Esser, D., Rauch, B., Siebers, B. (2014) Carbohydrate metabolism in Archaea: current insights into unusual enzymes and pathways and their regulation. Microbiol. Mol. Biol. Rev. $78(1), 89-175$.

[11] Brettin, T., Davis, J.J., Disz, T., Edwards, R.A., Gerdes, S., Olsen, G.J., Olson, R., Overbeek, R., Parrello, B., Pusch, G.D., Shukla, M., Thomason, J.A., Stevens, R., Vonstein, V., Wattam, A.R., Xia, F. (2015) RASTtk: A modular and extensible implementation of the RAST algorithm for building custom annotation pipelines and annotating batches of genomes. Sci. Rep. 5, https://doi.org/10.1038/srep08365.

[12] Bright, M., Espada-Hinojosa, S., Lagkouvardos, I., Volland, J.-M. (2014) The 
giant ciliate Zoothamnium niveum and its thiotrophic epibiont Candidatus

Thiobios zoothamnicoli: a model system to study interspecies cooperation. Front.

Microbiol. 5, 145, https://doi.org/10.3389/fmicb.2014.00145.

[13] Burggraf, S., Larsen, N., Woese, C.R., Stetter, K.O. (1993) An intron within the 16S ribosomal RNA gene of the archaeon Pyrobaculum aerophilum. Proc. Natl.

Acad. Sci. U. S. A. 90(6), 2547-2550.

[14] Casanueva, A., Galada, N., Baker, G.C., Grant, W.D., Heaphy, S., Jones, B., Yanhe, M., Ventosa, A., Blamey, J., Cowan, D.A. (2008) Nanoarchaeal 16S rRNA gene sequences are widely dispersed in hyperthermophilic and mesophilic halophilic environments. Extremophiles 12, 651-656.

[15] Chernyh, N.A., Mardanov, A. V., Gumerov, V.M., Miroshnichenko, M.L., Lebedinsky, A. V., Merkel, A.Y., Crowe, D., Pimenov, N. V., Rusanov, I.I., Ravin, N. V., Moran, M.A., Bonch-Osmolovskaya, E.A. (2015) Microbial life in Bourlyashchy, the hottest thermal pool of Uzon Caldera, Kamchatka. Extremophiles 19(6), 1157-1171.

[16] Clingenpeel, S., Kan, J., Macur, R.E., Woyke, T., Lovalvo, D., Varley, J., Inskeep, W.P., Nealson, K., McDermott, T.R. (2013) Yellowstone Lake Nanoarchaeota. Front. Microbiol. 4, 274, https://doi.org/10.3389/fmicb.2013.00274.

[17] Collingro, A., Köstlbacher, S., Mussmann, M., Stepanauskas, R., Hallam, S.J., Horn, M. (2017) Unexpected genomic features in widespread intracellular Bacteria: evidence for motility of marine Chlamydiae. ISME J. 11(10), 23342344.

[18] Danczak, R.E., Johnston, M.D., Kenah, C., Slattery, M., Wrighton, K.C., Wilkins, 
M.J. (2017) Members of the Candidate Phyla Radiation are functionally differentiated by carbon- and nitrogen-cycling capabilities. Microbiome 5(1), 112, https://doi.org/10.1186/s40168-017-0331-1.

[19] Darling, A.E., Jospin, G., Lowe, E., Matsen 4th, F.A., Bik, H.M., Eisen, J.A. (2014) PhyloSift: phylogenetic analysis of genomes and metagenomes. PeerJ 2, e243, https://doi.org/10.7717/peerj.243.

[20] Edgar, R. (2004) MUSCLE: multiple sequence alignment with high accuracy and high throughput. Nucleic Acids Res. 32, 1792-1797.

[21] Elkins, J.G., Podar, M., Graham, D.E., Makarova, K.S., Wolf, Y., Randau, L., Hedlund, B.P., Brochier-Armanet, C., Kunin, V., Anderson, I., Lapidus, A., Goltsman, E., Barry, K., Koonin, E. V., Hugenholtz, P., Kyrpides, N., Wanner, G., Richardson, P., Keller, M., Stetter, K.O. (2008) A korarchaeal genome reveals insights into the evolution of the Archaea. Proc. Natl. Acad. Sci. U. S. A. 105(23), $8102-8107$.

[22] Elling, F.J., Becker, K.W., Könneke, M., Schröder, J.M., Kellermann, M.Y., Thomm, M., Hinrichs, K.-U. (2016) Respiratory quinones in Archaea: phylogenetic distribution and application as biomarkers in the marine environment. Environ. Microbiol. 18(2), 692-707.

[23] Filker, S., Kaiser, M., Rosselló-Móra, R., Dunthorn, M., Lax, G., Stoeck, T. (2014) "Candidatus Haloectosymbiotes riaformosensis" (Halobacteriaceae), an archaeal ectosymbiont of the hypersaline ciliate Platynematum salinarum. Syst. Appl. Microbiol. 37(4), 244-251.

[24] Flores, G.E., Campbell, J.H., Kirshtein, J.D., Meneghin, J., Podar, M., Steinberg, 
J.I., Seewald, J.S., Tivey, M.K., Voytek, M.A., Yang, Z.K., Reysenbach, A.L. (2011) Microbial community structure of hydrothermal deposits from geochemically different vent fields along the Mid-Atlantic Ridge. Environ. Microbiol. 13(8), 2158-2171.

[25] Flores, G.E., Hunter, R.C., Liu, Y., Mets, A., Schouten, S., Reysenbach, A.-L. (2012) Hippea jasoniae sp. nov. and Hippea alviniae sp. nov., thermoacidophilic members of the class Deltaproteobacteria isolated from deep-sea hydrothermal vent deposits. Int. J. Syst. Evol. Microbiol. 62(Pt 6), 1252-1258.

[26] Flores, G.E., Shakya, M., Meneghin, J., Yang, Z.K., Seewald, J.S., Geoff Wheat, C., Podar, M., Reysenbach, A.-L. (2012) Inter-field variability in the microbial communities of hydrothermal vent deposits from a back-arc basin. Geobiology $10(4), 333-346$.

[27] Fujishima, K., Sugahara, J., Tomita, M., Kanai, A. (2010) Large-scale tRNA intron transposition in the archaeal order Thermoproteales represents a novel mechanism of intron gain. Mol. Biol. Evol. 27(10), 2233-2243.

[28] Fukushi, H., Hirai, K. (1992) Proposal of Chlamydia pecorum sp. nov. for Chlamydia strains derived from ruminants. Int. J. Syst. Bacteriol. 42(2), 306-308.

[29] Göker, M., Held, B., Lapidus, A., Nolan, M., Spring, S., Yasawong, M., Lucas, S., Glavina Del Rio, T., Tice, H., Cheng, J.-F., Goodwin, L., Tapia, R., Pitluck, S., Liolios, K., Ivanova, N., Mavromatis, K., Mikhailova, N., Pati, A., Chen, A., Palaniappan, K., Brambilla, E., Land, M., Hauser, L., Chang, Y.-J., Jeffries, C.D., Brettin, T., Detter, J.C., Han, C., Rohde, M., Sikorski, J., Woyke, T., Bristow, J., Eisen, J.A., Markowitz, V., Hugenholtz, P., Kyrpides, N.C., Klenk, H.-P. (2010) 
Complete genome sequence of Ignisphaera aggregans type strain (AQ1.S1 ${ }^{\mathrm{T}}$ ).

Stand. Genomic Sci. 3(1), 66-75.

[30] Grayston, J.T., Kuo, C.-C., Campbell, L.A., Wang, S.-P. (1989) Chlamydia pneumoniae sp. nov. for Chlamydia sp. strain TWAR. Int. J. Syst. Evol. Microbiol. 39(1), 88-90.

[31] Greening, C., Biswas, A., Carere, C.R., Jackson, C.J., Taylor, M.C., Stott, M.B., Cook, G.M., Morales, S.E. (2016) Genomic and metagenomic surveys of hydrogenase distribution indicate $\mathrm{H}_{2}$ is a widely utilised energy source for microbial growth and survival. ISME J. 10(3), 761-777.

[32] Hamilton-Brehm, S.D., Gibson, R.A., Green, S.J., Hopmans, E.C., Schouten, S., van der Meer, M.T.J., Shields, J.P., Damsté, J.S.S., Elkins, J.G. (2013) Thermodesulfobacterium geofontis sp. nov., a hyperthermophilic, sulfate-reducing bacterium isolated from Obsidian Pool, Yellowstone National Park. Extremophiles $17(2), 251-263$.

[33] Heider, J., Ma, K., Adams, M.W. (1995) Purification, characterization, and metabolic function of tungsten-containing aldehyde ferredoxin oxidoreductase from the hyperthermophilic and proteolytic archaeon Thermococcus strain ES-1. J. Bacteriol. 177(16), 4757-4764.

[34] Hohn, M.J., Hedlund, B.P., Huber, H. (2002) Detection of 16S rDNA sequences representing the novel phylum "Nanoarchaeota": Indication for a wide distribution in high temperature biotopes. Syst. Appl. Microbiol. 25, 551-554.

[35] Huber, H., Burggraf, S., Mayer, T., Wyschkony, I., Rachel, R., Stetter, K.O. (2000) Ignicoccus gen. nov., a novel genus of hyperthermophilic, 
chemolithoautotrophic Archaea, represented by two new species, Ignicoccus islandicus sp. nov. and Ignicoccus pacificus sp. nov. Int. J. Syst. Evol. Microbiol. 50(6), 2093-2100.

[36] Huber, H., Hohn, M.J., Rachel, R., Fuchs, T., Wimmer, V.C., Stetter, K.O. (2002) A new phylum of Archaea represented by a nanosized hyperthermophilic symbiont. Nature 417(6884), 63-67.

[37] Huber, R., Dyba, D., Huber, H., Burggraf, S., Rachel, R. (1998) Sulfur-inhibited Thermosphaera aggregans sp. nov., a new genus of hyperthermophilic archaea isolated after its prediction from environmentally derived 16S rRNA sequences. Int. J. Syst. Evol. Microbiol. 48(1), 31-38.

[38] Imanaka, H., Yamatsu, A., Fukui, T., Atomi, H., Imanaka, T. (2006) Phosphoenolpyruvate synthase plays an essential role for glycolysis in the modified Embden-Meyerhof pathway in Thermococcus kodakarensis. Mol. Microbiol. 61(4), 898-909.

[39] Itoh, T., Suzuki, K., Nakase, T. (1998) Occurrence of introns in the 16S rRNA genes of members of the genus Thermoproteus. Arch. Microbiol. 170(3), 155-161.

[40] Jarrell, K.F., Stark, M., Nair, D.B., Chong, J.P.J. (2011) Flagella and pili are both necessary for efficient attachment of Methanococcus maripaludis to surfaces. FEMS Microbiol. Lett. 319(1), 44-50.

[41] Jay, Z.J., Inskeep, W.P. (2015) The distribution, diversity, and importance of 16S rRNA gene introns in the order Thermoproteales. Biol. Direct 10, 35, https://doi.org/10.1186/s13062-015-0065-6.

[42] Jeon, J.H., Lim, J.K., Kim, M.-S., Yang, T.-J., Lee, S.-H., Bae, S.S., Kim, Y.J., 
Lee, S.H., Lee, J.-H., Kang, S.G., Lee, H.S. (2015) Characterization of the frhAGB-encoding hydrogenase from a non-methanogenic hyperthermophilic archaeon. Extremophiles 19(1), 109-118.

[43] Jochimsen, B., Peinemann-Simon, S., Völker, H., Stüben, D., Botz, R., Stoffers, P., Dando, P.R., Thomm, M. (1997) Stetteria hydrogenophila, gen. nov. and sp. nov., a novel mixotrophic sulfur-dependent crenarchaeote isolated from Milos, Greece. Extremophiles 1(2), 67-73.

[44] Kalvari, I., Argasinska, J., Quinones-Olvera, N., Nawrocki, E.P., Rivas, E., Eddy, S.R., Bateman, A., Finn, R.D., Petrov, A.I. (2018) Rfam 13.0: Shifting to a genome-centric resource for non-coding RNA families. Nucleic Acids Res. 46(D1), D335-D342.

[45] Kalvari, I., Nawrocki, E.P., Argasinska, J., Quinones-Olvera, N., Finn, R.D., Bateman, A., Petrov, A.I. (2018) Non-coding RNA analysis using the Rfam database. Curr. Protoc. Bioinforma. 62(1), e51, https://doi.org/10.1002/cpbi.51.

[46] Kearse, M., Moir, R., Wilson, A., Stones-Havas, S., Cheung, M., Sturrock, S., Buxton, S., Cooper, A., Markowitz, S., Duran, C., Thierer, T., Ashton, B., Meintjes, P., Drummond, A. (2012) Geneious Basic: an integrated and extendable desktop software platform for the organization and analysis of sequence data. Bioinformatics 28(12), 1647-1649.

[47] Kelley, J. 2017. Expanding Metabolic Diversity of Two Archaeal Phyla: Nanoarchaeota and Korarchaeota. M. Sc. Thesis, Biology Department, Portland State University, Portland, OR, USA.

[48] Kim, O.-S., Cho, Y.-J., Lee, K., Yoon, S.-H., Kim, M., Na, H., Park, S.-C., Jeon, 
Y.S., Lee, J.-H., Yi, H., Won, S., Chun, J. (2012) Introducing EzTaxon-e: a prokaryotic $16 \mathrm{~S}$ rRNA gene sequence database with phylotypes that represent uncultured species. Int. J. Syst. Evol. Microbiol. 62(Pt 3), 716-721.

[49] Kjems, J., Leffers, H., Olesen, T., Garrett, R.A. (1989) A unique tRNA intron in the variable loop of the extreme thermophile Thermofilum pendens and its possible evolutionary implications. J. Biol. Chem. 264(30), 17834-17837.

[50] Konstantinidis, K.T., Rosselló-Móra, R. (2015) Classifying the uncultivated microbial majority: a place for metagenomic data in the Candidatus proposal. Syst. Appl. Microbiol. 38(4), 223-230.

[51] Konstantinidis, K.T., Rosselló-Móra, R., Amann, R. (2017) Uncultivated microbes in need of their own taxonomy. ISME J. 11(11), 2399-2406.

[52] Krueger, F. Trim Galore! Babraham Bioinformatics. https://www.bioinformatics.babraham.ac.uk/projects/trim_galore/. (Accessed 2016).

[53] Krzywinski, M., Schein, J., Birol, I., Connors, J., Gascoyne, R., Horsman, D., Jones, S.J., Marra, M.A. (2009) Circos: an information aesthetic for comparative genomics. Genome Res. 19(9), 1639-1645.

[54] Lapage, S.P., Lessel, E.F., Skerman, V.B.D., Clark, W.A., Seeliger, H.P.R. 1992. International Code of Nomenclature of Bacteria. 1990 Revision. ASM Press, Washington, D.C.

[55] Lebedinsky, A. V., Mardanov, A. V., Kublanov, I. V., Gumerov, V.M., Beletsky, A. V., Perevalova, A.A., Bidzhieva, S.K., Bonch-Osmolovskaya, E.A., Skryabin, K.G., Ravin, N. V. (2014) Analysis of the complete genome of Fervidococcus 
fontis confirms the distinct phylogenetic position of the order Fervidicoccales and suggests its environmental function. Extremophiles 18(2), 295-309.

[56] Lee, H.S., Kang, S.G., Bae, S.S., Lim, J.K., Cho, Y., Kim, Y.J., Jeon, J.H., Cha, S.-S., Kwon, K.K., Kim, H.-T., Park, C.-J., Lee, H.-W., Kim, S. Il., Chun, J., Colwell, R.R., Kim, S.-J., Lee, J.-H. (2008) The complete genome sequence of Thermococcus onnurineus NA1 reveals a mixed heterotrophic and carboxydotrophic metabolism. J. Bacteriol. 190(22), 7491-7499.

[57] Lee, S.H., Kim, M.-S., Kim, Y.J., Kim, T.W., Kang, S.G., Lee, H.S. (2017) Transcriptomic profiling and its implications for the $\mathrm{H}_{2}$ production of a nonmethanogen deficient in the frhAGB-encoding hydrogenase. Appl. Microbiol. Biotechnol. 101(12), 5081-5088.

[58] Letunic, I., Bork, P. (2016) Interactive tree of life (iTOL) v3: an online tool for the display and annotation of phylogenetic and other trees. Nucleic Acids Res. 44(W1), W242-W245.

[59] Li, Y., Altman, S. (2004) In search of RNase P RNA from microbial genomes. RNA 10(10), 1533-1540.

[60] Lowe, T.M., Chan, P.P. (2016) tRNAscan-SE On-line: integrating search and context for analysis of transfer RNA genes. Nucleic Acids Res. 44(W1), W54W57.

[61] Lykke-Andersen, J., Aagaard, C., Semionenkov, M., Garrett, R.A. (1997) Archaeal introns: splicing, intercellular mobility and evolution. Trends Biochem. Sci. 22(9), $326-331$.

[62] Ma, K., Hutchins, A., Sung, S.J., Adams, M.W. (1997) Pyruvate ferredoxin 
oxidoreductase from the hyperthermophilic archaeon, Pyrococcus furiosus, functions as a CoA-dependent pyruvate decarboxylase. Proc. Natl. Acad. Sci. U. S. A. 94(18), 9608-9613.

[63] Mai, X., Adams, M.W. (1996) Purification and characterization of two reversible and ADP-dependent acetyl coenzyme A synthetases from the hyperthermophilic archaeon Pyrococcus furiosus. J. Bacteriol. 178(20), 5897-5903.

[64] Makarova, K., Wolf, Y., Koonin, E. (2015) Archaeal clusters of orthologous genes (arCOGs): an update and application for analysis of shared features between Thermococcales, Methanococcales, and Methanobacteriales. Life 5(1), 818-840.

[65] Makarova, K.S., Sorokin, A. V., Novichkov, P.S., Wolf, Y.I., Koonin, E. V. (2007) Clusters of orthologous genes for 41 archaeal genomes and implications for evolutionary genomics of archaea. Biol. Direct, 33, https://doi.org/10.1186/1745$6150-2-33$

[66] Marchler-Bauer, A., Bryant, S.H. (2004) CD-Search: protein domain annotations on the fly. Nucleic Acids Res. 32(Web Server issue), W327-W331.

[67] McCliment, E.A., Voglesonger, K.M., O’Day, P.A., Dunn, E.E., Holloway, J.R., Cary, S.C. (2006) Colonization of nascent, deep-sea hydrothermal vents by a novel archaeal and nanoarchaeal assemblage. Environ. Microbiol. 8(1), 114-125.

[68] McOrist, S., Gebhart, C.J., Boid, R., Barns, S.M. (1995) Characterization of Lawsonia intracellularis gen. nov., sp. nov., the obligately intracellular bacterium of porcine proliferative enteropathy. Int. J. Syst. Bacteriol. 45(4), 820-825.

[69] Meador, T.B., Gagen, E.J., Loscar, M.E., Goldhammer, T., Yoshinaga, M.Y., Wendt, J., Thomm, M., Hinrichs, K.-U. (2014) Thermococcus kodakarensis 
modulates its polar membrane lipids and elemental composition according to growth stage and phosphate availability. Front. Microbiol. 5, 10, https://doi.org/10.3389/fmicb.2014.00010.

[70] Mediannikov, O., Sekeyová, Z., Birg, M.-L., Raoult, D. (2010) A novel obligate intracellular gamma-proteobacterium associated with ixodid ticks, Diplorickettsia massiliensis, gen. nov., sp. nov. PLoS One 5(7), e11478, https://doi.org/10.1371/journal.pone.0011478.

[71] Menzel, P., Gudbergsdóttir, S.R., Rike, A.G., Lin, L., Zhang, Q., Contursi, P., Moracci, M., Kristjansson, J.K., Bolduc, B., Gavrilov, S., Ravin, N., Mardanov, A., Bonch-Osmolovskaya, E., Young, M., Krogh, A., Peng, X. (2015) Comparative metagenomics of eight geographically remote terrestrial hot springs. Microb. Ecol. 70(2), 411-424.

[72] Munson-McGee, J.H., Field, E.K., Bateson, M., Rooney, C., Stepanauskas, R., Young, M.J. (2015) Nanoarchaeota, their Sulfolobales host, and Nanoarchaeota virus distribution across Yellowstone National Park hot springs. Appl. Environ. Microbiol. 81(22), 7860-7868.

[73] Nakagawa, T., Ishibashi, J.-I., Maruyama, A., Yamanaka, T., Morimoto, Y., Kimura, H., Urabe, T., Fukui, M. (2004) Analysis of dissimilatory sulfite reductase and 16S rRNA gene fragments from deep-sea hydrothermal sites of the Suiyo Seamount, Izu-Bonin Arc, western Pacific. Appl. Environ. Microbiol. 70(1), 393403.

[74] Nawrocki, E.P., Burge, S.W., Bateman, A., Daub, J., Eberhardt, R.Y., Eddy, S.R., Floden, E.W., Gardner, P.P., Jones, T.A., Tate, J., Finn, R.D. (2015) Rfam 12.0: 
updates to the RNA families database. Nucleic Acids Res. 43(D1), D130-D137.

[75] Nawrocki, E.P., Eddy, S.R. (2013) Infernal 1.1: 100-fold faster RNA homology searches. Bioinformatics 29(22), 2933-2935.

[76] Nawrocki, E.P., Jones, T.A., Eddy, S.R. (2018) Group I introns are widespread in Archaea. Nucleic Acids Res. 46(15), 7970-7976.

[77] NCBI Resource Coordinators. (2017) Database resources of the National Center for Biotechnology Information. Nucleic Acids Res. 45(D1), D12-D17.

[78] Niederberger, T.D., Götz, D.K., McDonald, I.R., Ronimus, R.S., Morgan, H.W. (2006) Ignisphaera aggregans gen. nov., sp. nov., a novel hyperthermophilic crenarchaeote isolated from hot springs in Rotorua and Tokaanu, New Zealand. Int. J. Syst. Evol. Microbiol. 56(Pt 5), 965-971.

[79] Nishihara, M., Koga, Y. (1987) Extraction and composition of polar lipids from the archaebacterium, Methanobacterium thermoautotrophicum: effective extraction of tetraether lipids by an acidified solvent. J. Biochem. 101(4), 9971005.

[80] Nomura, N., Sako, Y., Uchida, A. (1998) Molecular characterization and postsplicing fate of three introns within the single rRNA operon of the hyperthermophilic archaeon Aeropyrum pernix K1. J. Bacteriol. 180(14), 36353643.

[81] Oger, P., Sokolova, T.G., Kozhevnikova, D.A., Chernyh, N.A., Bartlett, D.H., Bonch-Osmolovskaya, E.A., Lebedinsky, A. V. (2011) Complete genome sequence of the hyperthermophilic archaeon Thermococcus sp. strain AM4, capable of organotrophic growth and growth at the expense of hydrogenogenic or 
sulfidogenic oxidation of carbon monoxide. J. Bacteriol. 193(24), 7019-7020.

[82] Overbeek, R., Olson, R., Pusch, G.D., Olsen, G.J., Davis, J.J., Disz, T., Edwards, R.A., Gerdes, S., Parrello, B., Shukla, M., Vonstein, V., Wattam, A.R., Xia, F., Stevens, R. (2014) The SEED and the rapid annotation of microbial genomes using subsystems technology (RAST). Nucleic Acids Res. 42(Database issue), D206D214.

[83] Paper, W., Jahn, U., Hohn, M.J., Kronner, M., Näther, D.J., Burghardt, T., Rachel, R., Stetter, K.O., Huber, H. (2007) Ignicoccus hospitalis sp. nov., the host of “Nanoarchaeum equitans.” Int. J. Syst. Evol. Microbiol. 57(Pt 4), 803-808.

[84] Parks, D.H., Imelfort, M., Skennerton, C.T., Hugenholtz, P., Tyson, G.W. (2015) CheckM: assessing the quality of microbial genomes recovered from isolates, single cells, and metagenomes. Genome Res. 25(7), 1043-1055.

[85] Peng, Y., Leung, H.C.M., Yiu, S.-M., Chin, F.Y.L. (2010) IDBA-a practical iterative de Bruijn graph de novo assembler. In: Annual International Conference on Research in Computational Molecular Biology, Springer, pp. 426-440.

[86] Peng, Y., Leung, H.C.M., Yiu, S.M., Chin, F.Y.L. (2012) IDBA-UD: A de novo assembler for single-cell and metagenomic sequencing data with highly uneven depth. Bioinformatics 28(11), 1420-1428.

[87] Perevalova, A.A., Svetlichny, V.A., Kublanov, I. V., Chernyh, N.A., Kostrikina, N.A., Tourova, T.P., Kuznetsov, B.B., Bonch-Osmolovskaya, E.A. (2005) Desulfurococcus fermentans sp. nov., a novel hyperthermophilic archaeon from a Kamchatka hot spring, and emended description of the genus Desulfurococcus. Int. J. Syst. Evol. Microbiol. 55(Pt 3), 995-999. 
[88] Pisa, K.Y., Huber, H., Thomm, M., Müller, V. (2007) A sodium ion-dependent A1AO ATP synthase from the hyperthermophilic archaeon Pyrococcus furiosus. FEBS J. 274(15), 3928-3938.

[89] Podar, M., Makarova, K.S., Graham, D.E., Wolf, Y.I., Koonin, E. V., Reysenbach, A.-L. (2013) Insights into archaeal evolution and symbiosis from the genomes of a nanoarchaeon and its inferred crenarchaeal host from Obsidian Pool, Yellowstone National Park. Biol. Direct 8, 9, https://doi.org/10.1186/1745-6150-8-9.

[90] Rachel, R., Wyschkony, I., Riehl, S., Huber, H. (2002) The ultrastructure of Ignicoccus: evidence for a novel outer membrane and for intracellular vesicle budding in an archaeon. Archaea 1(1), 9-18.

[91] Randau, L., Münch, R., Hohn, M.J., Jahn, D., Söll, D. (2005) Nanoarchaeum equitans creates functional tRNAs from separate genes for their 5'-and 3'-halves. Nature 433(7025), 537-541.

[92] Randau, L., Pearson, M., Söll, D. (2005) The complete set of tRNA species in Nanoarchaeum equitans. FEBS Lett. 579(13), 2945-2947.

[93] Randau, L., Schröder, I., Söll, D. (2008) Life without RNase P. Nature 453(7191), $120-123$.

[94] Ravin, N. V., Mardanov, A. V., Beletsky, A. V., Kublanov, I. V., Kolganova, T. V., Lebedinsky, A. V., Chernyh, N.A., Bonch-Osmolovskaya, E.A., Skryabin, K.G. (2009) Complete genome sequence of the anaerobic, protein-degrading hyperthermophilic crenarchaeon Desulfurococcus kamchatkensis. J. Bacteriol. 191(7), 2371-2379.

[95] Rinke, C., Schwientek, P., Sczyrba, A., Ivanova, N.N., Anderson, I.J., Cheng, J.- 
F., Darling, A., Malfatti, S., Swan, B.K., Gies, E.A., Dodsworth, J.A., Hedlund, B.P., Tsiamis, G., Sievert, S.M., Liu, W.-T., Eisen, J.A., Hallam, S.J., Kyrpides, N.C., Stepanauskas, R., Rubin, E.M., Hugenholtz, P., Woyke, T. (2013) Insights into the phylogeny and coding potential of microbial dark matter. Nature 499(7459), 431-437.

[96] Rodriguez-R, L.M., Konstantinidis, K.T. (2016) The enveomics collection: a toolbox for specialized analyses of microbial genomes and metagenomes. PeerJ Prepr. (4), e1900v1, https://doi.org/10.7287/peerj.preprints.1900v1.

[97] Sato, T., Atomi, H., Imanaka, T. (2007) Archaeal type III RuBisCOs function in a pathway for AMP metabolism. Science 315(5814), 1003-1006.

[98] Schlegel, K., Leone, V., Faraldo-Gómez, J.D., Müller, V. (2012) Promiscuous archaeal ATP synthase concurrently coupled to $\mathrm{Na}^{+}$and $\mathrm{H}^{+}$translocation. Proc. Natl. Acad. Sci. U. S. A. 109(3), 947-952.

[99] Schopf, S., Wanner, G., Rachel, R., Wirth, R. (2008) An archaeal bi-species biofilm formed by Pyrococcus furiosus and Methanopyrus kandleri. Arch. Microbiol. 190(3), 371-377.

[100] Schouten, S., van der Meer, M.T.J., Hopmans, E.C., Rijpstra, W.I.C., Reysenbach, A.-L., Ward, D.M., Sinninghe Damsté, J.S. (2007) Archaeal and bacterial glycerol dialkyl glycerol tetraether lipids in hot springs of Yellowstone National Park. Appl. Environ. Microbiol. 73(19), 6181-6191.

[101] Schuster, L., Bright, M. (2016) A novel colonial ciliate Zoothamnium ignavum sp. nov. (Ciliophora, Oligohymenophorea) and its ectosymbiont Candidatus Navis piranensis gen. nov., sp. nov. from shallow-water Wood Falls. PLoS One 11(9), 
e0162834, https://doi.org/10.1371/journal.pone.0162834.

[102] Sokolova, T.G., Henstra, A.-M., Sipma, J., Parshina, S.N., Stams, A.J.M., Lebedinsky, A. V. (2009) Diversity and ecophysiological features of thermophilic carboxydotrophic anaerobes. FEMS Microbiol. Ecol. 68(2), 131-141.

[103] Sokolova, T.G., Jeanthon, C., Kostrikina, N.A., Chernyh, N.A., Lebedinsky, A. V., Stackebrandt, E., Bonch-Osmolovskaya, E.A. (2004) The first evidence of anaerobic $\mathrm{CO}$ oxidation coupled with $\mathrm{H}_{2}$ production by a hyperthermophilic archaeon isolated from a deep-sea hydrothermal vent. Extremophiles 8(4), $317-$ 323.

[104] Søndergaard, D., Pedersen, C.N.S., Greening, C. (2016) HydDB: A web tool for hydrogenase classification and analysis. Sci. Rep. 6, 34212, https://doi.org/10.1038/srep34212.

[105] Spang, A., Saw, J.H., Jørgensen, S.L., Zaremba-Niedzwiedzka, K., Martijn, J., Lind, A.E., van Eijk, R., Schleper, C., Guy, L., Ettema, T.J.G. (2015) Complex Archaea that bridge the gap between prokaryotes and eukaryotes. Nature 521(7551), 173-179.

[106] Stamatakis, A. (2014) RAxML version 8: a tool for phylogenetic analysis and post-analysis of large phylogenies. Bioinformatics 30(9), 1312-1313.

[107] Sugahara, J., Kikuta, K., Fujishima, K., Yachie, N., Tomita, M., Kanai, A. (2008) Comprehensive analysis of archaeal tRNA genes reveals rapid increase of tRNA introns in the order Thermoproteales. Mol. Biol. Evol. 25(12), 2709-2716.

[108] Takai, K., Horikoshi, K. (1999) Molecular phylogenetic analysis of archaeal intron-containing genes coding for rRNA obtained from a deep-subsurface 
geothermal water pool. Appl. Environ. Microbiol. 65(12), 5586-5589.

[109] Ultsch, A., Mörchen, F. (2005) ESOM-Maps: tools for clustering, visualization, and classification with Emergent SOM, Technical Report Dept. of Mathematics and Computer Science, University of Marburg, Germany, no. 46.

[110] Vannier, P., Marteinsson, V.T., Fridjonsson, O.H., Oger, P., Jebbar, M. (2011) Complete genome sequence of the hyperthermophilic, piezophilic, heterotrophic, and carboxydotrophic archaeon Thermococcus barophilus MP. J. Bacteriol. 193(6), 1481-1482.

[111] Waters, E., Hohn, M.J., Ahel, I., Graham, D.E., Adams, M.D., Barnstead, M., Beeson, K.Y., Bibbs, L., Bolanos, R., Keller, M., Kretz, K., Lin, X., Mathur, E., Ni, J., Podar, M., Richardson, T., Sutton, G.G., Simon, M., Soll, D., Stetter, K.O., Short, J.M., Noordewier, M. (2003) The genome of Nanoarchaeum equitans: insights into early archaeal evolution and derived parasitism. Proc. Natl. Acad. Sci. U. S. A. 100(22), 12984-12988.

[112] Wu, Y.W., Tang, Y.H., Tringe, S.G., Simmons, B.A., Singer, S.W. (2014) MaxBin: An automated binning method to recover individual genomes from metagenomes using an expectation-maximization algorithm. Microbiome 2(1), 26, https://doi.org/10.1186/2049-2618-2-26.

[113] Wurch, L., Giannone, R.J., Belisle, B.S., Swift, C., Utturkar, S., Hettich, R.L., Reysenbach, A.-L., Podar, M. (2016) Genomics-informed isolation and characterization of a symbiotic Nanoarchaeota system from a terrestrial geothermal environment. Nat. Commun. 7, 12115, http://doi.org/10.1038/ncomms12115. 
[114] Yoon, S.H., Ha, S.M., Kwon, S., Lim, J., Kim, Y., Seo, H., Chun, J. (2017) Introducing EzBioCloud: A taxonomically united database of 16S rRNA gene sequences and whole-genome assemblies. Int. J. Syst. Evol. Microbiol. 67(5), $1613-1617$.

[115] Yoshinaga, M.Y., Kellermann, M.Y., Rossel, P.E., Schubotz, F., Lipp, J.S., Hinrichs, K.-U. (2011) Systematic fragmentation patterns of archaeal intact polar lipids by high-performance liquid chromatography/electrospray ionization ion-trap mass spectrometry. Rapid Commun. Mass Spectrom. 25(23), 3563-3574.

[116] Zillig, W., Stetter, K.O., Prangishvilli, D., Schäfer, W., Wunderl, S., Janekovic, D., Holz, I., Palm, P. (1982) Desulfurococcaceae, the second family of the extremely thermophilic, anaerobic, sulfur-respiring Thermoproteales. Zentralblatt Für Bakteriol. Mikrobiol. Und Hyg. I. Abt. Orig. C Allg. Angew. Und Ökologische Mikrobiol. 3(2), 304-317.

[117] Zolghadr, B., Klingl, A., Koerdt, A., Driessen, A.J.M., Rachel, R., Albers, S.-V. (2010) Appendage-mediated surface adherence of Sulfolobus solfataricus. J. Bacteriol. 192(1), 104-110.

[118] Zuker, M. (2003) Mfold web server for nucleic acid folding and hybridization prediction. Nucleic Acids Res. 31(13), 3406-3415. 
Chapter 3: Deep-sea Hydrothermal Vent Metagenome-Assembled Genomes Provide Insight into the Phylum Nanoarchaeota

\author{
St. John E, Flores G, Meneghin J, Reysenbach AL (In review). Environmental \\ Microbiology Reports
}

\title{
Summary
}

Ectosymbiotic Nanoarchaeota live on the surface of diverse archaeal hosts. Despite a broad distribution in global geothermal systems, only three Nanoarchaeota have been successfully co-cultivated with their hosts, and until now no nanoarchaeotal cultures or genomes have been described from deep-sea hydrothermal vents. We recovered three nanoarchaeotal metagenome-assembled genomes (MAGs) from deep-sea hydrothermal vent sites at the Eastern Lau Spreading Center (M10-121), Guaymas Basin (Gua-46) and the Mid-Cayman Rise (MC-1). Based on average amino acid identity analysis, M10-121 is a novel species in the candidate genus Nanoclepta, while the other two MAGs represent novel genera in the Nanoarchaeota. Like previously sequenced Nanoarchaeota, each MAG encodes at least one split protein-coding gene. The MAGs also contain a mosaic of key nanoarchaeotal features, including CRISPR repeat regions and marker genes for the gluconeogenic pathway and archaeal flagella. MC-1 also encodes the pentose bisphosphate pathway, which may allow the nanoarchaeote to bypass several steps in glycolysis and produce ATP. 


\section{Introduction}

The Nanoarchaeota are ultra-small hyperthermophilic Archaea that have been detected at marine hydrothermal vents $[3,16,17,34]$ and terrestrial geothermal springs across the globe $[9,10,12,19,36]$. All cultivated Nanoarchaeota are obligate ectosymbionts that associate with unique hosts from the Crenarchaeota $[20,47,53]$. With their hosts, they may play a key role in colonizing newly-formed deep-sea hydrothermal vent deposits [34]. Despite their broad distribution and ecological importance however, no Nanoarchaeota genomes from deep-sea hydrothermal systems have been characterized.

To date, only three Nanoarchaeota have been successfully co-cultivated with their hosts. The marine lineage, Nanoarchaeum equitans, was obtained from a shallow hydrothermal system near Iceland [20], while the terrestrial taxa Candidatus Nanopusillus acidilobi [53] and Candidatus Nanoclepta minutus [47] were cultivated from geothermal springs in Yellowstone National Park (YNP), USA and Tikitere, New Zealand, respectively. The small genomes of cultivated Nanoarchaeota lack nearly all biosynthetic pathways and have split protein-coding genes [47,52,53], pointing to a pattern of genomic reduction and fragmentation. Although no functional ATP synthase has been identified in the genome of any cultivated Nanoarchaeota $[35,47,53]$, the genomes retain a core set of genes involved in transcription, translation and DNA replication. Both Cand. Nps. acidilobi and Cand. Ncl. minutus have slightly expanded genomes compared to $N$. equitans, encoding genes for gluconeogenesis and archaeal flagella [47,53]. Several putative Nanoarchaeota-host pairings from YNP also have been identified through single-cell genomics, due to the tendency of Nanoarchaeota to co-sort 
with their hosts $[22,40]$. These co-sorted genomes suggest that a wide diversity of crenarchaeotal hosts may associate with Nanoarchaeota across small geographic and spatial scales [22].

Here we report the assembly of three novel Nanoarchaeota metagenomeassembled genomes (MAGs) from three deep-sea hydrothermal vent systems in the Eastern Lau Spreading Center (ELSC), Guaymas Basin and the Mid-Cayman Rise. These MAGs broaden our understanding of the phylogenetic and genomic diversity of the Nanoarchaeota, while highlighting the need for continued sequencing and cultivation efforts in this lineage.

\section{Materials and methods}

Sample collection and processing

Hydrothermal vent deposits were collected in December 2009 from a thermocouple array placed on a hydrothermal vent in Guaymas Basin $\left(27^{\circ} 00.637^{\prime} \mathrm{N}\right.$, $111^{\circ} 24.378^{\prime}$ W) 14.8 days prior. Samples were collected using the human-occupied vehicle HOV Alvin. Additional hydrothermal deposits from Mariner vent field, ELSC $\left(22^{\circ} 10.821^{\prime} \mathrm{S}, 176^{\circ} 36.100^{\prime} \mathrm{W}\right)$ were sampled in 2015 using the remotely operated vehicle ROV Jason. Sample collection, subsampling, storage and DNA extraction were performed as previously described $[17,45]$.

Metagenomic sequencing, assembly and binning

Metagenomic libraries from Guaymas Basin and Eastern Lau Spreading Center (ELSC) were prepared and sequenced on the Illumina HiSeq at the Department of 
Energy, Joint Genome Institute (JGI) and Oregon State University, respectively. Metagenomic reads from Guaymas Basin also underwent quality control and assembly with SPAdes v. 3.11.1 [6] at the JGI. Poor quality sequences and adaptors were removed from ELSC metagenomic sequences using Trimmomatic [7] and trimmed reads were assembled with MegaHit v.1.1.1 [28,29]. Both metagenomes were binned based on tetranucleotide frequency and coverage using MetaBat v.0.32.4 [23]. Nanoarchaeota bins were identified with PhyloSift [13] and verified by concatenated ribosomal protein phylogenetic analysis.

Metagenomic reads from a diffuse-flow hydrothermal vent fluid sample (Von Damm vent field, Mid-Cayman Rise [3]) were downloaded from the NCBI Sequence Read Archive (SRA accession ERR1662245-ERR1662254 [27]). Initial binning with MetaBat produced three low-quality Nanoarchaeota bins. Contigs from these poorquality bins were extracted and manually re-binned using ESOM [51], generating a single higher quality bin. To further curate the bin, we calculated tetranucleotide counts of the contigs using an in-house Perl script. These counts were used to calculate a resemblance matrix using the Bray-Curtis similarity measure in Primer v.6.0 [11]. Hierarchical cluster analysis was then performed on the resemblance matrix, and multidimensional scaling plots were created to visualize the results. One cluster ( $>90 \%$ similarity) contained the majority of the high-quality contigs ( $>10000 \mathrm{bp}$ ) and was extracted as the final bin.

\section{Genomic analysis}

Completeness and contamination of the Nanoarchaeota MAGs, along with identification and annotation of tRNAs, rRNAs, CRISPR repeats, open reading frames 
and tRNA intron sequences were performed as previously described [47]. The completeness of the MAGs was also calculated by dividing the number of marker genes found in each MAG by the average marker gene count from all three cultivated Nanoarchaeota. Average amino acid identity comparisons were generated using the ANI/AAI Matrix Calculator tool [46]. Anvi'o was used to analyze and visualize pan and core nanoarchaeotal genomes $[14,15]$. The pangenome was generated using the 'anvipan-genome' command with the following parameters: --minbit 0.5, --mcl-inflation 6 and -use-ncbi-blast. COG and PFAM annotations in Anvi'o were also determined using BlastP [2]. Pairwise best-hit BlastP comparisons [2] were also used to identify genes shared by all cultivated Nanoarchaeota $($ E-value $<=0.00001)$. These shared genes were then placed into functional categories using the Archaeal Clusters of Orthologous Genes (arCOG) database $[31,32]$. Using the same method, the MAGs were each compared against the list of shared genes to identify homologues.

\section{Phylogenetic analysis}

Concatenated protein phylogenetic trees were constructed as described [47], using a set of eight ribosomal proteins ( $\mathrm{rpL} 2,15,18,24, \mathrm{rpS} 3,8,10,19)$. To generate small subunit ribosomal RNA gene trees, nanoarchaeotal 16S rRNA genes were aligned in Geneious v.10.0.2 [24] using the Clustal W aligner [26], and short clone sequences were added to the original alignment using the "Consensus Align" option. Curation and masking of hypervariable regions were performed manually. Maximum-likelihood phylogenetic trees were constructed and visualized as described [47]. Pairwise 16S rRNA gene comparisons were also performed using the Geneious aligner [24]. 
Data availability

The MAGs used in this study are available at https://bitbucket.org/alrlab/deepsea-hydrothermal-vent-nanoarchaeota-mags/src/master/. Metadata and sampling information have been deposited in Genbank for the ELSC (BioProject PRJNA495050, BioSample SAMN10217875) and Guaymas Basin samples (BioProject PRJNA469236, BioSample SAMN09093796).

\section{Results \& Discussion}

Phylogenetic analysis of nanoarchaeotal MAGs

To explore the diversity and coding potential of deep-sea Nanoarchaeota, we assembled metagenomes from three geographically distinct hydrothermal vent sites located in diverse geological settings (Table 2.1). Two metagenomic read sets were obtained by de novo sequencing, while the third was downloaded from the NCBI Sequence Read Archive (SRA). One nanoarchaeotal MAG was recovered from each of the three deep-sea hydrothermal vent metagenomes (Appendix B, File S2, B1-B3), and the position of all three MAGs in the Nanoarchaeota was confirmed using a concatenated ribosomal protein phylogenetic tree (Fig. 2.1). Although none of the MAGs were closed, each was compared to cultivated Nanoarchaeota using average amino acid identity (AAI) analysis (Fig. 2.2) and 16S rRNA gene sequence alignments, when applicable. Based on AAI comparisons, the ELSC nanoarchaeote (M10-121) is most closely related to the New Zealand taxon, Cand. Nanoclepta minutus (69\% AAI), and it likely represents a novel 


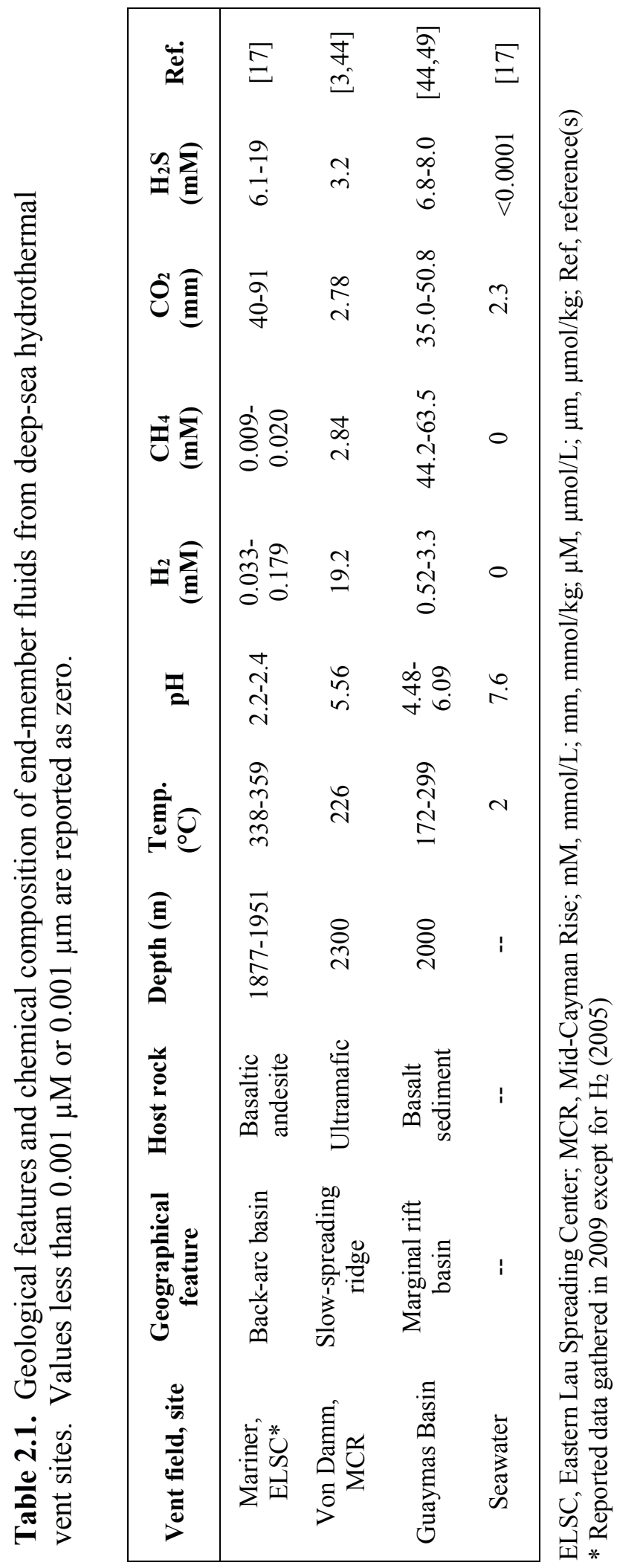




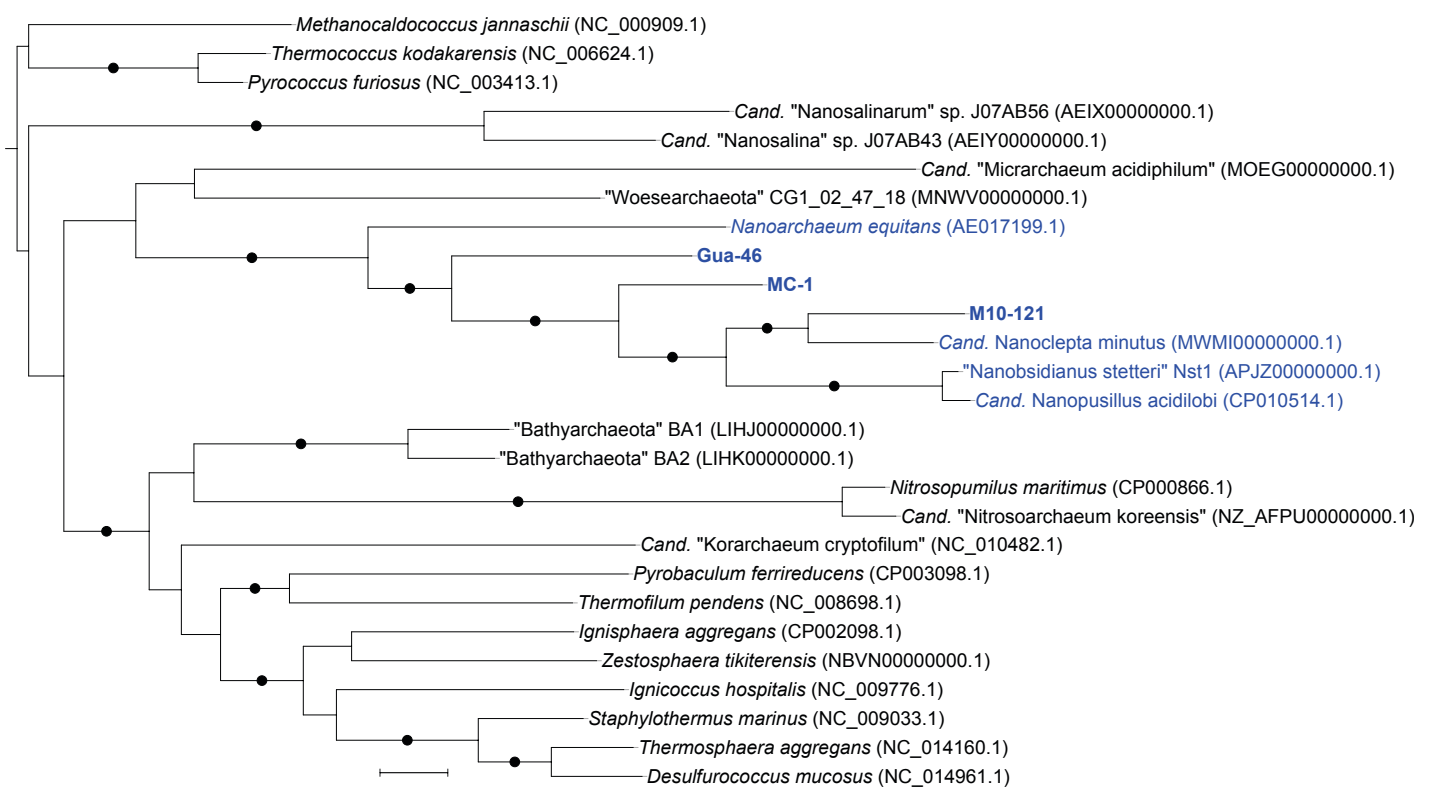

Figure 2.1. Maximum-likelihood phylogenetic tree based on eight concatenated ribosomal proteins. Members of the Nanoarchaeota are indicated in blue. The scale bar indicates 0.1 amino acid substitutions per site. Bootstrap support of $80-100 \%$ is indicated, based on 1000 replicate bootstrap trees. Members of the Euryarchaeota were used as the outgroups.

species in this genus [25]. The Mid-Cayman Rise MAG (MC-1) also shows the strongest similarity to Cand. Ncl. minutus by AAI (52\%) and 16S rRNA gene sequence similarity (87.5\%, Fig. 2.3), and it may represent the first species of a new genus in the Nanoarchaeota. AAI analysis also suggests that the Guaymas Basin MAG (Gua-46) represents a novel species in a second new genus, distinct from both $C$ and. Ncl. minutus and marine $N$. equitans (46\% AAI). Although Gua-46 is equally similar to these cultivated taxa based on AAI, its partial 16S rRNA gene (779 bp) shows much stronger 
gene sequence similarity to $N$. equitans $(91.3 \%)$ than to Cand. Ncl. minutus $(86.5 \%$;

Figure 2.3). While this discrepancy may be due to the partial length of the $16 \mathrm{~S}$ rRNA gene, it may also point to the inherent limitations of AAI in assessing the similarity of incomplete genomes. AAI (51\%) and 16S rRNA gene sequence similarity (92.8\%) also suggest that Gua-46 is more closely related to MC-1 than to any of its cultivated relatives, although the two MAGs represent two distinct, novel genera in the Nanoarchaeota.

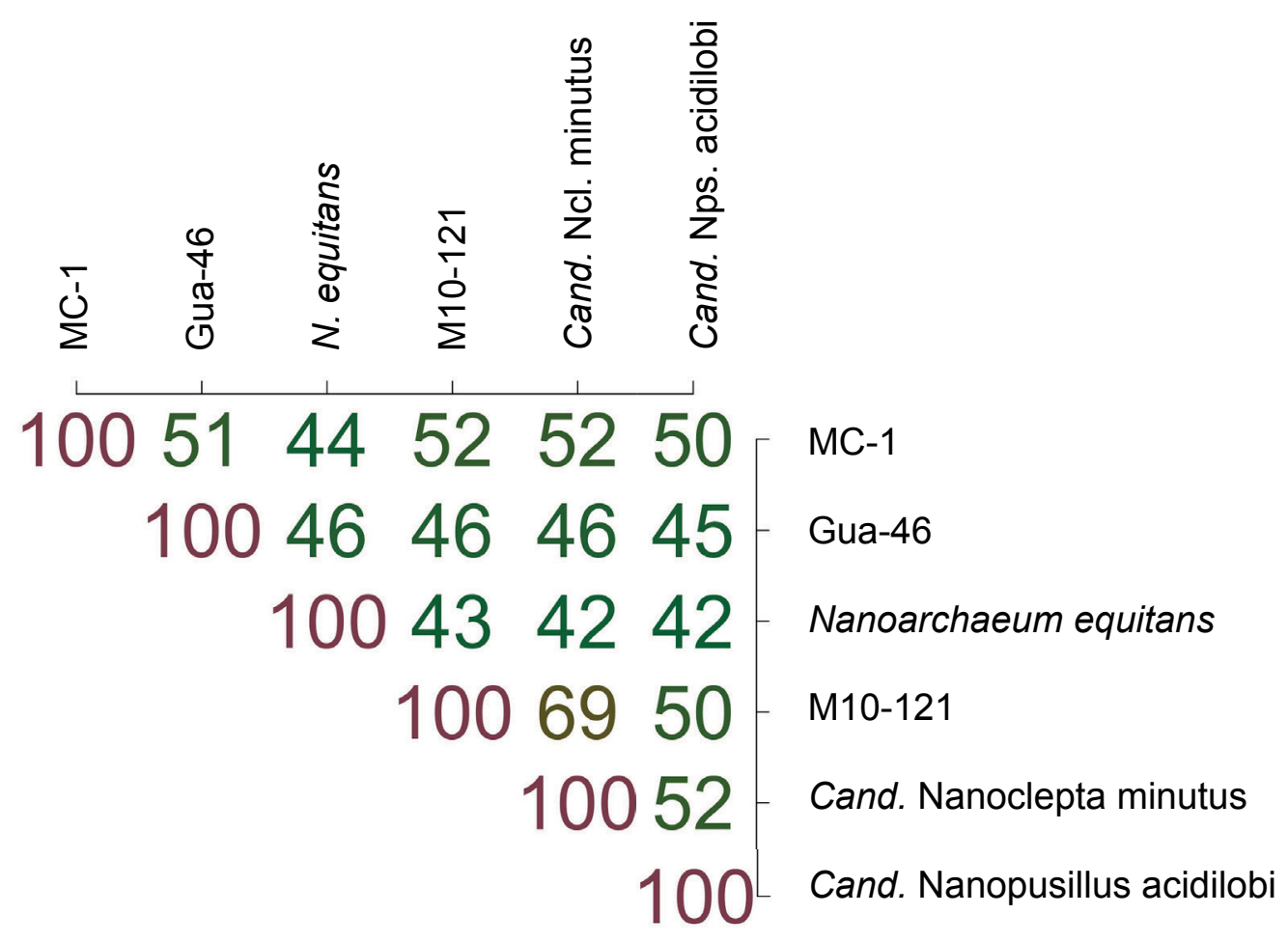

Figure 2.2. Average amino acid identity analysis of novel deep-sea Nanoarchaeota MAGs and their cultivated relatives 


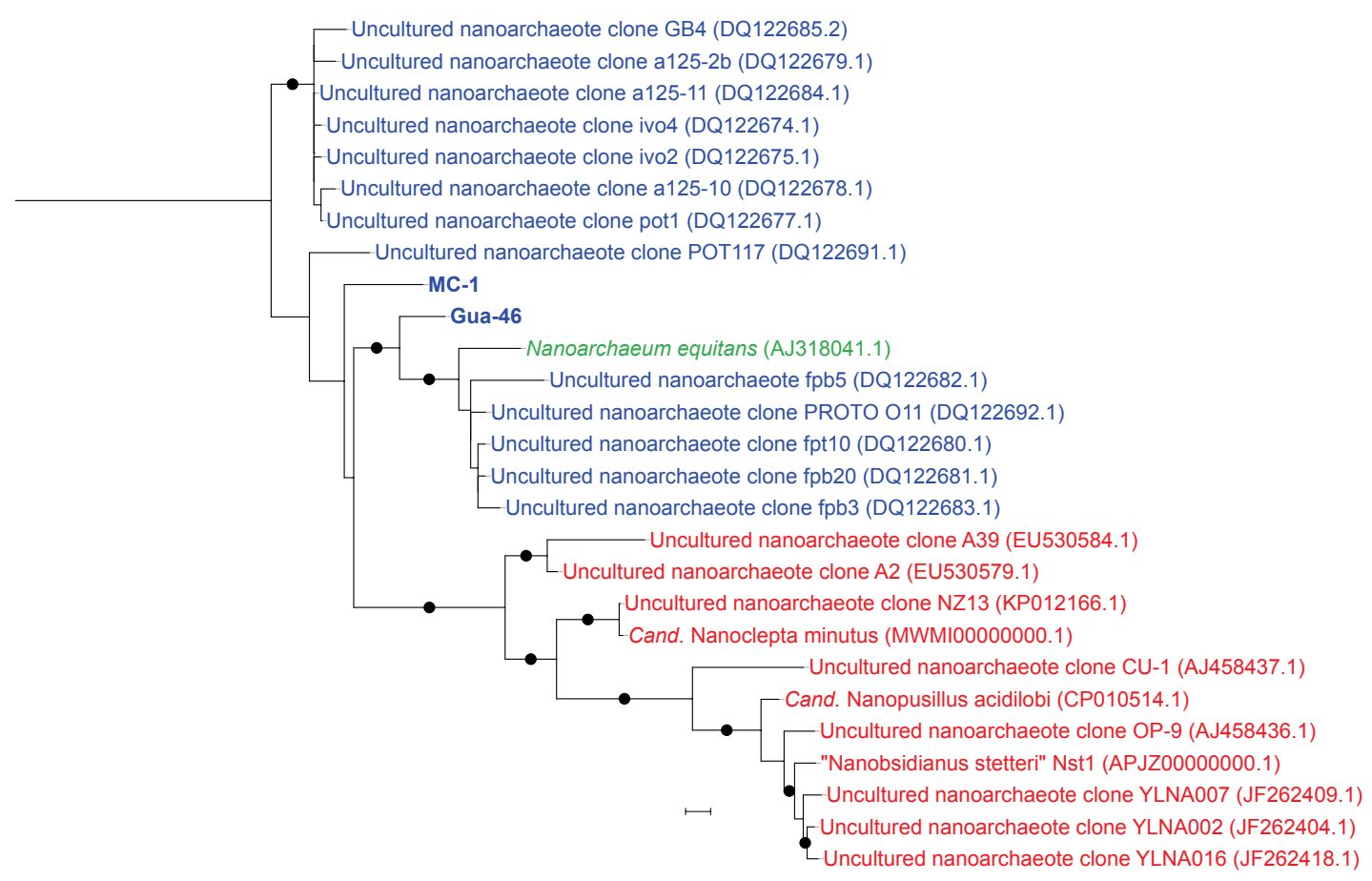

Figure 2.3. Maximum-likelihood phylogenetic analysis of nanoarchaeotal $16 \mathrm{~S}$ rRNA genes (710 nucleotide positions). Because no 16S rRNA gene sequence was identified in M10-121, the MAG is not represented in this analysis. Bootstrapping was performed using 1000 replicate trees, and bootstrap support of $80 \%$ and greater is shown. The scale bar indicates 0.01 substitutions per nucleotide. The outgroup consists of $16 \mathrm{~S}$ rRNA sequences from Ignisphaera aggregans AQ1.S1 ${ }^{\mathrm{T}}$, Desulfurococcus mucosus $\mathrm{O} 7 / 1^{\mathrm{T}}$ and Staphylothermus marinus $\mathrm{F}^{\mathrm{T}}{ }^{\mathrm{T}}$. Sequence color indicates environment type (red, terrestrial; green, shallow marine hydrothermal vent; blue, deep-sea hydrothermal vent).

Basic genomic features

The three Nanoarchaeota MAGs all have low contamination and are variable in length (Appendix B, File S2, Table B4). M10-121 is the most incomplete based on CheckM analysis (37.8\%; [40]), containing 65 of the archaeal marker genes used to estimate completion. Gua-46 and MC-1 are more complete (48.92\% and 67.99\%), with 85 and 108 marker genes, respectively. CheckM analysis likely underestimates the true completeness of symbionts and parasites like the Nanoarchaeota, whose genomes are 
highly reduced and do not contain the full set of archaeal marker genes. For example, the closed genomes of $N$. equitans and Cand. Nps. acidilobi are only estimated to be $73-74 \%$ complete by CheckM. Due to this limitation, directly comparing the number of marker genes found in each MAG to those identified in their cultivated relatives may provide a more accurate assessment of their relative completion. Based on comparison with the average marker genes recovered from $N$. equitans, Cand. Nps. acidilobi and Cand. Ncl. minutus, the MAGs are estimated to be $54.47 \%$ (M10-121), $71.23 \%$ (Gua-46) and $90.50 \%$ complete (MC-1).

Like previously sequenced Nanoarchaeota $[40,47,52,53]$, the three MAGs each encode at least one tRNA gene containing an intron sequence (Appendix B, File S2, Table B4-B5). None of the predicted intronic sequences found in the MAGs were identified as Group I or Group II introns (E-value $<=0.001$ ), and none of the introns had identical nucleotide sequences to other intronic regions in described Nanoarchaeota tRNA genes. None of the trans-encoded tRNA genes found in N. equitans [41] were identified in any of the MAGs. In our re-analysis of cultivated Nanoarchaeota genomes, we only recovered 41 of the tRNA genes found in $N$. equitans. However, we were able to identify additional intron-containing tRNAs in the Cand. Nps. acidilobi genome, which have thus far been unreported (Appendix B, File S2, Table B4-B5). Unlike N. equitans [42], both Gua-46 and MC-1 contain multiple RNase P protein subunits, suggesting RNase P may be functional in these lineages. Although no RNase $\mathrm{P}$ was identified in M10-121, it may be encoded in the unsequenced portion of the genome.

Several split protein-coding genes were found in the MAGs, similar to described Nanoarchaeota (Appendix B, File S2, Table B4, B6). Each MAG encodes a split gene 
for the large helicase-related (LHR) protein, which is split in all cultivated Nanoarchaeota genomes $[47,52,53]$. Notably, the LHR protein split site is conserved in all nanoarchaeotes in our analysis, with the exception of N. equitans. Several truncated genes were also identified, predominantly in M10-121. Due to the partial nature of the MAGs, we were unable to determine conclusively whether these truncated genes represent halves of split protein coding genes, or if they merely encode for shortened gene variants. However, several of the truncated genes align with the 5' or 3 ' regions of described split protein coding genes in other Nanoarchaeota, suggesting they may be true split genes. Some truncated genes are also the terminal open reading frames encoded on particular contigs, and thus they may be artificially shortened. However, the detection of split protein-coding genes across sequenced Nanoarchaeota genomes points to a shared history of genomic fragmentation [47].

\section{Comparative analysis of nanoarchaeotal coding potential}

All cultivated Nanoarchaeota genomes retain a common set of protein coding genes, predominantly involved in DNA repair and replication, ribosomal structure, transcription, translation and post-translational modification (Archaeal Clusters of Orthologous Genes (arCOG) clusters J, K, L and O; Appendix B, File S2, Table B7B10). Jarett et al. [22] recently proposed that Nanoarchaeota are under strong selective pressure to maintain the genes in these key functional groups. We identified several of these shared genes in the deep-sea nanoarchaeotal MAGs (Appendix B, File S2, Table B11-B14), including ribosomal proteins, genes involved in DNA replication and several subunits of the DNA-directed RNA polymerase. Pan-genomic analysis using Anvi'o 
$[14,15]$ also confirmed the presence of shared functional gene clusters across the MAGs and their cultivated relatives (Fig. 2.4). The recovery of these genes suggests that vital information-processing and replicative functions are maintained across nanoarchaeotal lineages.

Geographically distinct Nanoarchaeota may interact with diverse viral populations, as evidenced by CRISPR-Cas regions identified in N. equitans and Cand.

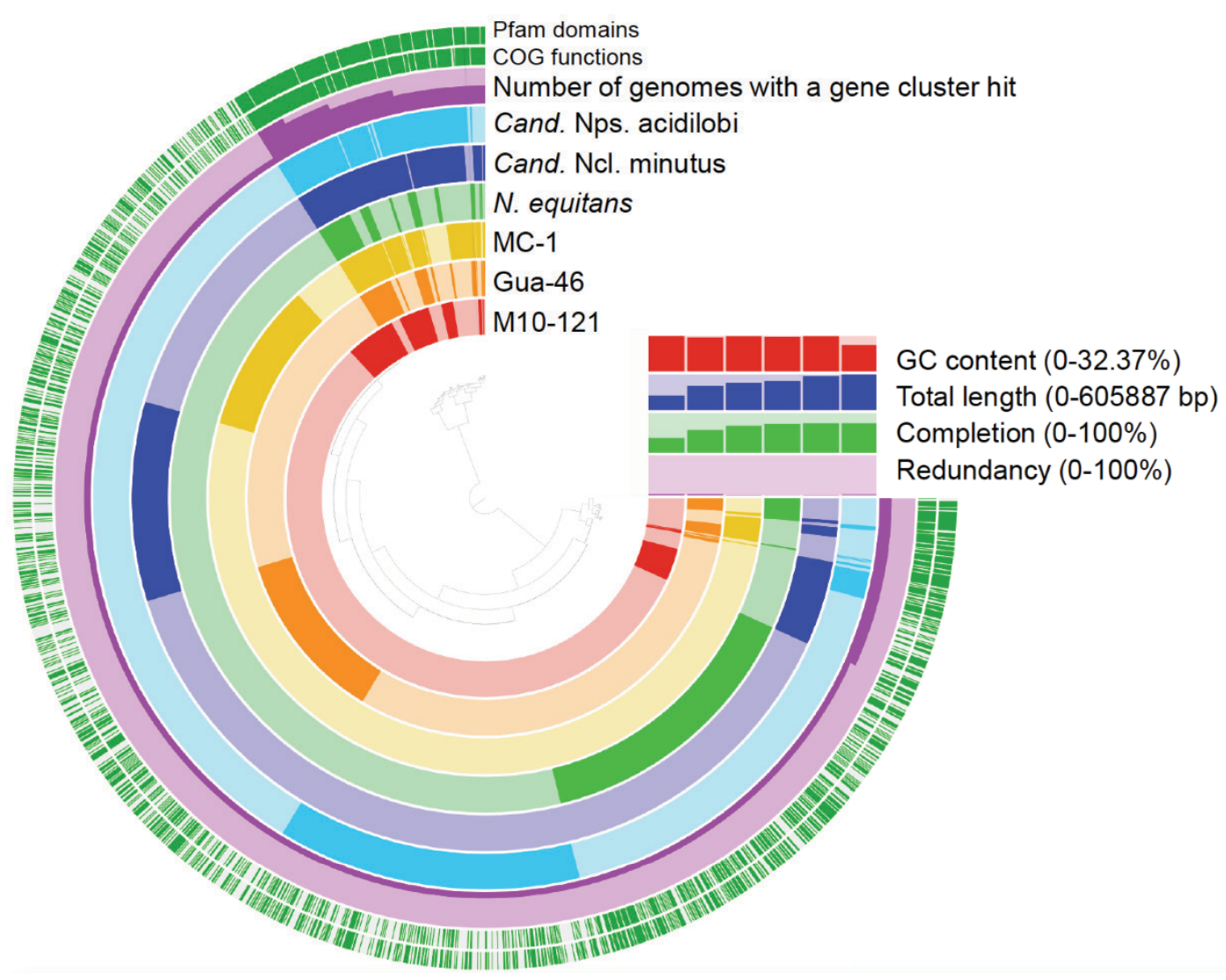

Figure 2.4. Pan-genome analysis of cultivated Nanoarchaeota and deep-sea nanoarchaeotal MAGs produced in Anvi'o [14,15]. Each MAG and cultivated Nanoarchaeota genome is shown as a separate layer, with genes ordered by functional categories. Shaded regions in each organism layer show the presence of genes in functional gene clusters. 
Ncl. minutus $[47,52]$ and integrated prophage DNA found in a single-cell nanoarchaeotal genome from YNP [36]. Although no CRISPR repeat regions were identified in Gua-46, the MAG contains an operon with three cas genes typically associated with a type III CRISPR-Cas cassette [33]. We also identified a putative CRISPR repeat region in MC-1, along with a separate cas6 gene that could be part of a type I or type III CRISPR-Cas system [33]. None of the MC-1 CRISPR repeat sequences showed significant similarity (E-value $<=0.00001)$ to viral sequence in the NCBI non-redundant nucleotide database [37]. However, given that deep-sea hydrothermal vents harbor large viral communities [38], it is likely these CRISPR repeats may correspond to viruses that have not yet been described.

Unlike their marine relative $N$. equitans, cultivated terrestrial Nanoarchaeota contain genes for the gluconeogenic pathway and express archaeal flagella $[47,53]$. Analysis of the deep-sea nanoarchaeotal MAGs suggests these traits may not be limited to terrestrial Nanoarchaeota. Although we were unable to identify a complete gluconeogenic pathway in any of the MAGs, M10-121 contains a bifunctional fructose1,6-bisphosphate aldolase/phosphatase (FBPA/ase), one of the marker genes for gluconeogenesis [53]. Both M10-121 and Gua-46 also contain one to three flaB genes, which encode for the long protein stalk of the archaeal flagella [1,50]. It is unclear whether or not nanoarchaeotal flagella are functional for motility, or if they perform an alternate role in host attachment and interaction [47,53]. However, the maintenance of archaeal flagellar genes in several of the Nanoarchaeota genomes may suggest they have a crucial function in these Nanoarchaeota. 
ATP generation in the Nanoarchaeota

Currently, it is unknown if the Nanoarchaeota have the ability to produce any ATP, or if they rely on their hosts for all ATP synthesis. It was previously suggested that N. equitans may utilize NADH from its host to generate a proton motive force using a sulfide:quinone oxidoreductase, which would be used to generate ATP, presumably via a partial ATP synthase [43]. However, structural analysis has shown that the N. equitans ATP synthase complex is not capable of conformational changes and is therefore nonfunctional [35]. Recently it was hypothesized that Nanoarchaeota from YNP might also tap into the host's electron transport chain as suggested for N. equitans [22]. However, instead of utilizing a sulfide:quinone oxidoreductase, these Nanoarchaeota could potentially use a cytochrome $b d$ ubiquinol oxidase, fueled by quinols from the host [22]. Although cytochrome $b d$ ubiquinol oxidase could contribute to the generation of a membrane potential [8], it is unclear what role this enzyme would play in nanoarchaeotal bioenergetics, since no ATP synthase has been identified in any terrestrial Nanoarchaeota genome to date $[40,47,53]$. Even if Nanoarchaeota were capable of generating a membrane potential, they would still be reliant on their host's ATP synthase complex to harness that potential for ATP production.

Without an ATP synthase, Nanoarchaeota may still be able to produce small amounts of ATP through substrate-level phosphorylation. Glycolysis was suggested as a means of ATP production in terrestrial Nanoarchaeota, based on analysis of the singlecell genome "Nanobsidianus stetteri" Nst1 from YNP [40]. However, the glycolytic pathway is incomplete both in "N. stetteri" Nst1 [40] and in the genomes of Cand. Nps. acidilobi and Cand. Ncl. minutus [47,53] and is therefore likely non-functional in these 


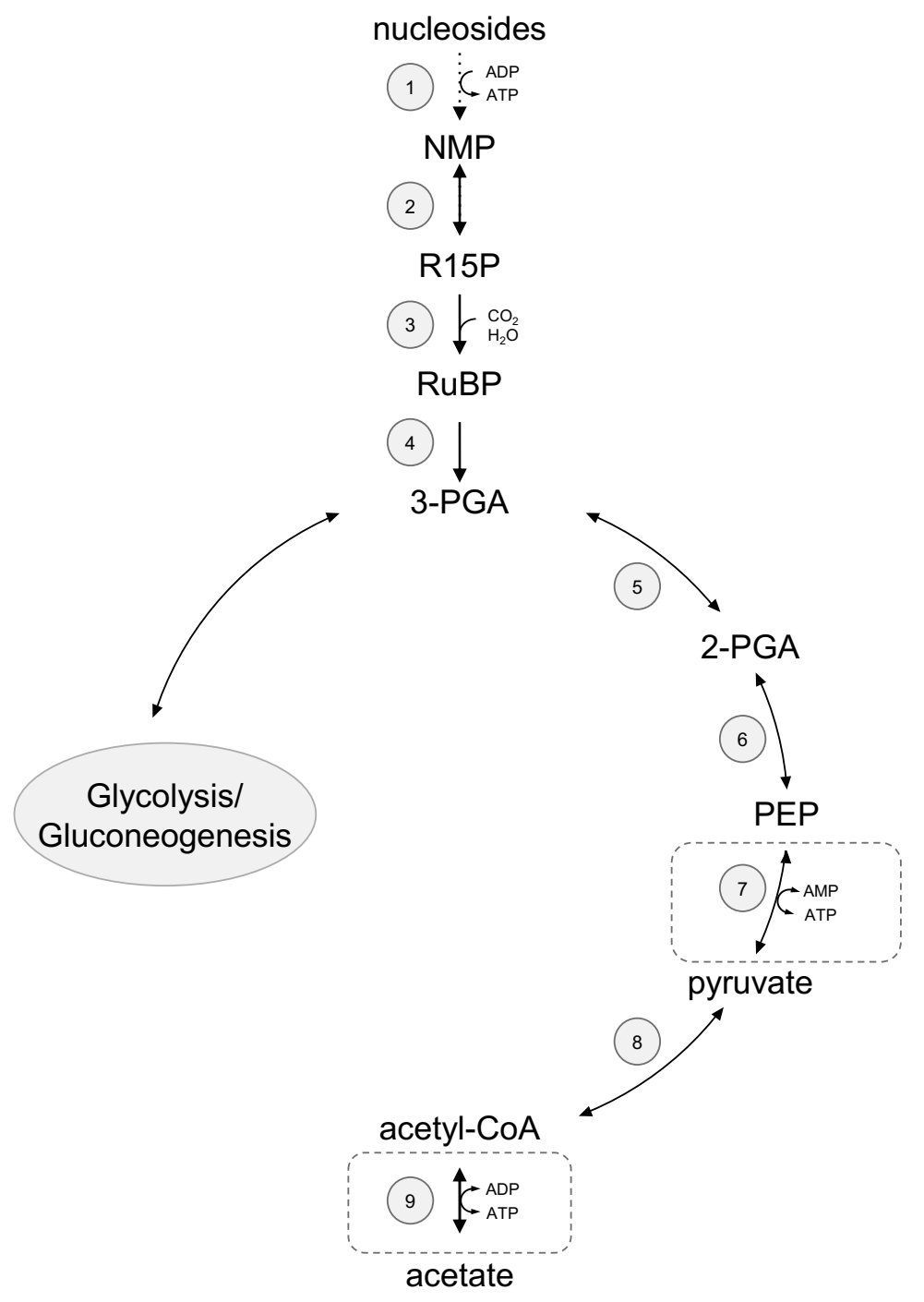

Figure 2.5. Reconstruction of the potential metabolic pathway for ATP generation in MC-1. Predicted genes: 1, putative nucleoside kinase (MC_288); 2, AMP phosphorylase (MC_480); 3, ribose-1,5-bisphosphate isomerase (MC_481); 4, type III Rubisco (MC_479); 5, phosphoglycerate mutase (MC_357); 6, enolase (MC_111); 7, phosphoenolpyruvate synthase (MC_225); 8, pyruvate:ferredoxin oxidoreductase (MC_146, 304); 9, acetyl-CoA synthetase (MC_147-149). Gene products: NMP, nucleoside monophosphate; R15P, ribose 1,5-bisphosphate; RuBP, ribulose 1,5bisphosphate; PGA, phosphoglycerate; PEP, phosphoenolpyruvate. 
lineages. Consistent with described Nanoarchaeota, none of the MAGs contained an evident, complete glycolytic pathway, and no ATP synthase or electron transport chain genes were detected. However, MC-1 does encode genes for the pentose bisphosphate pathway (Fig. 2.5), which would allow nanoarchaeotal cells to produce 3phosphoglycerate and bypass the missing steps in glycolysis [4,5]. The pentose bisphosphate pathway typically begins with nucleoside monophosphates, which may be produced by a putative nucleoside kinase (MC_288) that shows 35.1-37.4\% amino acid similarity to nucleoside kinases in Methanocaldococcus jannaschii and Aeropyrum pernix $[4,18]$. The gene also shows $25.6-28.5 \%$ similarity to a cytidine kinase and an ADP-dependent ribose 1-phosphate kinase found in T. kodakarensis, which feed into the pentose bisphosphate pathway at two different enzymatic steps [4]. Threephosphoglycerate produced by the pentose bisphosphate pathway could be shuttled into glycolysis, where ATP synthesis could be carried out using a phosphoenolpyruvate synthase, as shown in T. kodakarensis [21] and suggested for Cand. Nps. acidilobi and Cand. Ncl. minutus [47,53]. Acetyl coenzyme A synthase may then catalyze a second ATP-producing reaction [30]. If functional, this metabolic network would allow some deep-sea Nanoarchaeota to circumvent the early steps of glycolysis and produce limited ATP apart from their hosts. With a means of independent ATP production, Nanoarchaeota may be able to detach from their hosts for short periods of time, possibly facilitating infection of new host cells or rare host-switching events. However, cultivation of deep-sea Nanoarchaeota-host systems will be essential to determine if this pathway is functional, and what role it may play in host/symbiont interactions. 
Ecophysiology of deep-sea Nanoarchaeota and their hosts

Previous studies of cultivated Nanoarchaeota have shown a clear physiological distinction between marine and terrestrial lineages, with marine $N$. equitans lacking genes for archaeal flagella and gluconeogenesis that are found in terrestrial taxa $[40,47,52,53]$. However, our study suggests this apparent dichotomy does not exist. Genomic evidence of these key features is scattered across deep-sea nanoarchaeotal MAGs, with no clear pattern of distribution.

Although we do not propose any putative nanoarchaeotal-host pairings, the apparent absence of ATP synthase genes suggests that deep-sea Nanoarchaeota rely on intimate associations with host organisms, similar to their described relatives. Studies based on 16S rRNA gene sequencing have shown that deep-sea hydrothermal vents support diverse communities of Crenarchaeota, including lineages related to the marine N. equitans host, Ignicoccus, and many taxa that have not yet been described $[16,17,34,48]$. The ELSC metagenome also contained sequences most closely related to the New Zealand nanoarchaeote host organism, Zestosphaera. It is likely that deep-sea nanoarchaeotes associate with some, or many, of these crenarchaeotal hosts, and that the relationship between symbiont and host may influence which traits are retained or lost in particular nanoarchaeotal lineages. Host type may also vary significantly between different hydrothermal vent sites due to the diverse geochemical settings of the marine vent sites, which can strongly affect community structure [16,17]. Cultivation and single-cell genomic studies of deep-sea Nanoarchaeota will be key to understanding the scope of nanoarchaeotal diversity and the complexities of this symbiont-host interaction. 
Acknowledgements

This work was supported through grants from the National Aeronautics and Space Administration (NNX16AJ66G), the US-National Science Foundation (OCE1235432, OCE1558795, OCE0728391 and DEB1134877) and the Department of Energy Joint Genome Institute (Community Science Program award 339) to ALR and the Forbes-Lea Endowment Fund for Student Research award to ESJ. We thank the captain and crew members of the RV Thomas Thompson and the RV Atlantis, and the ROV Jason and HOV Alvin teams for assistance in collecting samples.

\section{Contributions}

ESJ performed genomic analysis of the MAGs and BlastP-based core-genome analysis, 16S rRNA gene and ribosomal protein phylogenetic analyses and average amino acid identity comparisons. JM performed iterative binning of the MC-1 MAG. Anvi'obased pan-genomic analysis was done by GF. ESJ and ALR prepared and edited the manuscript. 


\section{References}

[1] Albers, S.-V., Jarrell, K.F. (2015) The archaellum: how Archaea swim. Front. Microbiol. 6, 23, https://doi.org/10.3389/fmicb.2015.00023.

[2] Altschul, S.F., Gish, W., Miller, W., Myers, E.W., Lipman, D.J. (1990) Basic local alignment search tool. J. Mol. Biol. 215(3), 403-410.

[3] Anderson, R.E., Reveillaud, J., Reddington, E., Delmont, T.O., Eren, A.M., McDermott, J.M., Seewald, J.S., Huber, J.A. (2017) Genomic variation in microbial populations inhabiting the marine subseafloor at deep-sea hydrothermal vents. Nat. Commun. 8(1), 1114, https://doi.org/10.1038/s41467-017-01228-6.

[4] Aono, R., Sato, T., Imanaka, T., Atomi, H. (2015) A pentose bisphosphate pathway for nucleoside degradation in Archaea. Nat. Chem. Biol. 11(5), 355-360.

[5] Aono, R., Sato, T., Yano, A., Yoshida, S., Nishitani, Y., Miki, K., Imanaka, T., Atomi, H. (2012) Enzymatic characterization of AMP phosphorylase and ribose1,5-bisphosphate isomerase functioning in an archaeal AMP metabolic pathway. J. Bacteriol. 194(24), 6847-6855.

[6] Bankevich, A., Nurk, S., Antipov, D., Gurevich, A.A., Dvorkin, M., Kulikov, A.S., Lesin, V.M., Nikolenko, S.I., Pham, S., Prjibelski, A.D., Pyshkin, A. V., Sirotkin, A. V., Vyahhi, N., Tesler, G., Alekseyev, M.A., Pevzner, P.A. (2012) SPAdes: a new genome assembly algorithm and its applications to single-cell sequencing. J. Comput. Biol. 19(5), 455-477.

[7] Bolger, A.M., Lohse, M., Usadel, B. (2014) Trimmomatic: A flexible trimmer for Illumina sequence data. Bioinformatics 30(15), 2114-2120.

[8] Borisov, V.B., Gennis, R.B., Hemp, J., Verkhovsky, M.I. (2011) The cytochrome 
$b d$ respiratory oxygen reductases. Biochim. Biophys. Acta - Bioenerg. 1807(11), $1398-1413$.

[9] Casanueva, A., Galada, N., Baker, G.C., Grant, W.D., Heaphy, S., Jones, B., Yanhe, M., Ventosa, A., Blamey, J., Cowan, D.A. (2008) Nanoarchaeal 16S rRNA gene sequences are widely dispersed in hyperthermophilic and mesophilic halophilic environments. Extremophiles 12, 651-656.

[10] Chernyh, N.A., Mardanov, A. V., Gumerov, V.M., Miroshnichenko, M.L., Lebedinsky, A. V., Merkel, A.Y., Crowe, D., Pimenov, N. V., Rusanov, I.I., Ravin, N. V., Moran, M.A., Bonch-Osmolovskaya, E.A. (2015) Microbial life in Bourlyashchy, the hottest thermal pool of Uzon Caldera, Kamchatka. Extremophiles 19(6), 1157-1171.

[11] Clarke, K.R., Gorley, R.N. (2006) Primer V6: User Manual - Tutorial. Plymouth Marine Laboratory, Plymouth, England.

[12] Clingenpeel, S., Kan, J., Macur, R.E., Woyke, T., Lovalvo, D., Varley, J., Inskeep, W.P., Nealson, K., McDermott, T.R. (2013) Yellowstone Lake Nanoarchaeota. Front. Microbiol. 4, 274, https://doi.org/10.3389/fmicb.2013.00274.

[13] Darling, A.E., Jospin, G., Lowe, E., Matsen 4th, F.A., Bik, H.M., Eisen, J.A. (2014) PhyloSift: phylogenetic analysis of genomes and metagenomes. PeerJ 2, e243, https://doi.org/10.7717/peerj.243.

[14] Delmont, T.O., Eren, A.M. (2018) Linking pangenomes and metagenomes: the Prochlorococcus metapangenome. PeerJ 6, e4320, https://doi.org/10.7717/peerj.4320.

[15] Eren, A.M., Esen, Ö.C., Quince, C., Vineis, J.H., Morrison, H.G., Sogin, M.L., 
Delmont, T.O. (2015) Anvi'o: an advanced analysis and visualization platform for 'omics data. PeerJ 3, e1319, https://doi.org/10.7717/peerj.1319.

[16] Flores, G.E., Campbell, J.H., Kirshtein, J.D., Meneghin, J., Podar, M., Steinberg, J.I., Seewald, J.S., Tivey, M.K., Voytek, M.A., Yang, Z.K., Reysenbach, A.L. (2011) Microbial community structure of hydrothermal deposits from geochemically different vent fields along the Mid-Atlantic Ridge. Environ. Microbiol. 13(8), 2158-2171.

[17] Flores, G.E., Shakya, M., Meneghin, J., Yang, Z.K., Seewald, J.S., Geoff Wheat, C., Podar, M., Reysenbach, A.-L. (2012) Inter-field variability in the microbial communities of hydrothermal vent deposits from a back-arc basin. Geobiology 10(4), 333-346.

[18] Hansen, T., Arnfors, L., Ladenstein, R., Schönheit, P. (2007) The phosphofructokinase-B (MJ0406) from Methanocaldococcus jannaschii represents a nucleoside kinase with a broad substrate specificity. Extremophiles 11(1), 105114.

[19] Hohn, M.J., Hedlund, B.P., Huber, H. (2002) Detection of 16S rDNA sequences representing the novel phylum "Nanoarchaeota": Indication for a wide distribution in high temperature biotopes. Syst. Appl. Microbiol. 25, 551-554.

[20] Huber, H., Hohn, M.J., Rachel, R., Fuchs, T., Wimmer, V.C., Stetter, K.O. (2002) A new phylum of Archaea represented by a nanosized hyperthermophilic symbiont. Nature 417(6884), 63-67.

[21] Imanaka, H., Yamatsu, A., Fukui, T., Atomi, H., Imanaka, T. (2006) Phosphoenolpyruvate synthase plays an essential role for glycolysis in the 
modified Embden-Meyerhof pathway in Thermococcus kodakarensis. Mol. Microbiol. 61(4), 898-909.

[22] Jarett, J.K., Nayfach, S., Podar, M., Inskeep, W., Ivanova, N.N., Munson-McGee, J., Schulz, F., Young, M., Jay, Z.J., Beam, J.P., Kyrpides, N.C., Malmstrom, R.R. (2018) Single-cell genomics of co-sorted Nanoarchaeota suggests novel putative host associations and diversification of proteins involved in symbiosis.

Microbiome 6(161), https://doi.org/10.1186/s40168-018-0539-8.

[23] Kang, D.D., Froula, J., Egan, R., Wang, Z. (2015) MetaBAT, an efficient tool for accurately reconstructing single genomes from complex microbial communities. PeerJ 3, e1165, https://doi.org/10.7717/peerj.1165.

[24] Kearse, M., Moir, R., Wilson, A., Stones-Havas, S., Cheung, M., Sturrock, S., Buxton, S., Cooper, A., Markowitz, S., Duran, C., Thierer, T., Ashton, B., Meintjes, P., Drummond, A. (2012) Geneious Basic: An integrated and extendable desktop software platform for the organization and analysis of sequence data. Bioinformatics 28(12), 1647-1649.

[25] Konstantinidis, K.T., Rosselló-Móra, R., Amann, R. (2017) Uncultivated microbes in need of their own taxonomy. ISME J. 11(11), 2399-2406.

[26] Larkin, M.A., Blackshields, G., Brown, N.P., Chenna, R., Mcgettigan, P.A., McWilliam, H., Valentin, F., Wallace, I.M., Wilm, A., Lopez, R., Thompson, J.D., Gibson, T.J., Higgins, D.G. (2007) Clustal W and Clustal X version 2.0. Bioinformatics 23(21), 2947-2948.

[27] Leinonen, R., Sugawara, H., Shumway, M., International Nucleotide Sequence Database Collaboration. (2010) The sequence read archive. Nucleic Acids Res. 
39(Database issue), D19-D21.

[28] Li, D., Liu, C.-M., Luo, R., Sadakane, K., Lam, T.-W. (2015) MEGAHIT: an ultra-fast single-node solution for large and complex metagenomics assembly via succinct de Bruijn graph. Bioinformatics 31(10), 1674-1676.

[29] Li, D., Luo, R., Liu, C.-M., Leung, C.-M., Ting, H.-F., Sadakane, K., Yamashita, H., Lam, T.-W. (2016) MEGAHIT v1.0: A fast and scalable metagenome assembler driven by advanced methodologies and community practices. Methods $102,3-11$.

[30] Mai, X., Adams, M.W. (1996) Purification and characterization of two reversible and ADP-dependent acetyl coenzyme A synthetases from the hyperthermophilic archaeon Pyrococcus furiosus. J. Bacteriol. 178(20), 5897-5903.

[31] Makarova, K., Wolf, Y., Koonin, E. (2015) Archaeal clusters of orthologous genes (arCOGs): an update and application for analysis of shared features between Thermococcales, Methanococcales, and Methanobacteriales. Life 5(1), 818-840.

[32] Makarova, K.S., Sorokin, A. V., Novichkov, P.S., Wolf, Y.I., Koonin, E. V. (2007) Clusters of orthologous genes for 41 archaeal genomes and implications for evolutionary genomics of archaea. Biol. Direct, 33, https://doi.org/10.1186/17456150-2-33.

[33] Makarova, K.S., Wolf, Y.I., Alkhnbashi, O.S., Costa, F., Shah, S.A., Saunders, S.J., Barrangou, R., Brouns, S.J.J., Charpentier, E., Haft, D.H., Horvath, P., Moineau, S., Mojica, F.J.M., Terns, R.M., Terns, M.P., White, M.F., Yakunin, A.F., Garrett, R.A., van der Oost, J., Backofen, R., Koonin, E. V. (2015) An updated evolutionary classification of CRISPR-Cas systems. Nat. Rev. Microbiol. 
13(11), 722-736.

[34] McCliment, E.A., Voglesonger, K.M., O’Day, P.A., Dunn, E.E., Holloway, J.R., Cary, S.C. (2006) Colonization of nascent, deep-sea hydrothermal vents by a novel archaeal and nanoarchaeal assemblage. Environ. Microbiol. 8(1), 114-125.

[35] Mohanty, S., Jobichen, C., Chichili, V.P.R., Velázquez-Campoy, A., Low, B.C., Hogue, C.W.V., Sivaraman, J. (2015) Structural basis for a unique ATP synthase core complex from Nanoarchaeum equitans. J. Biol. Chem. 290(45), 2728027296.

[36] Munson-McGee, J.H., Field, E.K., Bateson, M., Rooney, C., Stepanauskas, R., Young, M.J. (2015) Nanoarchaeota, their Sulfolobales host, and Nanoarchaeota virus distribution across Yellowstone National Park hot springs. Appl. Environ. Microbiol. 81(22), 7860-7868.

[37] NCBI Resource Coordinators. (2017) Database resources of the National Center for Biotechnology Information. Nucleic Acids Res. 45(D1), D12-D17.

[38] Ortmann, A.C., Suttle, C.A. (2005) High abundances of viruses in a deep-sea hydrothermal vent system indicates viral mediated microbial mortality. Deep. Res. Part I Oceanogr. Res. Pap. 52(8), 1515-1527.

[39] Parks, D.H., Imelfort, M., Skennerton, C.T., Hugenholtz, P., Tyson, G.W. (2015) CheckM: assessing the quality of microbial genomes recovered from isolates, single cells, and metagenomes. Genome Res. 25(7), 1043-1055.

[40] Podar, M., Makarova, K.S., Graham, D.E., Wolf, Y.I., Koonin, E. V., Reysenbach, A.-L. (2013) Insights into archaeal evolution and symbiosis from the genomes of a nanoarchaeon and its inferred crenarchaeal host from Obsidian Pool, Yellowstone 
National Park. Biol. Direct 8, 9, https://doi.org/10.1186/1745-6150-8-9.

[41] Randau, L., Münch, R., Hohn, M.J., Jahn, D., Söll, D. (2005) Nanoarchaeum equitans creates functional tRNAs from separate genes for their 5'-and 3'-halves. Nature 433(7025), 537-541.

[42] Randau, L., Schröder, I., Söll, D. (2008) Life without RNase P. Nature 453(7191), $120-123$.

[43] Rawle, R.A., Hamerly, T., Tripet, B.P., Giannone, R.J., Wurch, L., Hettich, R.L., Podar, M., Copié, V., Bothner, B. (2017) Multi-omics analysis provides insight to the Ignicoccus hospitalis-Nanoarchaeum equitans association. Biochim. Biophys. Acta - Gen. Subj. 1861(9), 2218-2227.

[44] Reeves, E.P., McDermott, J.M., Seewald, J.S. (2014) The origin of methanethiol in midocean ridge hydrothermal fluids. Proc. Natl. Acad. Sci. 111(15), 5474-5479.

[45] Reysenbach, A.-L., Liu, Y., Banta, A.B., Beveridge, T.J., Kirshtein, J.D., Schouten, S., Tivey, M.K., Von Damm, K.L., Voytek, M.A. (2006) A ubiquitous thermoacidophilic archaeon from deep-sea hydrothermal vents. Nature 442(7101), $444-447$.

[46] Rodriguez-R, L.M., Konstantinidis, K.T. (2016) The enveomics collection: a toolbox for specialized analyses of microbial genomes and metagenomes. PeerJ Prepr., 4, e1900v1, https://doi.org/10.7287/peerj.preprints.1900v1.

[47] St. John, E., Liu, Y., Podar, M., Stott, M.B., Meneghin, J., Chen, Z., Lagutin, K., Mitchell, K., Reysenbach, A.-L. (In press) A new symbiotic nanoarchaeote (Candidatus Nanoclepta minutus) and its host (Zestosphaera tikiterensis gen. nov., sp. nov.) from a New Zealand hot spring. Syst. Appl. Microbiol., 
https://doi.org/10.1016/j.syapm.2018.08.005.

[48] Takai, K., Horikoshi, K. (1999) Genetic diversity of Archaea in deep-sea hydrothermal vent environments. Genetics 152(4), 1285-1297.

[49] Teske, A., De Beer, D., McKay, L.J., Tivey, M.K., Biddle, J.F., Hoer, D., Lloyd, K.G., Lever, M.A., Røy, H., Albert, D.B., Mendlovitz, H.P., MacGregor, B.J. (2016) The Guaymas Basin hiking guide to hydrothermal mounds, chimneys, and microbial mats: complex seafloor expressions of subsurface hydrothermal circulation. Front. Microbiol. 7(FEB), 1-23.

[50] Thomas, N.A., Bardy, S.L., Jarrell, K.F. (2001) The archaeal flagellum: a different kind of prokaryotic motility structure. Microbiol. Rev. 25(2), 147-174.

[51] Ultsch, A., Mörchen, F. (2005) ESOM-Maps: tools for clustering, visualization, and classification with Emergent SOM, Technical Report Dept. of Mathematics and Computer Science, University of Marburg, Germany, no. 46.

[52] Waters, E., Hohn, M.J., Ahel, I., Graham, D.E., Adams, M.D., Barnstead, M., Beeson, K.Y., Bibbs, L., Bolanos, R., Keller, M., Kretz, K., Lin, X., Mathur, E., Ni, J., Podar, M., Richardson, T., Sutton, G.G., Simon, M., Soll, D., Stetter, K.O., Short, J.M., Noordewier, M. (2003) The genome of Nanoarchaeum equitans: insights into early archaeal evolution and derived parasitism. Proc. Natl. Acad. Sci. U. S. A. 100(22), 12984-12988.

[53] Wurch, L., Giannone, R.J., Belisle, B.S., Swift, C., Utturkar, S., Hettich, R.L., Reysenbach, A.-L., Podar, M. (2016) Genomics-informed isolation and characterization of a symbiotic Nanoarchaeota system from a terrestrial geothermal environment. Nat. Commun. 7, 12115, 
http://doi.org/10.1038/ncomms12115. 


\section{Chapter 4: Conclusion}

The research presented in this thesis provides key insights into the Nanoarchaeota, one of several novel phyla discovered over the past four decades of archaeal research $[1-3,13,17]$. The cultivation of the first Nanoarchaeota-host system revolutionized archaeal biology, revealing that Archaea engage in close, interspecies relationships with other Archaea. Today, this lifestyle is thought to be widespread across several archaeal lineages $[1,5,6,9]$. However, many aspects of nanoarchaeotal ecophysiology remain enigmatic, due to the limited amount of genetic material available. In this thesis, direct cultivation, phylogenetic analysis and comparative genomics are used to reveal previously unknown diversity in the Nanoarchaeota, both on the functional and taxonomic level.

In Chapter 2, anaerobic cultivation was used to isolate a novel Nanoarchaeota and its host from a geothermal spring in Tikitere, New Zealand. The New Zealand nanoarchaeote (Candidatus Nanoclepta minutus) was compared to its cultivated relatives on the genomic level. Despite their large geographical separation, Cand. Ncl. minutus showed distinct similarities to terrestrial lineages from Yellowstone National Park (YNP), encoding genes for gluconeogenesis and archaeal flagella which are not found in the shallow marine nanoarchaeote, Nanoarchaeum equitans [12,14,15]. However, Cand. Ncl. minutus also encoded for a CRISPR-Cas system like N. equitans [14]. The phylogenetic placement of Cand. Ncl. minutus and its host Zestosphaera tikiterensis was determined using a multi-faceted approach, which showed that Cand. Ncl. minutus is a new genus in the Nanoarchaeota, while Z. tikiterensis is a novel genus in the Crenarchaeota. Z. tikiterensis was also purified in axenic culture, described and 
compared to its closest relative. Although Z. tikiterensis represents a novel genus, it shared some key features with the distantly-related nanoarchaeote host Acidilobus sp. 7A from YNP, including genes associated with a heterotrophic lifestyle and an outer S-layer [22].

In light of the similarities between the New Zealand and YNP Nanoarchaeota and their divergence from $N$. equitans, the studies presented in Chapter 3 focused on the relationship between cultivated terrestrial and shallow marine Nanoarchaeota and their undescribed deep-sea relatives. Phylogenetic and genomic analysis were used to assess if marine and terrestrial nanoarchaeotes from various geothermal settings show consistent, observable differences, either on the phylogenetic or genomic scale. Three metagenomeassembled genomes (MAGs) from diverse deep-sea hydrothermal vent environments were assembled and described. Based on phylogenetic reconstruction, the three MAGs represented two new genera and an additional novel species of Nanoarchaeota. However, terrestrial and marine Nanoarchaeota did not resolve into distinct monophyletic lineages. Comparative genomic analysis of the MAGs also revealed a patchy distribution of functional genes previously thought to be limited to terrestrial Nanoarchaeota. The phylogenetic relatedness of these Nanoarchaeota and the distribution of key marker genes suggests a complex evolutionary history between marine and terrestrial nanoarchaeotal lineages, with no clear pattern to delineate the two. One of the deep-sea Nanoarchaeota MAGs from the Mid-Cayman Rise also contained a novel pathway for potential ATP production. If functional, the pathway may allow certain Nanoarchaeota to produce low amounts of ATP independent from their hosts. 
In light of the studies presented in this thesis, an integrated view of nanoarchaeotal biology and ecophysiology has begun to emerge (Fig. 3.1A-B). To date, all cultivated Nanoarchaeota share an ectosymbiotic lifestyle with hosts from the Crenarchaeota [12,20,22]. Metabolic building blocks such as lipids, amino acids, cofactors and nucleotides are likely shuttled from hosts to their Nanoarchaeota, due to the reduced biosynthetic capabilities of nanoarchaeotes [18,20-22]. Likely, this transfer of nutrients is shuttled through a pore-type structure bridging the Nanoarchaeota and host. Although this direct connection has only been verified in the N. equitans-I. hospitalis system [11], electron microscopy suggests it may be further distributed across nanoarchaeotal lineages [20,22], as discussed in Chapter 2.

The method by which ATP synthesis and energy generation occur in the Nanoarchaeota still remains unclear. However, the apparent absence of a complete ATP synthase complex or glycolytic pathway in described Nanoarchaeota $[14,16-18,20,22]$ indicates that most nanoarchaeotes likely rely on ATP provided by their hosts. The discovery of the pentose bisphosphate pathway in one nanoarchaeotal MAG suggests some limited ATP production may be possible in deep-sea Nanoarchaeota. However, direct cultivation will be necessary to determine whether or not this pathway is functional.

The means by which nanoarchaeotes and their hosts recognize one another, initiate attachment and maintain their association is not yet fully understood. Thus far, $I$. hospitalis, the host of $N$. equitans is unique among nanoarchaeote hosts due to its double membrane system (Fig. 3.1B), which may be crucial in the attachment of $N$. equitans [11]. In contrast, terrestrial hosts from New Zealand and YNP encode for 


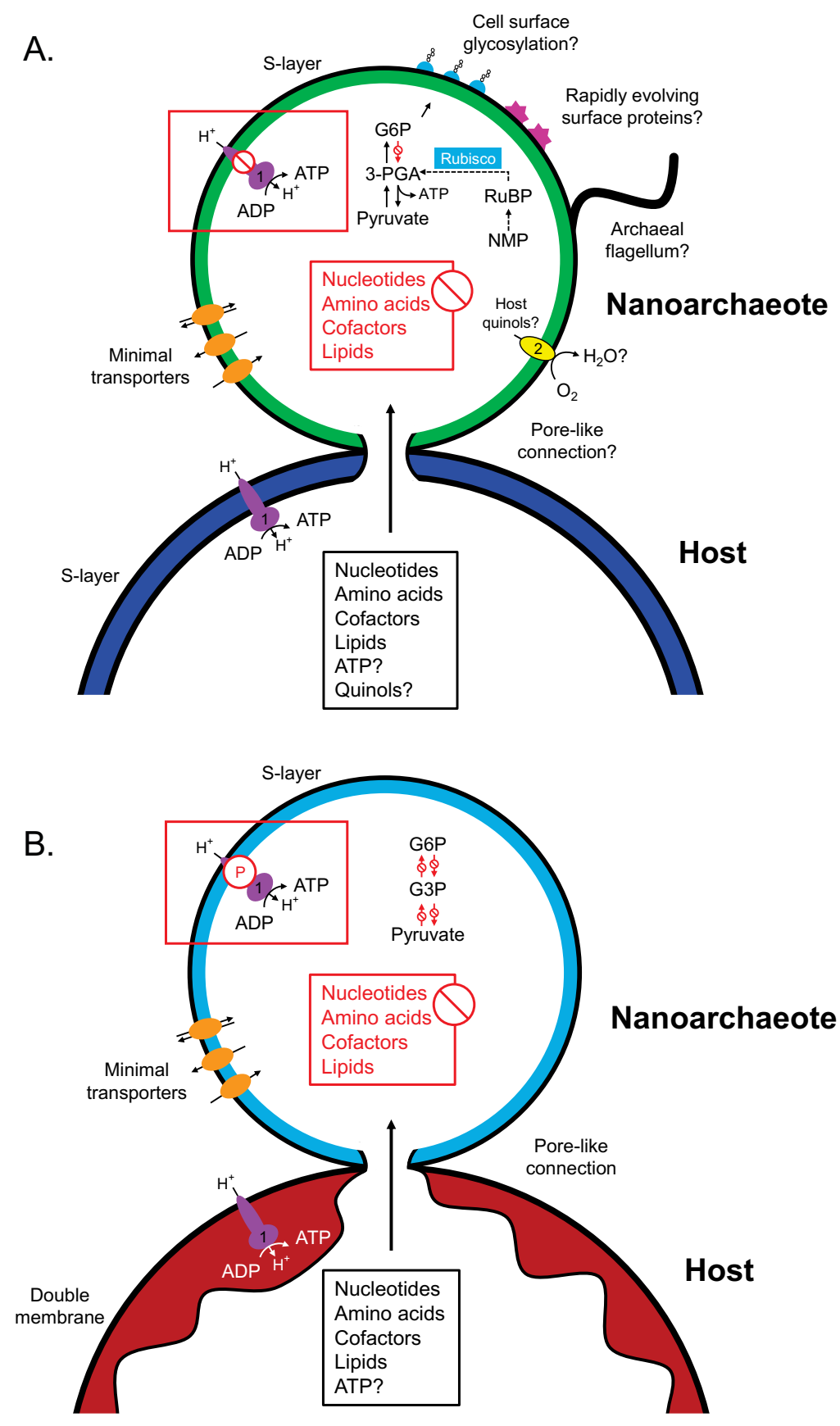

Figure 3.1. Current understanding of metabolism in the Nanoarchaeota and nanoarchaeote-host interactions. (A) Features from terrestrial nanoarchaeotes and deepsea nanoarchaeotal MAGs, shown with a prototypical non-Ignicoccus host; (B) features of N. equitans and its host I. hospitalis. G6P, glucose 6-phosphate; NMP, nucleoside monophosphate; 3-PGA, 3-phosphoglycerate; RuBP, ribulose 1,5-bisphosphate; 1, ATP synthase complex; 2 , cytochrome $b d$ ubiquinol oxidase; $\mathrm{P}$, partial; $\varnothing$, absent/not detected. Genes from the pentose bisphosphate pathway are indicated with dashed lines. 
S-layers [18,20,22]. The presence of archaeal flagella, glycosylated cell surfaces and rapidly-evolving surface proteins (Fig. 3.1A) have all been implicated in the attachment between terrestrial nanoarchaeotes and their hosts $[14,18,22]$, and may also play a role in deep-sea high-temperature Nanoarchaeota-host systems, as discussed in Chapter 3. However, the exact role of these various systems still remains unclear.

Looking forward, the next steps in nanoarchaeotal research can build on the analyses in this thesis by further exploring the interaction between the Nanoarchaeota and their hosts. In the laboratory setting, cultivated terrestrial nanoarchaeotes do not reach the high concentrations seen in the $N$. equitans-I. hospitalis co-culture $[13,20,22]$. Nonetheless, comparative transcriptomics and proteomics may be a valuable tool to further understand these systems. By comparing gene transcription and protein expression in terrestrial Nanoarchaeota-host co-cultures and isolated host cultures, the effects of nanoarchaeote infection on diverse hosts may be elucidated, as shown in the $N$. equitans-I. hospitalis pairing [7,8]. Differences in host response to nanoarchaeote infection may also clarify whether different Nanoarchaeota-host systems more strongly resemble parasitic or commensal relationships. As previously demonstrated in the $N$. equitans/I. hospitalis system [10], metabolomics may also be used to assess the effects of symbiont infection on host physiology, particularly in terms of ATP consumption.

The New Zealand nanoarchaeote, Cand. Ncl. minutus, also provides a unique opportunity for studying the effects of other community members on interspecies interaction. Cand. Ncl. minutus grows to higher densities in the mixed enrichment culture setting as compared to pure co-cultures, suggesting that other lineages in the enrichment community may positively affect the host/symbiont pairing. To assess the 
potential effects of other microbial species on Cand. Ncl. minutus and its host, individual microbes isolated from the enrichment cultures (described in Chapter 2) could be added to pure nanoarchaeote-host co-cultures. By tracking growth response and applying differential transcriptomic, proteomic or metabolomic approaches to these cultures, the various effects of non-host lineages from the natural environment could be observed. Additionally, nanoarchaeotal research would greatly benefit from the continued cultivation of Nanoarchaeota-host systems from diverse environments. With their putative novel pathway for ATP generation, Nanoarchaeota from the Mid-Cayman Rise represent an especially vital lineage for cultivation. Assessing the functionality of this pathway and its apparent effect on the nanoarchaeote-host symbiosis may provide crucial insights into the evolution of host dependency in this phylum. Additional sites for targeted nanoarchaeotal cultivation would include geographically distinct deep-sea hydrothermal vent sites and hot springs with diverse biogeochemical conditions. As more nanoarchaeotes and their hosts are described from these diverse environments, patterns may become clear regarding the mechanism of host/symbiont interaction and the role that environment type, host taxonomy and nanoarchaeote genomics play in this complex association. 
References

[1] Baker, B.J., Comolli, L.R., Dick, G.J., Hauser, L.J., Hyatt, D., Dill, B.D., Land, M.L., Verberkmoes, N.C., Hettich, R.L., Banfield, J.F. (2010) Enigmatic, ultrasmall, uncultivated Archaea. Proc. Natl. Acad. Sci. U. S. A. 107(19), 88068811.

[2] Barns, S.M., Delwiche, C.F., Palmer, J.D., Pace, N.R. (1996) Perspectives on archaeal diversity, thermophily and monophyly from environmental rRNA sequences. Proc. Natl. Acad. Sci. U. S. A. 93(17), 9188-9193.

[3] Barns, S.M., Fundyga, R.E., Jeffries, M.W., Pace, N.R. (1994) Remarkable archaeal diversity detected in a Yellowstone National Park hot spring environment. Proc. Natl. Acad. Sci. U. S. A. 91(5), 1609-1613.

[4] Brochier-Armanet, C., Boussau, B., Gribaldo, S., Forterre, P. (2008) Mesophilic Crenarchaeota: Proposal for a third archaeal phylum, the Thaumarchaeota. Nat. Rev. Microbiol. 6, 245-252.

[5] Castelle, C.J., Brown, C.T., Anantharaman, K., Probst, A.J., Huang, R.H., Banfield, J.F. (2018) Biosynthetic capacity, metabolic variety and unusual biology in the CPR and DPANN radiations. Nat. Rev. Microbiol. 16(10), 629-645.

[6] Castelle, C.J., Wrighton, K.C., Thomas, B.C., Hug, L.A., Brown, C.T., Wilkins, M.J., Frischkorn, K.R., Tringe, S.G., Singh, A., Markillie, L.M., Taylor, R.C., Williams, K.H., Banfield, J.F. (2015) Genomic expansion of domain Archaea highlights roles for organisms from new phyla in anaerobic carbon cycling. Curr. Biol. 25(6), P690-P701.

[7] Giannone, R.J., Huber, H., Karpinets, T., Heimerl, T., Küper, U., Rachel, R., 
Keller, M., Hettich, R.L., Podar, M. (2011) Proteomic characterization of cellular and molecular processes that enable the Nanoarchaeum equitans-Ignicoccus hospitalis relationship. PLoS One 6(8), e22942, https://doi.org/10.1371/journal.pone.0022942.

[8] Giannone, R.J., Wurch, L.L., Heimerl, T., Martin, S., Yang, Z., Huber, H., Rachel, R., Hettich, R.L., Podar, M. (2015) Life on the edge: functional genomic response of Ignicoccus hospitalis to the presence of Nanoarchaeum equitans. ISME J. 9(1), $101-114$.

[9] Golyshina, O. V., Toshchakov, S. V., Makarova, K.S., Gavrilov, S.N., Korzhenkov, A.A., La Cono, V., Arcadi, E., Nechitaylo, T.Y., Ferrer, M., Kublanov, I. V., Wolf, Y.I., Yakimov, M.M., Golyshin, P.N. (2017) “ARMAN” Archaea depend on association with euryarchaeal host in culture and in situ. Nat. Commun. 8, 60, https://doi.org/10.1038/s41467-017-00104-7.

[10] Hamerly, T., Tripet, B.P., Tigges, M., Giannone, R.J., Wurch, L., Hettich, R.L., Podar, M., Copié, V., Bothner, B. (2015) Untargeted metabolomics studies employing NMR and LC-MS reveal metabolic coupling between Nanoarchaeum equitans and its archaeal host Ignicoccus hospitalis. Metabolomics 11, 895-907,

[11] Heimerl, T., Flechsler, J., Pickl, C., Heinz, V., Salecker, B., Zweck, J., Wanner, G., Geimer, S., Samson, R.Y., Bell, S.D., Huber, H., Wirth, R., Wurch, L., Podar, M., Rachel, R. (2017) A complex endomembrane system in the archaeon Ignicoccus hospitalis tapped by Nanoarchaeum equitans. Front. Microbiol. 8, 1072, https://doi.org/10.3389/fmicb.2017.01072.

[12] Huber, H., Hohn, M.J., Rachel, R., Fuchs, T., Wimmer, V.C., Stetter, K.O. (2002) 
A new phylum of Archaea represented by a nanosized hyperthermophilic symbiont. Nature 417(6884), 63-67.

[13] Jahn, U., Gallenberger, M., Paper, W., Junglas, B., Eisenreich, W., Stetter, K.O., Rachel, R., Huber, H. (2008) Nanoarchaeum equitans and Ignicoccus hospitalis: new insights into a unique, intimate association of two Archaea. J. Bacteriol. $190(5), 1743-1750$.

[14] Jarett, J.K., Nayfach, S., Podar, M., Inskeep, W., Ivanova, N.N., Munson-McGee, J., Schulz, F., Young, M., Jay, Z.J., Beam, J.P., Kyrpides, N.C., Malmstrom, R.R. (2018) Single-cell genomics of co-sorted Nanoarchaeota suggests novel putative host associations and diversification of proteins involved in symbiosis. Microbiome 6(161), https://doi.org/10.1186/s40168-018-0539-8.

[15] Jungbluth, S.P., Amend, J.P., Rappé, M.S. (2017) Metagenome sequencing and 98 microbial genomes from Juan de Fuca Ridge flank subsurface fluids. Sci. Data 4, 170037, https://doi.org/10.1038/sdata.2017.37.

[16] Mohanty, S., Jobichen, C., Chichili, V.P.R., Velázquez-Campoy, A., Low, B.C., Hogue, C.W.V., Sivaraman, J. (2015) Structural basis for a unique ATP synthase core complex from Nanoarchaeum equitans. J. Biol. Chem. 290(45), 2728027296.

[17] Munson-McGee, J.H., Field, E.K., Bateson, M., Rooney, C., Stepanauskas, R., Young, M.J. (2015) Nanoarchaeota, their Sulfolobales host, and Nanoarchaeota virus distribution across Yellowstone National Park hot springs. Appl. Environ. Microbiol. 81(22), 7860-7868.

[18] Podar, M., Makarova, K.S., Graham, D.E., Wolf, Y.I., Koonin, E. V., Reysenbach, 
A.-L. (2013) Insights into archaeal evolution and symbiosis from the genomes of a nanoarchaeon and its inferred crenarchaeal host from Obsidian Pool, Yellowstone National Park. Biol. Direct 8, 9, https://doi.org/10.1186/1745-6150-8-9.

[19] Spang, A., Saw, J.H., Jørgensen, S.L., Zaremba-Niedzwiedzka, K., Martijn, J., Lind, A.E., van Eijk, R., Schleper, C., Guy, L., Ettema, T.J.G. (2015) Complex Archaea that bridge the gap between prokaryotes and eukaryotes. Nature 521(7551), 173-179.

[20] St. John, E., Liu, Y., Podar, M., Stott, M.B., Meneghin, J., Chen, Z., Lagutin, K., Mitchell, K., Reysenbach, A.-L. (In press) A new symbiotic nanoarchaeote (Candidatus Nanoclepta minutus) and its host (Zestosphaera tikiterensis gen. nov., sp. nov.) from a New Zealand hot spring. Syst. Appl. Microbiol., https://doi.org/10.1016/j.syapm.2018.08.005.

[21] Waters, E., Hohn, M.J., Ahel, I., Graham, D.E., Adams, M.D., Barnstead, M., Beeson, K.Y., Bibbs, L., Bolanos, R., Keller, M., Kretz, K., Lin, X., Mathur, E., Ni, J., Podar, M., Richardson, T., Sutton, G.G., Simon, M., Soll, D., Stetter, K.O., Short, J.M., Noordewier, M. (2003) The genome of Nanoarchaeum equitans: insights into early archaeal evolution and derived parasitism. Proc. Natl. Acad. Sci. U. S. A. 100(22), 12984-12988.

[22] Wurch, L., Giannone, R.J., Belisle, B.S., Swift, C., Utturkar, S., Hettich, R.L., Reysenbach, A.-L., Podar, M. (2016) Genomics-informed isolation and characterization of a symbiotic Nanoarchaeota system from a terrestrial geothermal environment. Nat. Commun. 7, 12115, http://doi.org/10.1038/ncomms12115. 


\section{Appendix A. Supplementary methods}

\section{Lipid extraction and analysis}

Wet $\mathrm{NZ3}^{\mathrm{T}}$ biomass (approx. $0.1 \mathrm{~g}$ ) was thawed and extracted to recover lipids using a modified Bligh and Dyer method [9]. The cells were suspended in methanol $(\mathrm{MeOH} ; 1 \mathrm{~mL})$ and chloroform $(1 \mathrm{~mL})$. Following further tip sonication (5 min) and centrifugation (5 min; $13000 \mathrm{rpm}$ ), the organic layer was collected. The residual pellet was reextracted and organic layers were combined. Water $(1.35 \mathrm{~mL})$ and $10 \%$ aqueous $\mathrm{NaCl}(0.15 \mathrm{~mL})$ were then added, the resultant biphasic mixture was centrifuged (5 min, $3500 \mathrm{rpm}$ ). The organic layer was transferred and dried under a stream on $\mathrm{N}_{2}$.

The lipid extract was subjected to acidic methanolysis by heating with $5 \%$ methanolic $\mathrm{HCl}$ at $100^{\circ} \mathrm{C}$ for $3 \mathrm{~h}$ in order to remove polar head groups as described [79]. Resulting core lipids were analyzed by LCMS.

Analysis of core lipids was carried out using a modified version of the method described by Elling et al [22]. Samples dissolved in chloroform/methanol (1:1) were analyzed by UHPLC-ESI-MS on a system comprising of a Shimadzu 8040-LCMS system equipped with photodiode array detector and triple quadrupole low resolution MS utilizing an ESI source for ionization and Q3 scanning from 300 to $2000 \mathrm{~m} / \mathrm{z}$. LCMS chromatography was conducted using a Waters Acquity BEH C18 $1.7 \mu \mathrm{m}, 2 \times 150 \mathrm{~mm}$ column at $45^{\circ} \mathrm{C}$. A linear gradient elution profile was employed, with solvents comprised of solvent $\mathrm{A}\left(\mathrm{MeOH} / \mathrm{NH}_{3} /\right.$ formic acid 100:0.1:0.4) and solvent B (2propanol/ $\mathrm{NH}_{3} /$ formic acid 100:0.1:0.4). Initial elution conditions were $100 \%$ solvent $\mathrm{A}$, which was held for 10 min. The percentage of solvent B was then increased to $24 \%$ (v/v) at $15 \mathrm{~min}$ from sample injection, then increased linearly to $65 \%$ at $70 \mathrm{~min}$, to $90 \%$ at 75 
min. and held at this composition for $5 \mathrm{~min}$ before being reduced to initial conditions over $1 \mathrm{~min}$. The column was equilibrated for 9 min prior to a subsequent injection being made. A flow rate of $0.2 \mathrm{ml} \mathrm{min}^{-1}$ was employed.

Lipids were identified by comparison of MS data with published information $[69,115]$ 


\section{Appendix B. List of supplementary files}

File $\mathbf{S 1}$

This file contains tables that correspond to data in Chapter 2, as detailed below. The document is approximately 5 megabytes in size and is saved in the extensible markup language (XML) format. Contents can be viewed in Microsoft Office XML Handler.

Table A1. Annotations for the New Zealand nanoarchaeote, strain Ncl-1.

Table A2. Annotations for the New Zealand host organism, strain $\mathrm{NZ3}^{\mathrm{T}}$.

Table A3. Characteristics of intron sequences predicted in nanoarchaeote tRNA genes.

Table A4. Descriptions of Candidatus Nanoclepta minutus, Zestosphaera gen. nov. and Zestosphaera tikiterensis sp. nov., based on the digital protologues CA00029, GA00064 and TA00512, respectively.

File S2

This file holds supplementary tables for Chapter 3, as listed below. The XML file is readable in Microsoft Office XML Handler and is approximately 418 megabytes in size.

Table B1. M10-121 gene annotations, produced using RAST and the arCOG database.

Table B2. Annotations for the Guaymas Basin Nanoarchaeota, Gua-46, predicted by the RAST server and arCOG database.

Table B3. MC-1 gene annotations, produced using RAST and significant arCOG $(\mathrm{E}<=0.00001)$ gene predictions.

Table B4. Key genomic features of novel Nanoarchaeota MAGs and their cultivated relatives.

Table B5. Comparison of predicted transfer RNA introns found in previously described Nanoarchaeota genomes and MAGs.

Table B6. Split protein-coding genes identified in previously described Nanoarchaeota and MAGs.

Table B7. Genes shared in cultivated Nanoarchaeota based on pairwise best-hit BlastP comparisons between each genome.

Table B8. Cand. Nanoclepta minutus genes used in core genome analysis.

Table B9. Genes from Nanoarchaeum equitans used in the core genome analysis, identified per protocols described in Materials and Methods.

Table B10. Cand. Nanopusillus acidilobi genes, predicted as described in Materials and Methods.

Table B11. M10-121 core gene homologues, identified by pairwise best-hit BlastP analysis $(\mathrm{E}<=0.00001)$ comparing M10-121 to each cultivated Nanoarchaeota genome.

Table B12. Gua-46 core gene homologues, identified as described in Table B11.

Table B13. MC-1 core gene homologues, identified using methods described in Table B11.

Table B14. Core genes identified in all cultivated Nanoarchaeota and all deepsea vent MAGs.

File S3 
Concatenated ribosomal protein alignment used to construct Figure 1.8. This text file is 71 kilobytes in size and can be opened with a text editor. 